A "Cool Kids" Cognitive-Behavioral Therapy Group for Youth with Anxiety Disorders:

Part 2, Analysis of the Process and Outcome of Responders Versus Nonresponders

I. Lundkvist-Houndoumadi \& M. Thastum

Pragmatic Case Studies in Psychotherapy, http://pcsp.libraries.rutgers.edu

Volume 9, Module 2, Article 4, pp. 179-274, 06-26-13 [copyright by authors]

EDITOR'S NOTE: This is the second of a two-part series documenting a cognitive-behavioral therapy group for six children, aged 8-12, with a variety of anxiety disorders. This article, Part 2, reviews the process and outcome of all six children, with a focus on the process and outcome differences between responders and nonresponders. The first article, Part 1, presents an in-depth investigation of the process and outcome in the group of one of the clients, Erik, who responded most positively to the therapy. It should also be noted that this article is based on an earlier, unpublished version of this paper that provides more details about the study and is available from the authors (Lundkvist-Houndoumadi \& Thastum, 2011).

\title{
A "Cool Kids" Cognitive-Behavioral Therapy Group for Youth with Anxiety Disorders: Part 2, Analysis of the Process and Outcome of Responders Versus Nonresponders IRENE LUNDKVIST-HOUNDOUMADI $^{\text {a,b }}$, \& MIKAEL THASTUM ${ }^{\text {a }}$
}

${ }^{a}$ The Anxiety Disorder Clinic for Children and Adolescents, Dept. of Psychology, Aarhus University, Denmark

Correspondence regarding this article should be addressed to Irene Lundkvist-Houndoumadi, Department of Psychology and Behavioural Sciences, Aarhus University, Bartholins Allé 9, 8000 Aarhus C., Denmark. Email: irenelh@psy.au.dk

\section{ABSTRACT}

This case study involves a therapy group of four boys and two girls aged 8-12 who suffered from multiple anxiety disorders. The children and their families were treated for 10 sessions over three months with the "Cool Kids" cognitive-behavioral therapy (CBT) program developed by Rapee and his colleagues (2006). The treatment, which took place in a university training clinic in Aarhus, Denmark, was conducted in a group format, with both children and their families taking an active part, and included cognitive restructuring, gradual exposure, child management training, and skills training in areas such as assertiveness. Outcome was measured by change over time on standardized self-report measures, on diagnosis, and on an overall judgment based on all the data on a "Clinical Global Impression-Improvement of Anxiety Scale" ("CGI-I"). Four of the cases, the "responders," showed successful outcomes on standardized measures, while two, the "nonresponders," did not. This case study looks both qualitatively and quantitatively at the process and outcome of each child and family, exploring the differences between the responders and nonresponders.

Key words: childhood anxiety disorders; Cool Kids Program; Cognitive Behavior Therapy (CBT); parental inclusion; embedded case study; clinical case studies

\section{CASE CONTEXT AND METHOD}

Anxiety disorders are the most common psychiatric disorders among children and adolescents (Vasey \& Dadds, 2001) with severe negative consequences in academic and interpersonal functioning. Randomized clinical trial evidence has accumulated for the efficacy of 
A "Cool Kids" Cognitive-Behavioral Therapy Group for Youth with Anxiety Disorders:

Part 2, Analysis of the Process and Outcome of Responders Versus Nonresponders

I. Lundkvist-Houndoumadi \& M. Thastum

Pragmatic Case Studies in Psychotherapy, http://pcsp.libraries.rutgers.edu

Volume 9, Module 2, Article 4, pp. 179-274, 06-26-13 [copyright by authors]

Cognitive Behavior Therapy (CBT) in reducing anxiety disorders in children (e.g. Ishikawa, Okajima, Matsuoka, \& Sakano, 2007), and etiologic evidence implicates familial and contextual influences in the development and maintenance of childhood anxiety disorders (see Hudson \& Rapee, 2009). Child anxiety research has witnessed a surge of interest in evidence based treatments and the possibility of accruing additional effects in case of inclusion of a family component to CBT. Nevertheless, apart from data supporting the effectiveness of exposure to fear-provoking stimuli and the importance of cognitive change in CBT (Nauta, 2005), predictors of outcome and mechanisms of change have been understudied (Rapee, Schniering \& Hudson, 2009). More evidence is needed on the ways different elements and processes in CBT contribute to children profiting from therapy, and the role parents may have in this seen in the light of children's differential response to treatment. The present embedded case study is designed to contribute to this evidence by exploring possible mechanisms of change that are related to four issues: i) motivation and engagement, ii) the cognitive and behavior components of therapy, iii) parenting behaviors, and iv) group format.

In the present case study, a group of six children with a variety of anxiety disorders - four boys and two girls, aged 8-12 - were seen in cognitive-behavioral group therapy by graduatestudents in the Anxiety Disorder Clinic for Children and Adolescents in the Department of Psychology at the University of Aarhus. The therapy manual was adapted from "The Cool Kids Program” developed by Rapee and colleagues (2006). The case of one of the clients with the most positive outcome, Erik, has been written up in an earlier, accompanying case study (Lundkvist-Houndoumadi \& Thastum, 2013). This "Case of Erik" article presents contextual information about the group therapy, including the clinical setting of the group, issues of confidentiality, procedures for recruitment and assessment measures, the structure, content, and nature of the treatment program, and the outcome evaluation procedures.

Just to summarize, the instruments employed (see Lundkvist-Houndoumadi \& Thastum, 2013, Table 2) included:

- Anxiety Disorders Interview Schedule for DSM-IV (ADIS-C/P; Albano \& Silverman, 1996).

- Strengths and Difficulties Questionnaire (SDQ; Goodman \& Scott, 1999).

- Beck Youth Inventories of Emotional and Social Impairment (BYI; Beck, Beck \& Jolly, 2001).

- Spence Children’s Anxiety Scale (SCAS; Spence, 1998).

- Children’s Anxiety Life Inference Scale (CALIS; Lyneham et al., in preparation).

- Special measures (constructed by the first author) assessing both the child's and parents' views on the nature of the child's anxiety and the impact of the therapy group on that anxiety.

- A Clinical Global Impression-Improvement of Anxiety Scale (CGI-I) rating, based on all the quantitative and qualitative information gained at this assessment. This is a single rating (1-7) of the child's condition in comparison to his/her condition prior to the initiation of treatment based on behaviors, symptoms, and functioning in all aspects of the child's life. 
A "Cool Kids" Cognitive-Behavioral Therapy Group for Youth with Anxiety Disorders:

Part 2, Analysis of the Process and Outcome of Responders Versus Nonresponders

I. Lundkvist-Houndoumadi \& M. Thastum

Pragmatic Case Studies in Psychotherapy, http://pcsp.libraries.rutgers.edu

Volume 9, Module 2, Article 4, pp. 179-274, 06-26-13 [copyright by authors]

The first five instruments were administered pre-treatment, post-treatment, and at 3-month and 15-month follow-up; and the results by client are presented in Appendix A. The last two instruments were only administered at the 15-month follow-up.

\section{CLIENTS}

The demographic characteristics and relevant clinical data of the six children are presented in Table 1. As can be seen, at referral three of the children had a specific phobia as their primary diagnosis, while the remaining had multiple anxiety disorders with generalized anxiety disorder (GAD) being their primary diagnosis.

\section{GUIDING CONCEPTION}

A description of the guiding conception of the therapy is presented in the accompanying "Case of Erik" article (Lundkvist-Houndoumadi \& Thastum, 2013) in this two-article series. The topics covered include the nature of childhood anxiety disorders, cognitive behavior therapy (CBT) with children with anxiety disorders, the role of cognitions in CBT with children with anxiety, the inclusion of the family in CBT, and how the Cool Kids Program used logically follows from the more general guiding conception.

\section{4-7 ${ }^{1}$. ASSESSMENT, CASE FORMULATION, COURSE OF THERAPY, AND CASE MONITORING FOR THE SIX CLIENTS IN THE GROUP}

The diagnoses given at the different points in time and the CGI-I ratings of the group members are summarized in Table 1 . Below each case will be presented separately, starting with a general description of each child when seeking therapy together with a short historical background, followed by a brief account of the course of treatment, illustrating: family's engagement in therapy, response to therapy components and parental inclusion in therapy, concluding with the child's response to treatment at the different assessment points, i.e., posttreatment, 3-month follow-up and 15-month follow-up.

Each case is accompanied in Appendix B by a case formulation, which gives a summary understanding of each child's symptoms and difficulties. Case formulations follow a model proposed by Carr (1999), that distinguishes between the following types of factors: predisposing factors that increase the likelihood a child will develop psychological problems; precipitating factors that trigger the onset or marked exacerbation of psychological difficulties; maintaining factors that perpetuate psychological problems once they have developed; and protective factors that prevent further deterioration and have implications for prognosis. For a fully described example of a sample case formulation, see that of Erik presented in the Part 1 article in this series (Lundkvist-Houndoumadi \& Thastum, 2013; section 5, "Case Formulation and Treatment Plan").

\footnotetext{
${ }^{1}$ This section is numbered "4-7" to indicate its parallel to sections 4-7 of a typical PCSP case study-specifically, “4. Assessment of the Client's Problems, Goals, Strengths, and History”; ”5. Formulation and Treatment Plan”;

”6. Course of Therapy”; and "7. Therapy Monitoring and Use of Feedback Information.”
} 
A "Cool Kids" Cognitive-Behavioral Therapy Group for Youth with Anxiety Disorders:

Part 2, Analysis of the Process and Outcome of Responders Versus Nonresponders

I. Lundkvist-Houndoumadi \& M. Thastum

Pragmatic Case Studies in Psychotherapy, http://pcsp.libraries.rutgers.edu

Volume 9, Module 2, Article 4, pp. 179-274, 06-26-13 [copyright by authors]

The clients are listed below in an order based on their CGI-I ratings (see Table 1), as follows: Very Much Improved (rating of 1), Erik; Much Improved (rating of 2), Niels, Stine, and Tom; and Minimally Improved (rating of 3), Mark and Lene.

\section{Individual Clients Who Were Very Much Improved}

\section{$\underline{\text { 1. Erik }}$}

a. The client. When Erik came for therapy, he was 12 years old and was in 5th grade. He has a Danish ethnic background, comes from a working class family and lived in a neighborhood, where most families had a different cultural background than his. Erik lived with his brother and both his parents, who were working full time at that time. Erik's mother suffered from anxiety herself and had seen a psychologist in the past that, as she claimed, did not help her. Erik's brother, aged 9, suffered from encopresis and had daily problems with defecation.

b. History. Erik's parents described him as a child who always had a fearful temperament. He had been developmentally behind and although no physical problems were identified, he first learned to walk when he was 1.5 years old. Erik's anxiety problems manifested when he was 9 years old and the family was referred to a child psychiatrist. He was initially diagnosed with Obsessive Compulsive Disorder (OCD) and later with Generalized Anxiety Disorder (GAD) and he attended individual sessions at a child psychiatrist once every two weeks for about one and a half year. Erik had some learning difficulties and according to his teachers he was about one year behind in school. The intelligence test, WISC-III, revealed that his processing speed, attention span and auditory short term memory were below what was expected for his age group.

c. Status at the time of referral. Erik's parents wrote in the referral letter:

Erik can stay home alone to a limited extent, but only if he knows where we are and for how long we are gone...he cannot transport himself from the leisure club to the sports hall (ca.500 meters)...his disorder is a big handicap for him in everyday life.

As can be seen in Table 1, Erik was given the following diagnoses: Generalized Anxiety Disorder (GAD) as the primary diagnosis; Specific Phobia of Blood-Injection-Injury Type and Animal type; Social Phobia; and Separation Anxiety Disorder (SAD). He was concerned about his own and his family's health and things he heard about, as for example war and terrorists. Furthermore, he was worried something might happen to his parents and he feared he might be kidnapped. Erik was generally very afraid of situations, where he might have gotten hurt and avoided many situations because of that. He avoided going to the dentist and he had not learned how to swim, nor learned how to ride a bike. He was concerned about what others thought of him and avoided asking shop assistants for help.

On the basis of the parents' report on SCAS and SDQ, Erik was positioned in the clinical population on several subscales, which was also the case for the mother's reports on CALIS, indicating that the anxiety problems interfered greatly with Erik's and her personal life. Erik did not seem to believe he had any significant anxiety problems at the diagnostic interview, but a 
A "Cool Kids" Cognitive-Behavioral Therapy Group for Youth with Anxiety Disorders:

Part 2, Analysis of the Process and Outcome of Responders Versus Nonresponders

I. Lundkvist-Houndoumadi \& M. Thastum

Pragmatic Case Studies in Psychotherapy, http://pcsp.libraries.rutgers.edu

Volume 9, Module 2, Article 4, pp. 179-274, 06-26-13 [copyright by authors]

different picture emerged from the SCAS and the SDQ, where he was placed in the clinical range on some subscales indicating anxiety, while his self-confidence was under the mean. See

Appendix A for tables of results on all the quantitative measures, with one table per child.

d. Engagement in therapy. In the first sessions Erik did not complete his homework assignments, because he claimed he was not afraid. He told his parents he did not really want to come to the Anxiety Clinic, because he had been studied by psychologists, doctors, psychiatrist, etc. for so many years and was tired of it. Furthermore he did not like being the eldest in the group. However, Erik became more motivated after the house visit, where he was presented with the principles of exposures, something he quickly seemed to understand the logic of and as the father said:

He just really wants to get over his anxiety. For instance, he said the other day: I will never get a girlfriend because I am such a wimp. What motivates him to continue [the program] is that he desperately wants to be able to do the same things as his friends. The other day he was really sad because he was thinking about this. The defeats he experiences really bother him.

Erik's father generally appeared disengaged in the first sessions, not taking part in the conversations. When he was presented with the parental homework assignments, he handed them directly over to his wife, commenting they were not relevant for him, as she was the one suffering from anxiety. Nevertheless, a couple of times he tried doing detective thinking exercises with Erik and after the fourth session, when he came alone to therapy and the principles of exposures were explained, he seemed more interested in the therapy. He even offered to leave earlier from work for the house visit that was planned the following week and said they were very motivated to help Erik, because his anxiety also gave them "logistic problems". At the same time he worried that they might have been pressuring Erik too much, possibly because they wanted to be "good and active" and have something to present to the rest of the group. In contrast to the father, Erik's mother was very motivated from the start and worked on her own homework assignments while providing important information about situations Erik feared.

e. Response to therapy components. Erik had difficulties understanding how to complete the detective thinking exercises and explained, "it is hard for me to know what to write down, when I am not in the [feared] situation”. When encouraged to explain to his parents what he had learned, he was unable to. The mother described how, when she tried to talk reason to Erik about his fear of being kidnapped, he responded: "When one day it happens, then you can go and tell all those psychiatrists and psychologists: What did I tell you?!” The parents were encouraged to try and do some detective thinking instead of reassuring him that nothing would happen, but as the father described it did not go well:

I think we were too hard on him when we tried to do the detective thinking. He couldn't put words on what it was he was afraid of and then we asked him a lot of questions... We asked him what was the evidence for that he was afraid of, but of course he didn't have any evidence...'But where can you feel it? In your hands? Where?' we asked, then he yelled: 'I don't know!' And he started crying. He gets sad because he wants to answer but he can't, and of course we also get very sad about it. 
A "Cool Kids" Cognitive-Behavioral Therapy Group for Youth with Anxiety Disorders:

Part 2, Analysis of the Process and Outcome of Responders Versus Nonresponders

I. Lundkvist-Houndoumadi \& M. Thastum

Pragmatic Case Studies in Psychotherapy, http://pcsp.libraries.rutgers.edu

Volume 9, Module 2, Article 4, pp. 179-274, 06-26-13 [copyright by authors]

In that incident Erik was unable to answer the detective thinking questions and might have felt that his parents were questioning his anxiety feelings instead of being understanding. Due to his cognitive difficulties it was decided not to pressure him to do cognitive restructuring. Nevertheless, the mother tried to assist him in detective thinking by coming up with suggestions that she claimed helped Erik, as when he stopped worrying while in the dentist's waiting room.

Erik along with his parents made a gradual stepladder involving him cycling or walking to different places first in the company of others and then alone, for gradually longer distances. Soon after Erik made impressive progress, skipping a lot of the steps and reaching the end goal quickly. He mentioned that using worry surfing had helped him by paying attention to things around him and noticing how anxiety was a wave that would go away.

An important component of therapy turned out to be the in vivo exposures session in the shopping mall, because Erik's debilitating anxiety in social situations became obvious. Nevertheless, after commenting: "it doesn't look like I have a choice” he agreed to ask a clerk if she would help him find a present for his mother. As the student therapists described, after entering the shop, he was "like glued to the floor" and nothing could make him change his mind and complete the step. After that session Erik started doing a lot of exposures on his own, even though he commented that stepladders were "silly" and he preferred not to talk much about it, taking a big step on days he felt like it. On his own initiative he went to a shop assistant and asked about something, he stayed home by himself and went to his friend's house on foot.

As part of the social skills training Erik role played in the session with the other children and told them about his problems at school where he felt he had to do whatever others asked him to. When asked to be assertive and tell someone it was not ok to cheat and go in front of the line, after some thought he said: "Don’t mind me, but what about the ones standing in line behind me?” illustrating his low self-esteem.

f. Parental inclusion in therapy. Erik’s mother was very interested in gaining knowledge concerning "parenting an anxious child", which was the focus of the third session. When talking about how parents of anxious children have a tendency to overprotect them, she described an incident where Erik had told her, he would like to try to go somewhere by himself. "I told him: then you can call me when you get there and I can call you, when I finish from work." She started laughing, realizing how she was being overprotective. During the course of therapy, she seemed to become more and more aware of this, while trying to alter her behavior.

According to the mother Erik came to believe more in himself during therapy and had gotten more assertive, while she had learned to acknowledge her own anxiety and trust he was able to manage more situations. Furthermore, she described how she had started pushing Erik to do more things. For example in a situation where he said he was hungry, she told him and his brother that they had to buy something on their own. Erik had afterwards come out of the shop and expressed his surprise that the clerk had been so kind, indicating that his negative expectations were challenged so that cognitive restructuring could occur.

g. Response to treatment as assessed at three points in time. Evaluating Erik's progress in relationship to the treatment goals his parents wrote in their workbooks at the conclusion of the treatment:

Erik can ride his bike and get from $\mathrm{A}$ to $\mathrm{B}$ on his own, he can be home alone, he can go to shops with others and the negative thoughts happen currently about 0-1 a week". The mother 
A "Cool Kids" Cognitive-Behavioral Therapy Group for Youth with Anxiety Disorders:

Part 2, Analysis of the Process and Outcome of Responders Versus Nonresponders

I. Lundkvist-Houndoumadi \& M. Thastum

Pragmatic Case Studies in Psychotherapy, http://pcsp. libraries.rutgers.edu

Volume 9, Module 2, Article 4, pp. 179-274, 06-26-13 [copyright by authors]

noted which goals she herself had achieved: "Not to transfer my anxiety to Erik, not to always try and reassure him everything will be fine when something is difficult, push him a little bit.

As can be seen in the first table in Appendix A, statistically significant changes were found at post-treatment for Erik, indicating the reduction of anxiety as measured on the subscales of SCAS child $_{\text {. }}$ (Panic/agoraphobia, OCD, Total), SCAS mother $_{\text {(GAD, Social Phobia, Total) and SCAS }}$ father (GAD, Social Phobia, OCD, Total) and clinical change was found on all subscales except the Anxiety of Physical Injury (API) subscale. According to CALIS $_{\text {mother }}$, anxiety no longer interfered as much in either Erik's or the family's life (statistically significant change and large effect were found).

At the 3 month follow-up Erik did not fulfill the criteria for any diagnosis and the father commented that Erik's worries had decreased by $80 \%$ when compared to pre-treatment, while some worries had disappeared altogether. Erik agreed with his parents that he was much better and when asked what he thought had contributed to this, he replied: “This thing here [treatment]. I got the push I needed". The ratings on the scales were similar to those at post treatment with the exception of CALIS child $_{\text {which }}$ was very elevated, most likely due to the fact that it was not answered correctly, since one of the student therapists recorded that Erik experienced difficulties when completing that questionnaire. It might be that he was tired, possibly also due to his concentration difficulties since CALIS was the last to be administered.

At the 15-month follow-up no diagnosis was given and the ratings on the scales were similar to the last assessment with some additional improvements, a statistically significant change on separation

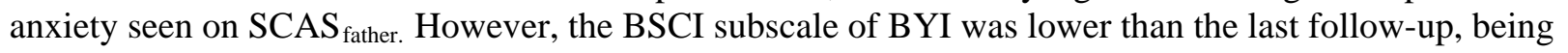
very similar to pre- and post-treatment. The parents described Erik's problems as follows: "There is a little bit of many things [he is anxious about] but it is very little compared to how it was". The mother mentioned an instance when Erik had hurt himself.

I can now comfort him much better than I could before...Y You can now talk reason to him in a way you couldn't before. He is better in accepting it and might also think of a similar situation, when everything went fine.

Erik himself mentioned being afraid of taking the bus alone and walking alone in the night, but added that:

I think I am about to be free of all my problems. I can't actually remember the last time I had an anxiety problem. I can do many more things now. Earlier I was for example afraid of going outside to buy things for my mother. If she asks me to do that now, I just say: Yes sure, of course I can do it. So I think differently about things now. And I believe in myself more now than I did before I came here. It [therapy] has helped me go on with my life.

From all the clinical information obtained on Erik, he was judged to be "Very much improved" (1) on the CGI-I scale because there were no indications of elevated anxiety, functioning was good and only minimal/subclinical symptoms were present, showing substantial change when compared to pre-treatment. 
A "Cool Kids" Cognitive-Behavioral Therapy Group for Youth with Anxiety Disorders:

Part 2, Analysis of the Process and Outcome of Responders Versus Nonresponders

I. Lundkvist-Houndoumadi \& M. Thastum

Pragmatic Case Studies in Psychotherapy, http://pcsp.libraries.rutgers.edu

Volume 9, Module 2, Article 4, pp. 179-274, 06-26-13 [copyright by authors]

\section{Individual Clients Who Were Much Improved}

\section{$\underline{\text { 2. Niels }}$}

a. The client. When Niels came to therapy he was 8 years old, attended $2^{\text {nd }}$ grade and lived with both his parents and younger sister. Niels would become afraid and sad in new and unfamiliar situations, he had few friends and preferred keeping to himself instead of seeking other people. Besides his best friend, he had difficulties making new friends and his parents were concerned that his social difficulties would increase later on, if something was not done.

b. History. Niels suffered from sleep terrors when he was 1-2 years old and the parents had to stay for hours with him, so he could fall asleep again. Furthermore, he suffered from encopresis, which had gotten better when treatment started. He had never been able to play on his own for more than $5 \mathrm{~min}$. at a time and he was easily distracted. According to his parents he started worrying when he was 3 years old and his sister was born, while they also had their own psychological difficulties. His mother had suffered from depression, possibly since she gave birth to Niels, but got worse and received treatment after her second childbirth. At the time of referral she was finishing with group therapy and getting off antidepressants. The father had also suffered from depression, which had been present on and off since he was 15 but got worse at the same time as his wife and he received treatment. The parents said they had rejected Niels at times, when he needed their comfort, because they were preoccupied with their own problems and the father was concerned they might have been too strict, describing how he could easily get angry at Niels, when he was not feeling good.

While depressed, Niels’ parents had trouble responding to his needs and it was difficult for Niels to separate from them, crying when being dropped off at kindergarten. These issues can be indicative of an initially insecure attachment style, which according to Bowlby (1982) characterizes children who do not experience responsiveness and sensitivity from their caregiver, and do not trust that a caretaker will protect them. Niels' negative irritable mood and attachment difficulties are common emotional symptoms in infants of depressed mothers, and these children at times withdraw into a depressed mood themselves or they mimic their parent's anger in order to avoid their parent's insensitivity (Conger, Patterson, \& Ge, 1995; Murray et al., 1999). Children with an insecure attachment may experience chronic vigilance and anxiety, which may set the stage for the development of an anxiety disorder, and there are findings indicating that primary school children, who were classified as avoidantly or ambivalently attached, reported higher levels of worry (Muris, Meesters, Merckelbach, \& Huelsenbeck, 2000).

The parents contacted the school psychologist for the first time when Niels was in the first grade and he went to Sandplay therapy for one year. Concurrently the mother was offered some therapy sessions, where she learned how to be more involved when interacting with her son and that seemed to repair to some degree the mother-child relation and Niels began to trust others more. Additionally, the school psychologist administered the WISC-III and the Rorschach test, from which it was concluded that Niels was of normal intelligence with indications of suppressed anxiety and the family was referred to the Anxiety Clinic. 
A "Cool Kids" Cognitive-Behavioral Therapy Group for Youth with Anxiety Disorders:

Part 2, Analysis of the Process and Outcome of Responders Versus Nonresponders

I. Lundkvist-Houndoumadi \& M. Thastum

Pragmatic Case Studies in Psychotherapy, http://pcsp.libraries.rutgers.edu

Volume 9, Module 2, Article 4, pp. 179-274, 06-26-13 [copyright by authors]

c. Status at the time of referral. In the referral letter parents wrote:

Niels doesn't like being in big gatherings. He prefers knowing the people and feeling they like him. He is very uncertain if he does things right... he has a big need for reassurance.

Niels has reacted with anger when there was something that didn’t suit him. For a period this changed to him being sad instead. His mood can change very quickly. There is a very limited number of children he associates with. He thinks a lot of things ahead of time instead of living in the present and this anticipation about future events raises his anxiety.

Niels’ parents could recognize some of his difficulties in themselves, indicating that Niels possibly inherited their inhibited temperament, as they for instance did not want to talk in front of many people or throw themselves into unknown situations and the father commented that he hoped to be able to personally get something out of the program. Niels was diagnosed with: GAD, SAD and Social Phobia and was very preoccupied about things that could happen to his parents, worried when he parted from them, avoided talking to other adults and did not talk in class. He would often say: "I am not good at...”, “I can’t...” "What if...”, and his teachers were concerned because they thought he looked like a very sad boy. He had trouble sitting quietly and changed activities very often, which the mother thought, might be a cry for attention.

In the assessment interview Niels did not report any excessive worrying, but his social phobia was evident and when given the opportunity to paint in the additional time, he made some very shocking sketches about death, the devil, a man jumping from the top of a jail-with smoke coming out and landing on dog poop-etc. On the scales completed by the mother at pretreatment, he was situated in the clinical group on SDQ (emotional symptoms, hyperactivity) and on SCAS-P (panic/agoraphobia, GAD, Social Phobia), while on the basis of Niels' self-ratings he was situated in the clinical group on the SAD subscale of SCAS-C and over the normative mean on the BYI depression subscale, and below on the BYI self-concept subscale.

d. Engagement in therapy. In the first sessions Niels was very quiet and his body language indicated he was not feeling comfortable being there. When he noticed others receiving rewards (stickers) and praise for participation, he asked "If I do this [raise my hand], will I then get a sticker?” and then he slowly raised his hand. Gradually he became more active in the sessions and looked very happy when praised for his hard work in participating. At first he would answer questions in a very low voice, while looking down at the table, but he later on talked more loudly and practiced having eye contact with the person he was talking to.

Although he had difficulties with hyperactivity, it appeared he was listening and would comment on things he heard. Concerning the parents' motivation the student therapist commented: "throughout the program they have been very motivated and they have adopted a lot of the tools from the program." The father mentioned how they talked about things related to the program on a daily basis, but had decided not to pressure Niels to do too much homework that involved completing exercises in the workbook because they wanted to maintain his motivation.

e. Response to therapy components. The first treatment component in the Cool Kids Program, detective thinking, was not incorporated in Niels' way of handling anxiety provoking situations and it was difficult for him to talk about the things he was very afraid of. Nevertheless, 
A "Cool Kids" Cognitive-Behavioral Therapy Group for Youth with Anxiety Disorders:

Part 2, Analysis of the Process and Outcome of Responders Versus Nonresponders

I. Lundkvist-Houndoumadi \& M. Thastum

Pragmatic Case Studies in Psychotherapy, http://pcsp.libraries.rutgers.edu

Volume 9, Module 2, Article 4, pp. 179-274, 06-26-13 [copyright by authors]

at home he was able to complete some detective thinking exercises with the help of his parents and generate some alternative thoughts concerning situations he feared, which his parents afterwards encouraged him to face.

After being introduced to the principles of gradual exposures, the first stepladder was planned with the end goal: "be able to answer to teacher's questions in class" and despite a two week delay to inform the teacher and organize its implementation, Niels managed to achieve his end goal four weeks later. Besides the progress seen in the classroom, Niels started on his own initiative talking to others and both parents commented they were gladly surprised by this more independent behavior on the part of Niels. A new stepladder was implemented concerning the sleeping situation, after being inspired by another family and when progress came rapidly, the goal set for the next stepladder was Niels being able to sleep at his best friend's house.

The father believed stepladder to be a very useful tool when talking about things that were difficult for his son, while Niels generated some alternative thoughts after his beliefs were challenged in the exposures. This was exemplified when comparing what Niels wrote in his workbook in one of the first sessions: "My biggest worry is to ask questions because it is hard and what will the others think of me?" and what he said about it in one of the last sessions: "It is good and it's not hard at all." Niels also made progress in relation to his separation anxiety, as he managed to go alone to a field trip and apart from the first day, when he missed his parents, he had had a good time. Before the end of treatment, Niels managed to also reach his second goal of sleeping at his friends' house and the reward was that the father helped him build a hut.

f. Parental inclusion in therapy. A session that can be very informative on how parents behave when their child is anxious is the in vivo exposures session. There it became apparent that Niels' parents were good in assisting him before, during and after the exposures, when they wrote down a plan for the next exposures they should work on. Another important session that can provide a telling picture of the family is the house visit where the student therapist saw a very affectionate (gave hugs to each other) and accepting family (letting him build a shop in the kitchen, which meant moving around on lot of things), writing in her notes:

The visit gave me more qualitative information and impressions that made me in a higher degree certain that the family was good on its way in tackling their situation...Both parents agree that they are doing better in the family now compared to before therapy start and I think the fact that the parents tried being with Niels on his own premises was very important, since positive interactions are important.

In one of the last session the father commented on how happy he was to find out the positive influence praise had on his son: "There is now more room to be happy... It could for example, be about a thing Niels has achieved, like building something out of Lego" 
A "Cool Kids" Cognitive-Behavioral Therapy Group for Youth with Anxiety Disorders:

Part 2, Analysis of the Process and Outcome of Responders Versus Nonresponders

I. Lundkvist-Houndoumadi \& M. Thastum

Pragmatic Case Studies in Psychotherapy, http://pcsp.libraries.rutgers.edu

Volume 9, Module 2, Article 4, pp. 179-274, 06-26-13 [copyright by authors]

g. Response to treatment as assessed at three points in time. Evaluating Niels’ progress in relationship to the treatment goals his parents wrote in their workbook at the conclusion of the treatment:

He is more active in class, sleeps at his best friend's house, greets people more, seems more self confident, he has gotten better at sleeping, and accepting things the way they are. We have reached better understanding of the problems and are better able to tackle them, we use more praising and do not allow alternative ways out [related to avoiding anxiety provoking situations].

As shown in the second table in Appendix A, at post treatment the mother's ratings on SDQ indicated increased prosocial behavior (statistically significant change and large effect) that may be related to Niels' progress in handling social situations. Her ratings of Niels' anxiety on SCAS-P were much higher than the father's and placed him in the clinical group, in line with previous findings (Barrett, Dadds \& Rapee 1996; Cobham, Dadds \& Spence 1998) that indicate there is a tendency for mothers to give higher anxiety ratings than fathers, while it is possible Niels learned how to open up and share his worries during therapy, raising mother's awareness and contributing to higher ratings when compared to pre-treatment.

Niels' self-ratings on anxiety (SCAS-C) were very similar to pre-treatment, but as can be seen on the changed scores on CALIS (statistically significant change and large effect was found), anxiety did not interfere as much in his life.

Three months post treatment Niels no longer fulfilled the criteria for a diagnosis, while both parents and Niels gave similar ratings on the scales measuring anxiety. At the 15-month follow-up Niels was still diagnosis free as anxiety no longer interfered in his life, as assessed on ADIS-P. Compared to pre-treatment the mother rated Niels' social anxiety and panic/agoraphobia as decreased in a statistically significant manner, and considered that anxiety did not interfere as much in his life (statistically significant change and large effect on CALIS). Niels' self-ratings indicated an elevation in his self-concept (statistically significant change and large effect on BYI), but placed him in the clinical group on various subscales on SCAS-C: generalized anxiety, social phobia, separation anxiety and total. Nevertheless, Niels did not report any interference in his life due to anxiety (statistically significant change and large effect on CALIS).

Niels reported more anxiety symptoms compared to his parents which is in accordance to previous findings (Mendlowitz et al. 1999, Nauta et al., 2003; Wood et al. 2003) that indicate a tendency for parents to report a more pronounced decrease in anxiety symptoms in comparison to children's assessment after the end of CBT and FCBT interventions, a tendency primarily seen in boys. It is possible that the fact that boys usually show more externalizing symptoms when experiencing problems, also as seen in Niels' outbursts of anger, may be related to difficulties in expressing thoughts and feelings linked to their anxiety, which changes through therapy. At the 15-month follow-up Niels' father commented:

In a way he is like: everything goes fine and I can do everything, but then again something holds him back. He is worried he is not as good as the others, but he gets things done 
A "Cool Kids" Cognitive-Behavioral Therapy Group for Youth with Anxiety Disorders:

Part 2, Analysis of the Process and Outcome of Responders Versus Nonresponders

I. Lundkvist-Houndoumadi \& M. Thastum

Pragmatic Case Studies in Psychotherapy, http://pcsp.libraries.rutgers.edu

Volume 9, Module 2, Article 4, pp. 179-274, 06-26-13 [copyright by authors]

anyway. It's probably more some kind of social anxiety; meet new people and come out. But it doesn't take up so much space as it did.

From all the clinical information obtained, Niels is judged to be: "Much improved” (2) on the CGI-I scale, because although he still experienced some anxiety, this seemed related to his inhibited temperament, and it did not hold him back from doing the things he wanted to, showing increased functioning instead.

\section{Stine}

a. The client. When Stine came to therapy for her dog phobia, she was 9 years old and her parents described her as very well functioning, managing well at school and having many friends. She lived with both her parents and her younger sister, aged 5. Stine was very open from the first meeting, showing no sign of nervousness or shyness.

b. History. Stine was always a very outgoing and active child that would jump into new situations without needing her parents' reassurance. When she was an infant, about 8-9 months old, a dog had barked in her face and she got very scared. Since this episode she would run to her pedagogues when she saw a dog and a few years later, when on a kindergarten field trip, a large dog pushed her in a cold stream. Stine's anxiety became more intense after this incident and one and a half year later the parents sought help from the school psychologist, who consulted them to buy a dog. They did not follow this advice, but instead tried hypnosis; however, after two therapy sessions the psychotherapist concluded that Stine was too young for that type of treatment.

c. Status at the time of referral. The father wrote in the referral letter:

Since she was little, she has been very afraid of dogs and other fast moving animals. Over the years she has learned to accept calm dogs, but when she has an arrangement to go and play or family visits, she is always concerned whether there will be any dogs present. This has resulted in Stine's younger sister being even more afraid of dogs than Stine, because she has always seen how Stine panics when a dog is approaching her.

The parents had tried on separate occasions to accept or punish Stine for her reactions, but did not think either had been effective, while it was taking a lot of space in their daily life, as they had to avoid situations where she might encounter dogs: "Stine calls her grandfather and asks him to remove his dog before visiting him and avoids going to the summer house because there are many dogs.” Stine was diagnosed with a specific phobia of animal type based on the ADIS-P interview; however, the self-rated scales completed at pre-treatment showed no significant problems, placing Stine outside the clinical range and that may be related to the specificity of her anxiety problem.

d. Engagement in therapy. Stine was motivated from the first session, was very active, always raising her hand to answer questions and quickly understood and completed the exercises. At first she had some trouble sitting still in her seat for longer time intervals, but when allowed to draw, she was better able to concentrate on what was said. The family did exposures whenever that was possible-almost every day, the student therapists’ impression being: 
A "Cool Kids" Cognitive-Behavioral Therapy Group for Youth with Anxiety Disorders:

Part 2, Analysis of the Process and Outcome of Responders Versus Nonresponders

I. Lundkvist-Houndoumadi \& M. Thastum

Pragmatic Case Studies in Psychotherapy, http://pcsp.libraries.rutgers.edu

Volume 9, Module 2, Article 4, pp. 179-274, 06-26-13 [copyright by authors]

The family (mother and Stine) seems very motivated to use the tools they learn in the program and work towards their goal in an organized manner. The mother is very active and the father clearly wishes a change, but rarely participates in the work towards that change.

This might indicate a more active role played by the mother, which was also obvious in the therapy sessions. Nevertheless, the father seemed interested in the program, smiling and nodding to what was said in the sessions.

e. Response to therapy components. Detective thinking did not seem to be of great help for Stine's anxiety, the mother commenting that it was always the same situations and thoughts that were present. The family therefore started doing exposures before it was introduced in the program and they had incorporated in their program bicycling three times a week through a park, which they re-named from "dog-park" to "lake-park”. The father described how Stine managed to pass by a dog without acting "hysterically” as earlier, i.e. she did not cry or yell, but was very calm, and she received a lot of praise from her parents.

The family planned and successfully completed gradual exposures, having worry surfing as a backup tool if Stine should have problems with her encounters with dogs. Stine's progress in therapy also became apparent at the in vivo session when she went gladly to meet the dog and managed in the end to sit with it in her arms. Stine seemed proud because she functioned as a role model for Lene (the other child in therapy with a dog phobia), and she received a lot of praise from everyone present, Stine's mother taking a lot of pictures on her mobile for the father to see, as he had not been able to come to that session.

Stine was very good at using the tools outside therapy; she for instance explained assertiveness training to her younger sister after she was introduced to it and used worry surfing in school in situations that made her anxious. In addition, when she visited a friend and noticed a lot of dogs walking freely in the garden she at first felt overwhelmed, but then immediately made a stepladder that involved first building some sort of a cage for the dogs, and after she had gotten used to them, they let them free and she was able to play ball with them. Furthermore, Stine was good in taking initiatives to face her fear on her own and when her class planned to go on a field trip, she at the dinner table the evening before decided to ask her teacher whether they could go to the forest that had dogs. She also talked to her class about the program, proudly informing them about her progress and it seemed as if the parents were good in communicating to her how it was not something she should be embarrassed of, while supporting her initiatives.

f. Parental inclusion in therapy. The mother expressed how happy she was for being part of the program, where she felt understood, as the parents had up until then often been criticized for not having brought up Stine right and were sometimes blamed for Stine's anxiety. It had been a relief to feel understood that the problem was serious, having a big impact on the family, although some of the other families may have had even more serious problems.

During the course of treatment the family was very good at working independently, without needing assistance by the student therapist to plan stepladders. When the mother wanted to plan a stepladder for Stine to start practicing being with the grandfather's dog, which Stine had rated as the one she was most afraid of, Stine commented that the steps were too difficult 
A "Cool Kids" Cognitive-Behavioral Therapy Group for Youth with Anxiety Disorders:

Part 2, Analysis of the Process and Outcome of Responders Versus Nonresponders

I. Lundkvist-Houndoumadi \& M. Thastum

Pragmatic Case Studies in Psychotherapy, http://pcsp.libraries.rutgers.edu

Volume 9, Module 2, Article 4, pp. 179-274, 06-26-13 [copyright by authors]

and additional steps were included, indicating good family communication and cooperativeness. In the following session Stine was very happy that she managed to call her grandfather on her own initiative and had ended up being able to walk the dog. The parents had taken a lot of pictures, so she could show them to the group and Stine received a lot of praise by everyone in the group, while it had already been planned when to visit the grandfather again. Overall, the family were able to work as a team with a common goal and Stine would do a lot of exposures in between sessions, making steady progress.

g. Response to treatment as assessed at three points in time. At the last session Stine seemed to have reached her goal of therapy, namely be able to be near dogs without excessive fear and the parents expressed their gratitude for having been part of the program, which had also had a positive effect on their younger daughter. Their everyday life had gotten easier, and although Stine would still scan around her to see whether there were any dogs, she did not avoid any situations because of that and the parents felt competent to manage on their own. As shown in Table 3 in Appendix A, at post-treatment the ratings of Stine's anxiety were very similar to pre-treatment and no statistically significant change was found on any subscales except on SCAS $_{\text {father }}$ : GAD. When considering whether significant changes are found on the scales it is important to have in mind that the pre-treatment scores were very low.

At the three-month follow-up Stine did not obtain a diagnosis and the parents described how she could stay at her grandfather's house with his dog, without them having to take any precautions, while she had told them that she enjoyed being there a lot. Anxiety ratings decreased when compared to pre-treatment (statistically significant change and large effect was found on SCAS-C: GAD and large effect was found on Anxiety of Physical Injuries subscale) and according to Stine anxiety did not interfere any longer in her life (a large effect was present on CALIS when compared to post-treatment).

At the 15-month assessment Stine once more did not fulfill the criteria for a diagnosis

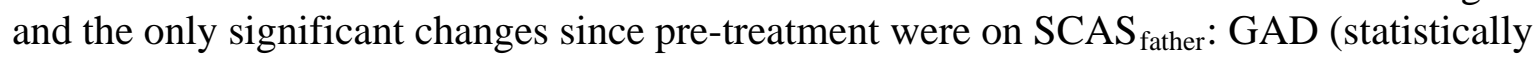
significant and large effect) and API (large effect), while ratings were overall very low. The mother explained: "I think that when she is face to face with a dog, she is as afraid of it, as she was before, but now she takes that deep breath and the way she tackles it is much better.” In Stine's words:

It [the anxiety problem] has gotten much better after the program. I dare do many more things. I have bicycled home from my friends' house and things like that, without being afraid. I couldn't do that before, or if I did, I would have been very nervous, I remember that no matter where I was, I always thought: 'I have to get away from here'.

From all the clinical information obtained on Stine she was judged to be: "Much improved" (2) on the CGI-I scale, because although at times she still experienced intense anxiety when facing a dog, she was notably better as she no longer avoided situations because of this and she was able to tackle her fear, showing increased functioning. 
A "Cool Kids" Cognitive-Behavioral Therapy Group for Youth with Anxiety Disorders:

Part 2, Analysis of the Process and Outcome of Responders Versus Nonresponders

I. Lundkvist-Houndoumadi \& M. Thastum

Pragmatic Case Studies in Psychotherapy, http://pcsp.libraries.rutgers.edu

Volume 9, Module 2, Article 4, pp. 179-274, 06-26-13 [copyright by authors]

\section{Tom}

a. The client. When Tom came to therapy he was 8 years old and attended first grade. He lived in a farm a bit outside of a village with his older sister and both his parents, who were teachers at the school he attended. He was a very kind and considerate boy with many friends in school, but he suffered from sleep problems and had a general tendency to worry, mainly in relation to separating from parents and facing unexpected events.

b. History. Tom was described by his parents as a child that had always been very fearful. His motoric and verbal skills had been his strengths; however he avoided conflicts, had a tendency to cry and was very vulnerable. Furthermore, he had a lot of trouble when he was about to start school, because there were many children and teachers he did not know. The parents had tried to talk about Tom's anxieties with the school doctor, but had not received any help, so they tried to talk to him about his worries, while being supportive and showing him, they were there for him.

Tom's mother was diagnosed with post partum depression after giving birth to him, which was recognized about four months later and following medication and psychotherapy, she gradually got better. In that period she had tried to be as she said "a cognitively good mother", using her knowledge concerning how she should interact with Tom, but was concerned he might have felt neglected during that period and believed that the emotional binding between them took place when she got better two years later. Like Tom, his father had been afraid of darkness when he was little. Three years before referral time he was admitted for six months in the hospital because of stress and he explained that when stressed he would easily get annoyed and yell at the children, something that was very hard for Tom, who would react by becoming very sad. Tom's father had gotten gradually better after he got a sickness leave from his work and when the same symptoms presented themselves a couple of years later, he got help from a life coach.

Tom's tendency to react with fear, when confronted with unfamiliar situations, may be explained by him having an inhibited temperament that refers to stable behavioral and emotional reactions that characterize children who are more reserved, guarded and introverted (Kagan, 1992). According to Hirshfeld and colleagues (1992) behavioral inhibition places children at risk for the development of anxiety disorders, in case it is present throughout their younger years. At the same time, young children of parents with mood disorders, as was the case for Tom, are at risk of manifesting behavioral inhibition (Rosenbaum et al., 2000), while mother's depression is likely to impede the development of a secure attachment contributing further to the development of anxiety.

c. Status at the time of referral. Tom obtained multiple diagnoses at the time of referral, namely GAD, SAD, specific phobia related to darkness, lightning and thunder. He could react intensely, when parting from his parents and was worried about them: "What if something happens to you?” He also would get very anxious when others reacted intensely and was generally concerned about situations he could not prepare himself for. Parents believed the anxiety symptoms were most evident at bed time, as Tom had difficulties falling asleep and had nightmares frequently, so that they often had to stay with him for a long time, until he slept. On the basis of the pre-treatment assessment, Tom was situated in the clinical range on multiple 
A "Cool Kids" Cognitive-Behavioral Therapy Group for Youth with Anxiety Disorders:

Part 2, Analysis of the Process and Outcome of Responders Versus Nonresponders

I. Lundkvist-Houndoumadi \& M. Thastum

Pragmatic Case Studies in Psychotherapy, http://pcsp.libraries.rutgers.edu

Volume 9, Module 2, Article 4, pp. 179-274, 06-26-13 [copyright by authors]

subscales on SCAS, which were related to the diagnoses given, while on BYI he was placed under the mean on the self-concept scale and over the mean on the anxiety and depression scale.

d. Engagement in therapy. Tom was at first reluctant to open up to the student therapists and it was difficult for him to acknowledge his anxiety difficulties. The parents were very motivated and cooperative from start. They worked independently on the exercises and contributed with good social initiatives in the parental group, as they for example arranged that the parents took turns to bake a cake for the therapy sessions. They made a special effort to motivate Tom, as when following learning about detective thinking, they suggested they could go home and watch a cartoon with a detective. Half-way in the program they were concerned, because Tom seemed to be tired of the homework and they tried to vary the time of the day they did it while telling him, he did not need to do some of his school work.

e. Response to therapy components. At therapy start Tom had some trouble identifying which thoughts made him anxious, but he quickly understood detective thinking, being good at posing questions in order to generate alternative thoughts. He tried doing detective thinking on the thoughts he had concerning sleeping away from his parents and afterwards claimed: "Now I am no longer worried, because I have said to my head, that nothing will happen, because nothing ever happens". However, it was the student therapists' impression that this claim was related to Tom's difficulty accepting the fact that he was anxious.

Early in therapy a situation presented itself for doing exposures, as Tom was invited by his grandparents to go to the circus, which demanded travelling by train and sleeping away from home, two situations that he feared intensely. Nevertheless, Tom was motivated to go and the parents assisted him in doing detective thinking and gradual exposures the week before the trip, as a way to prepare him. On some occasions detective thinking would work, as for instance after having the alternative thought: "I might not be able to have time to get off the train at the right station, but my grandparents will then pick us up at the next station” resulting in the anxiety rating to drop significantly, while the thought: "the train will sidetrack" was challenged with the realistic thought: "The chance that something will happen is not so big and there will probably be someone that can help” but did not result in the anxiety decreasing.

Furthermore, the parents made some flashcards with detective thinking for Tom, who after the trip claimed that he was not afraid of trains any more and looked more self-confident during the sessions.

After this successful exposure the family planned a stepladder involving Tom being able to sleep alone in his room, worry surfing being a great help in order for him to be able to sleep without his parents comforting him. When some situations seemed more difficult than expected, the stepladder was re-evaluated and changed and Tom made steady progress. Overall, both Tom and his parents' showed great understanding of all the treatment components and they incorporated them in their way of working towards their goals.

f. Parental inclusion in therapy. The parents were very engaged in the therapy process and showed great interest in hearing how they could help Tom overcome his anxiety. When introduced to parenting techniques they commented they knew about the principles from their 
A "Cool Kids" Cognitive-Behavioral Therapy Group for Youth with Anxiety Disorders:

Part 2, Analysis of the Process and Outcome of Responders Versus Nonresponders

I. Lundkvist-Houndoumadi \& M. Thastum

Pragmatic Case Studies in Psychotherapy, http://pcsp.libraries.rutgers.edu

Volume 9, Module 2, Article 4, pp. 179-274, 06-26-13 [copyright by authors]

work (they are teachers), but mentioned they had difficulties in taking into consideration Tom's temperament because their own and their daughter's temperament were different.

This became evident when in the in vivo exposures session they showed up with red clown noses and a big smile, while Tom next to them looked very anxious and embarrassed. In this session Tom was at first unwilling to do any of the embarrassing suggestions his parents made, but agreed to the student therapists' suggestion to buy something from a store on his own while trying to be assertive. After empathizing better with Tom's experience of the situation the parents suggested exposures he was willing to do, while they were good at coaching and supporting him.

The parents' concerns related to parenting an anxious child were talked about at the house visit, where they were encouraged to be more sensitive to the signals Tom was sending concerning what situations he could handle, while the positive sides of a more inhibited temperament were also pointed out. In turn, parents encouraged Tom to work on assertiveness behavior with the mother maintaining an optimistic outlook, believing Tom would learn those skills quickly, since as she commented he had done impressive progress with all other things he was introduced to in the program. The parents expressed how they were very happy to have found out how to be better in supporting Tom and having tools in order for them to help him progress.

g. Response to treatment as assessed at three points in time. Evaluating Tom's progress in relationship to the treatment goals his parents completed the following in their workbooks at the last session:

Tom is now able to sleep alone in his room, he is still nervous trying new things, but -after among other things the session at the shopping mall—he has become more self-confident. He thinks that he is capable, and no longer says he is afraid of irrational things. We no longer see the same degree of separation anxiety in Tom and we are now able to prioritize our adult life and will soon go on a weekend without the children.

At post treatment, as shown in Table 4 in Appendix A, Tom's anxiety had decreased (statistical significance and large effect was found) as measured on BYI (anxiety), SCAS-C

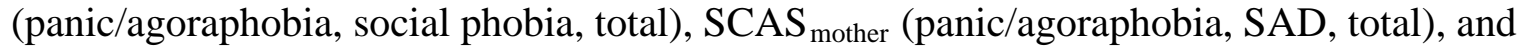
SCAS $_{\text {father }}$ (panic/agoraphobia, SAD, GAD, total). Nevertheless, the ratings of the parents placed Tom in an anxiety disordered group (clinical change was found only on the social phobia subscale), although Tom's ratings were not as high (clinical change was found on all subscales, except API and SAD) and neither the mother nor Tom believed that the anxiety interfered as much in his life (large effect on CALIS).

At the 3-month follow-up, additional decrease (statistically significant and large effect) of anxiety problems was found when compared to pre-treatment parent ratings on SDQ (emotional symptoms), on SCAS-P (panic/agoraphobia, GAD, SAD, total) and Tom's scores on SCAS-C (panic/agoraphobia, GAD, social phobia, SAD, total), indicating a higher self-concept and decreased depressive symptoms on BYI. Tom did not fulfill the criteria for any diagnosis and the 
A "Cool Kids" Cognitive-Behavioral Therapy Group for Youth with Anxiety Disorders:

Part 2, Analysis of the Process and Outcome of Responders Versus Nonresponders

I. Lundkvist-Houndoumadi \& M. Thastum

Pragmatic Case Studies in Psychotherapy, http://pcsp.libraries.rutgers.edu

Volume 9, Module 2, Article 4, pp. 179-274, 06-26-13 [copyright by authors]

parents explained how the program components were incorporated in Tom's way of handling his anxiety.

At the 15 month follow-up the ratings on the subscales measuring anxiety were a bit higher than at the previous follow-up, this deterioration being statistical significant and

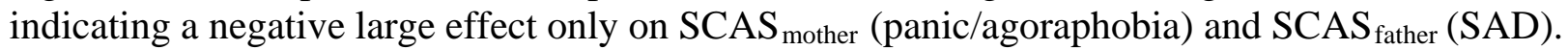
Although there were indications of separation anxiety in some situations, it was not something that interfered with Tom's everyday life and therefore no diagnosis was given. At the interview the mother wrote the following (note that she was not able to come to the interview but was sent the questions via e-mail and wrote down her responses):

The areas of anxiety are still there. This means that Tom still needs help and support in the situations that are anxiety provoking for him. Not as often as before and not to the same degree. But he is e.g., very afraid to separate from us and travel by train.

The father said:

I don't think it [the anxiety] will ever disappear. However I believe it has gotten better with Tom. But for example when he heard we would come here and he would have to talk to you alone he felt insecure. It is that separation anxiety which results in him feeling bad when we are not together. Or maybe not bad, but it affects him. It gets less and less but it is still there.

From all the clinical information obtained on Tom, he is judged to be: "Much improved" (2) on the CGI-I scale, because although he at times still experiences intense anxiety, he shows increased functioning and is notably better at tackling his fears.

\section{Individual Clients Who Minimally Improved}

\section{$\underline{\text { 5. Mark }}$}

a. The client. When Mark came to therapy he was 9 years old and attended 3rd grade at a Christian school. He had no siblings and lived with both his parents. Mark often got nervous, avoided unfamiliar situations and was described as a perfectionist, the mother commenting he had gotten that from her. When meeting new people he needed time in order to open up and although he was well behaved when with other people, at home he could react with a very intense temperament.

b. History. The parents described Mark as an infant with a fearful (inhibited) temperament, who did not want to explore unfamiliar situations and never wanted to play on his own, preferring instead to be with his parents, mainly his mother. As a child at times he woke up in the night with a scream, for no apparent reason, and ran into the parents' bedroom to continue sleeping there. According to his parents, Mark’s anxiety appeared two years prior to referral, after some burglars had robbed their house. His mother contacted the school psychologist, who informed them about the anxiety clinic, and soon after they started treatment.

c. Status at the time of referral. Mark's parents wrote in their referral letter: "He is unable to sleep alone in his room. He can go home from school on his own, but he doesn't dare go 
A "Cool Kids" Cognitive-Behavioral Therapy Group for Youth with Anxiety Disorders:

Part 2, Analysis of the Process and Outcome of Responders Versus Nonresponders

I. Lundkvist-Houndoumadi \& M. Thastum

Pragmatic Case Studies in Psychotherapy, http://pcsp.libraries.rutgers.edu

Volume 9, Module 2, Article 4, pp. 179-274, 06-26-13 [copyright by authors]

inside the house alone if someone else isn't at home.” Furthermore, when Mark was home, he was afraid of going inside a room if one of his parents wasn't already in there. Mark was given the diagnosis of specific phobia, as his fears were related to the burglars but there were no indications of re-experiencing the traumatic event (ruling out Posttraumatic Stress Disorder). The parents went to great lengths, in order to help Mark avoid distressing situations and for instance transferred his bed when friends visited him in order to avoid the embarrassment of them knowing about him sleeping in his parents' bedroom. There were some conflicts at home, because Mark preferred being with his mother and she had a tendency to let Mark have his way for the "sake of peace". In addition, Mark had problems with enuresis and he had just started treatment, involving an alarm going off when the bed got wet. At the assessment interview the parents described Mark as a perfectionist and very concerned about others' opinion, indicating a tendency for social phobia:

Mark is very perfectionistic. If he makes a drawing that isn't perfect he will throw it out. He is afraid of answering incorrectly [at school] and he is afraid of everything unknown and of what others will think of him.

As it can be seen in Table 5 in Appendix A, prior to therapy Mark scored above the normative mean on the BYI on all subscales (except self-concept) and was situated in the clinical group on all SCAS-C subscales (except GAD) as well as on SCAS-P (API, SAD, total). When bearing in mind the diagnosis given these findings are somewhat surprising, as they indicate that Mark is anxious of many things. In addition, the self-ratings reveal that he is overall more anxious than the mother is aware of, though she believes his anxieties interfere a lot in her

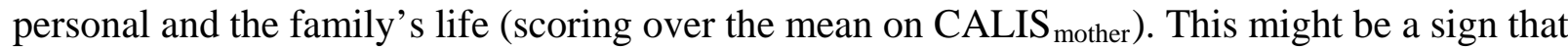
communication in the family is not very open and Mark does not share his anxieties with his mother, who seemed less attuned to his concerns and was more worried about their interference in the family's life.

The differences in the reports of Mark and his mother (Mark giving higher ratings) can be related to the findings of Manassis and colleagues (2009) that concluded how differences in responses of mothers and children were modestly related to maternal reports of family problems. In addition, child-reported anxiety was predicted by child-reported depression and coping in terms of avoidance and support-seeking, all of which issues were present in Mark's case. The assessment indicated that Mark showed low self-efficacy prior to treatment, which could have implications in the treatment, since children with low self-efficacy are unlikely to try different strategies to cope with fear-evoking situations, resulting in avoidant behavior and a failure to master such situations (Suveg \& Zeman, 2004).

d. Engagement in therapy. At the beginning both Mark and his parents seemed very motivated and Mark wrote in his workbook: "I would like to be able to sleep alone in my own room.” However, after the first session, Mark’s mother called the student therapist, and talked about how he did not want to attend the program, claiming it had not helped him. Nevertheless, the family came to the next session after the mother had made an agreement with Mark that he would get 10 DKK for each homework assignment he completed. Surprisingly, the parents had forgotten to do their own homework and this happened again in the following session, even though the student therapist emphasized the importance of it. It was the student therapist's 
A "Cool Kids" Cognitive-Behavioral Therapy Group for Youth with Anxiety Disorders:

Part 2, Analysis of the Process and Outcome of Responders Versus Nonresponders

I. Lundkvist-Houndoumadi \& M. Thastum

Pragmatic Case Studies in Psychotherapy, http://pcsp.libraries.rutgers.edu

Volume 9, Module 2, Article 4, pp. 179-274, 06-26-13 [copyright by authors]

impression that it was difficult for Mark to complete his homework and he was not very motivated, having trouble concentrating during the last sessions.

e. Response to therapy components. Initially Mark had some difficulties understanding detective thinking and was confused about the roles of the detective and himself. Nonetheless, he managed to do some exercises with his mother, but his anxiety did not drop after doing detective thinking: "I know there are no burglars, but it is hard to believe it" and he got tired of repeating the same questions related to his fear.

A stepladder was planned with the end goal: “to fall asleep alone in my parents' room," where the father would start being in the room for 30 minutes and then gradually for shorter time intervals, on which Mark commented "he can't do that! [challenging his father's willingness]" and seemed happy his father also had to make an effort. In the next couple of weeks Mark did some exposures and managed to have the parents for only $4 \mathrm{~min}$. in the room before they left at bed time. In addition, the family made one more stepladder: "Being able to come home to an empty house." However, the parents had trouble finding time to practice this and Mark did not want to revise the stepladder, in order for it to be easier to implement. His parents e-mailed to the student therapist:

He thinks it is hard practicing and today the degree of anxiety was rated as 8 . He is trying and it is obvious to us, he gradually dares do more and more. He didn't understand worry surfing and it is difficult talking with him about it. As I see it, this is what he anyway does. He can't explain which strategies he uses; it's just something that has to be done.

In the in vivo exposures session Mark's tendency for social phobia and avoidance was noticeable, but he succeeded doing most of the planned exposures. Mark was able before the end of treatment to fall asleep in his own room, knowing one of his parents would sleep there and the family was encouraged to make a stepladder with the end goal: "Mark sleeping alone in his room.” In addition, Mark agreed to change the stepladder related to him staying home alone, so that it was logistically easier to implement, but even after the revision, the family still had trouble finding time to practice the stepladder.

f. Parental inclusion in therapy. Parents' homework assignments stimulated a discussion concerning the principles of reinforcement and punishment, where it became apparent that Mark's parents did not follow the same guidelines when reacting to Mark's behavior, while both tended to support Mark's avoidance of feared situations. Mark was very preoccupied with the rewards he would receive for the exposures and mentioned that he would like a laptop as a reward, claiming he could easily persuade his parents to buy such an expensive reward. When the student therapist tried to encourage Mark to choose a reward that was not a material good, he responded with "Then she [his mother] has to see me play football!” and the mother looking embarrassed, explained that it was not that she did not want to see him play, she was just not so fond of football.

Mark got over his enuresis problem while in therapy, the parents writing in an e-mail to the student-therapist: 
A "Cool Kids" Cognitive-Behavioral Therapy Group for Youth with Anxiety Disorders:

Part 2, Analysis of the Process and Outcome of Responders Versus Nonresponders

I. Lundkvist-Houndoumadi \& M. Thastum

Pragmatic Case Studies in Psychotherapy, http://pcsp.libraries.rutgers.edu

Volume 9, Module 2, Article 4, pp. 179-274, 06-26-13 [copyright by authors]

that is probably not something you should mention to Mark, as you principally do not know anything about the pad-project... When looking back it has been too hard doing both at the same time. Now we can better concentrate on the Aarhus-project.

Even though the parents claimed they would be more engaged in therapy, they did not come to the next session with Mark because two of Mark's classmates had been robbed. The parents had difficulties finding detective thinking questions in order to challenge Mark's anxious thoughts and a house visit was arranged, where the missed session was reviewed.

During the house visit, a mother called and asked if she could visit with her son. After asking Mark, the father lied to her saying they had to run for some errands in the city because Mark did not want the boy to meet the student therapist and find out about the program. This was again indicative of a family with a lot of secrecy and lack of open communication. Mark's mother was not present at the house visit because of a business trip and she did not come to the next session either. This presented problems as according to the student therapist there could be no follow-up of certain issues discussed with the mother. In the last sessions the parents seemed worried, because they had not reached the end goal: "Mark being able to come home to an empty house,” and after the summer Mark would no longer be allowed to stay at school, until the parents finished work.

g. Response to treatment as assessed at three points in time. Although Mark was able to sleep in his own room after the end of therapy, he wanted his father to sleep in the same room as him and he feared staying home alone. As shown in Table 5 in Appendix A, the self ratings at post-treatment were very similar to pre-treatment and Mark remained in the clinical group on SCAS-C on all subscales, significantly deteriorating on GAD (statistical significance and large effect was evident). Nevertheless, a positive large effect was identified on the API subscale of SCAS-P. On BYI Mark only completed the BSCI scale, because as the mother wrote: "the questionnaire has been a very big challenge for Mark to complete”.

As at pre-treatment, Mark rated overall his anxiety much higher than his parents, the differences being more pronounced in the subscales referring to internal processes (as OCD and GAD), which is similar to the findings of Nauta and colleagues (2004) and may be explained by the fact that Mark did not share all of his thoughts and feelings with his parents that were more aware of observable behavioral symptoms (such as physical injury fears) related to Mark's anxiety, which can be seen in light of the lack of open communication at home.

At the three-moth follow-up Mark fulfilled the criteria for the specific phobia diagnosis (CSR=7-8), since the father still slept in Mark's room. A statistically significant positive change was found on some subscales of the SCAS-C (panic/agoraphobia, SAD, total) and the total ratings of both parents on SCAS-P decreased (statistically significant change). According to the mother the generalized anxiety also decreased (statistically significant change as seen on SCAS$\mathrm{P}$ ), as well as the interference of anxiety in Mark's and the family's life (statistically significant change and large effect on CALIS). The BYI ratings also showed a positive change (statistical significant change and large effect were found on the anxiety and depression subscales). 
A "Cool Kids" Cognitive-Behavioral Therapy Group for Youth with Anxiety Disorders:

Part 2, Analysis of the Process and Outcome of Responders Versus Nonresponders

I. Lundkvist-Houndoumadi \& M. Thastum

Pragmatic Case Studies in Psychotherapy, http://pcsp.libraries.rutgers.edu

Volume 9, Module 2, Article 4, pp. 179-274, 06-26-13 [copyright by authors]

At the 15-month follow-up Mark's self-ratings on SCAS-C and SCAS-P indicated further anxiety decrease (statistically significant decrease in the total ratings), whereas parental ratings were somewhat similar to the previous assessment. Mark was not given the diagnosis of specific phobia because no interference was reported in everyday life, but that was due to the fact that the family had gotten an au pair girl staying in their house. As they reported:

After therapy we managed that Mark was able to sleep in his own room. He does that still, so this is not a problem any longer. But the au-pair girl is now also the one sleeping in the room closest to the door and if she isn't there, he doesn't feel safe. Then he thinks more about it. And when he gets back from school she is here and that is also the reason why we got her. So the anxiety is still there.

From all the clinical information obtained on Mark, he is judged to be: "Minimally improved" (3) on the CGI-I scale, because there was only little clinically meaningful reduction of symptoms and little change in functional capacity that can be attributed to the treatment.

\section{$\underline{6 .}$ Lene}

a. The client. When Lene came to therapy she was 8 years old and lived with her parents and her older sister in a two-bedroom apartment. Lene looked older than her age (wore size 41 in shoes), but in contrast to her physical appearance appeared childish because of her difficulties in pronouncing some letters. Other than Lene's phobia for dogs, no other sign of anxiety was evident from the first meeting.

b. History. Lene was described as a child with an easy temperament, reaching the milestones in cognitive and social development according to the norms. Since Lene was six months and until she became two years, her father was the main caretaker, since he was not working. He had been afraid of dogs himself as a child and as a grown-up he claimed to dislike them. Lene had been afraid of dogs, since she was very little and she was accusing her father for transferring his anxiety to her. The father worried this might be true, because he had always protected her from dogs, lifting her up if he saw a dog close by. Lene had been bullied in school because of her height and her speech difficulties, nevertheless she enjoyed going to school and was at that time managing fine academically and socially. The mother had suffered from separation anxiety since she was little and until she got her own children. She occasionally had panic attacks and was therefore seeing a psychologist. In addition, Lene's sister had also had some attacks, during which she felt she could not breathe.

c. Status at the time of referral. In the referral letter the mother wrote: "Lene is afraid of animals, worst of all dogs and it is something that affects both her and the rest of the family in everyday life" and at the assessment interview Lene was diagnosed with specific phobia of animal type. The family felt forced to avoid situations in which there was a high probability of meeting dogs, like going to the beach, and considered selling their "allotment" garden house, because the neighbors had many cats. It was the first time the family turned to professional help for Lene's anxiety problems and the mother explained how they were very motivated but lacked skills to help Lene. In the assessment interview it was primarily the mother who talked, while the father 
A "Cool Kids" Cognitive-Behavioral Therapy Group for Youth with Anxiety Disorders:

Part 2, Analysis of the Process and Outcome of Responders Versus Nonresponders

I. Lundkvist-Houndoumadi \& M. Thastum

Pragmatic Case Studies in Psychotherapy, http://pcsp.libraries.rutgers.edu

Volume 9, Module 2, Article 4, pp. 179-274, 06-26-13 [copyright by authors]

sat laid back with his hands crossed and left from the interview alone, without saying goodbye to Lene.

The father was working night shifts (15.00 - 24.00) and slept in a bed in Lene's sister's room, when he got home from work. Lene slept together with her mother and woke up with a scream, if her mother wasn't next to her. The only rating indicating an anxiety problem on the scales completed at the time of referral was on the API (Anxiety of Physical Injuries) subscale of the SCAS $_{\text {mother, }}$ which situated Lene in the clinical range. An unexpected finding was that Lene's report on the anger subscale on BYI was much higher than the mean of the norm group.

d. Engagement in therapy. Lene and both her parents did their homework for the first sessions and that involved mainly exercises on detective thinking. Lene told her student therapist she found the gradual exposures boring, because the steps were either too easy or too difficult. She also commented that "If I really wanted too, it would go much faster [moving up the stepladder] but I don't really bother" and explained how she would rather do other things, like play with her friends. Her lack of motivation and the fact that the parents were not able to encourage her to do exposures, resulted in a very slow progression in the stepladder. Nevertheless, at the in vivo exposures session Lene was able to make progress and after this session both herself and her mother had renewed motivation for doing exposures, practicing every day in the following week. However, the mother argued that this would not have been possible if she had not taken leave from work. The father did not assist in the exposures, and the mother explained that it was her who wanted them to seek help, while the father was not very motivated.

e. Response to therapy components. Lene, contrary to her mother's wishes, would rather do her homework alone, and would get annoyed when she was asked the detective thinking question: "What are you afraid might happen?” While Lene's anxiety would subside after doing detective thinking, the next time she stood in front of a dog she became again extremely anxious. A list of gradual exposures to dogs was then made with Lene and her parents having as end target: "Being able to go alone in the park". It was noticed that whenever the father came up with some ideas for steps, they were either directly or indirectly rejected by the mother, indicating that the parents experienced difficulties working together and possibly had a conflictual relationship.

At the in vivo exposures session, Lene did gradual exposures with a dog together with Stine and the mother was very good in coaching Lene, first approaching the dog herself and afterwards encouraging her to do the same. Lene managed to pat the dog and go for a walk with it, receiving a lot of praise and the mother getting very moved, in contrast to the father who did not comment on anything and was standing at some distance. 
A "Cool Kids" Cognitive-Behavioral Therapy Group for Youth with Anxiety Disorders:

Part 2, Analysis of the Process and Outcome of Responders Versus Nonresponders

I. Lundkvist-Houndoumadi \& M. Thastum

Pragmatic Case Studies in Psychotherapy, http://pcsp.libraries.rutgers.edu

Volume 9, Module 2, Article 4, pp. 179-274, 06-26-13 [copyright by authors]

f. Parental inclusion in therapy. From the first session there seemed to be some communication problems in the family, as the father came with Lene one hour before therapy would start, while the mother came in time and looked very perplexed seeing them there. The mother was very emotional from the first session, obviously being tired of the consequences Lene's anxiety had, saying that: "I would like that all dogs in [the name of their town] would be shot!”

The mother's parenting style and way of interacting with her children became apparent in the parents' group discussions. When parents were asked to give examples of how they might be reinforcing negative behavior of their children she said: "I always run around trying to find which course she would like to eat for dinner," indicating that the mother tended to overextend herself in order to please Lene. On another occasion, when the psychologist asked if there was a parent that had a problem so that s/he could describe how problem solving could be used, Lene's mother presented her problem with her eldest daughter not wanting to go to school the following day. She responded negatively to most of the solutions suggested by the group, because she could not make her daughter go to school if she did not want to- "She gets very sad and I can't do that. I tried once, but it wasn't successful" —and thought that giving a reward was problematic because: "It would have to be a very big reward, a large amount of money, in order for her to accept that." Another parent said she could tell her: "If you don't go to school there will be consequences," and the mother replied: "That would be really hard for me to do. It is very difficult to force her. It would be very difficult for me to decide for her." She finally decided to let her stay home and talk about what it would take for her to go to school the day after that.

The above situation is a good illustration of how the children in the family were not pressured to do anything they did not want to and it highlights the mother's difficulty to act as an authority figure. On some occasions the mother arrived at some insights as when on one occasion while completing some of the parents' homework assignments she realized how she had been reinforcing Lene's avoidance of anxiety provoking situations and tried changing that.

At the house visit the father was absent due to his working hours that allowed him to be together with his family only on weekends. The mother was frustrated because it was difficult to make arrangements with dog owners for doing exposures and when they finally had made an arrangement, Lene came with the excuse that the therapist had not told her she should do that step. As a result, the mother wanted the student therapist to be present when they would plan the new stepladder, once more the mother not being able to act as an authority figure. While the student therapist reminded the mother it was important to include the father in the newly planned stepladder, he had not been informed about it in the next session.

The mother stated half-way in the program:

"I don’t feel like there is any progress. I have tried to shift to having a different view on dogs and their owners. So now it is me that makes progress this week and then I hope Lene will also next week."

The mother was always the one to practice exposures, as Lene claimed her father: "is too annoying” and did not want to do the exposures with him, after he had asked her to do something 
A "Cool Kids" Cognitive-Behavioral Therapy Group for Youth with Anxiety Disorders:

Part 2, Analysis of the Process and Outcome of Responders Versus Nonresponders

I. Lundkvist-Houndoumadi \& M. Thastum

Pragmatic Case Studies in Psychotherapy, http://pcsp.libraries.rutgers.edu

Volume 9, Module 2, Article 4, pp. 179-274, 06-26-13 [copyright by authors]

she was very afraid of (was much higher on the stepladder). The father did not seem to know the stepladders that were planned and unlike the mother was not as sensitive to what Lene thought was difficult.

Furthermore, in contrast to the mother, the father did not seem engaged in the discussions in the parents' group and did not seem to understand how he could be maintaining or even exacerbating Lene's anxiety. He would tell stories in front of her where he or a colleague faced an "angry" dog and became afraid. Furthermore, he claimed their pet (a hamster) bites and when the student therapist said it probably wouldn't hurt, he said "It definitely hurts half as much as being bitten by a dog and that's a lot, because I have tried it!” When the psychologist talked about how parents could act as positive role models and asked Lene's father whether he had come over his anxiety with dogs, the father responded by giving a very long description of his last encounter with a big dog. He did not show any understanding of how he could act as a role model, while his detailed descriptions of "evil" dogs made it clear he had not gotten over his fear.

The father's lack of engagement during treatment was also manifested by his not completing the questionnaires at post treatment. At the three-month follow-up none in the family did, while it was not possible to get a copy of the family's workbooks, as they could not find them at the 15-month follow-up and did not respond to e-mails sent to them.

g. Response to treatment as assessed at three points in time. Although Lene had on some occasions succeeded being near a dog without panicking, and had even sat with a dog at the in vivo exposures session, she was still afraid of dogs at post treatment and avoided situations because of this. A change occurred in the mother, who said she was happy that she no longer got irritated and frustrated with Lene's anxiety and anxious behavior. The program had helped the mother gain a better understanding of anxiety and they tried to fight it, which had been beneficial for her and Lene as well, adding: "We have gotten a very good tool-method to tackle a lot of things which can be scary in everyday life.”

As shown in Table 6 in Appendix A, at post-treatment there were indications of deterioration that were statistically significant on multiple subscales on BYI (measuring selfconcept: BSCI; anxiety: BAI; depression: BDI). In addition, a negative large effect was found on

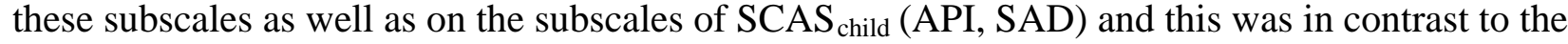
mother's ratings on SCAS-P, which indicated a positive large effect on the API subscale. These findings may be explained by the fact that the mother had stopped supporting Lene's avoidance of dogs and she therefore was confronted with her fears.

At the three-month follow-up Lene still fulfilled the criteria for the diagnosis of Specific Phobia, Animal Type (CSR=5), while no completed scales were obtained at this follow-up. At the 15 -month follow-up Lene again received the same diagnosis $(\mathrm{CSR}=6)$ and she described how she was still afraid of dogs but had somewhat improved. The ratings were overall very similar to posttreatment. Statistically significant change and large effect was found on the anxiety and

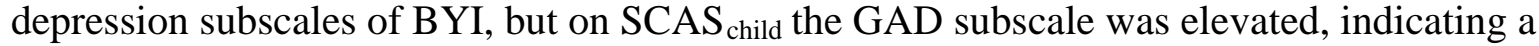
statistically significant deterioration. The most evident discrepancy in the ratings of Lene and her parents (Lene overall rating her anxiety much higher than her parents), were on the GAD subscale and may be explained by the fact that worrying is not observable by others and Lene did not talk 
A "Cool Kids" Cognitive-Behavioral Therapy Group for Youth with Anxiety Disorders:

Part 2, Analysis of the Process and Outcome of Responders Versus Nonresponders

I. Lundkvist-Houndoumadi \& M. Thastum

Pragmatic Case Studies in Psychotherapy, http://pcsp.libraries.rutgers.edu

Volume 9, Module 2, Article 4, pp. 179-274, 06-26-13 [copyright by authors]

with her parents about her worries, who rated based on external manifestations of the anxiety. This observation argues in favor of including both parents and children in the rating of anxiety, as anxiety is an internalizing disorder and it is problematic if only parents' ratings were included.

From all the clinical information obtained on Lene, she is judged to be: "Minimally improved" (3) on the CGI-I scale, because there is only little clinically meaningful reduction of symptoms and little change in functional capacity.

\section{CONCLUDING EVALUATION OF THE THERAPY'S PROCESS AND OUTCOME}

\section{Measures Of Outcome}

Effect Sizes for the Group as a Whole

A series of Wilcoxon signed-rank tests for related samples were computed and effect sizes were calculated on the ratings of children and mothers on the SCAS (total and primary diagnosis score) and CALIS (child and family interference score) at the following time-intervals: a) pre-post treatment, b) pre-3 months follow-up and c) pre-15 months follow-up. In Table 2 the mean and effect sizes of the group are presented.

Results indicate that at post-treatment, although mothers' rating of their children's total anxiety score on the SCAS did not reveal any effect at post treatment, their rating of their children's primary diagnosis had decreased in severity showing a large effect size $(r=0.91)$. Further, at post treatment, on the CALIS the mothers no longer believed that anxiety interfered in family life to the same degree $(r=0.90)$. At the three-month follow-up both mothers and children rated the total anxiety lower, revealing effect sizes of .82 and .78, respectively. At the 15-month follow-up the mothers again reported a decreased total anxiety $(\mathrm{r}=0.82)$ and lower interference in family life ( $\mathrm{r}=0.90)$, while none of the children's self-ratings showed large effect sizes at this time.

\section{Assessment of Individual Responses to Treatment}

The ranking of cases according to their response to treatment is presented in Table 3, based on different combinations of the two criteria of change utilized: a) statistically significant change in a positive direction, b) clinical change. From the different rankings of treatment outcome it becomes apparent that one child, Erik, shows response to treatment with a ranking of 1, fulfilling the strictest criteria: statistical significant change and clinical change on both children's and mothers' ratings at the different points in time and the different measures.

When examining the response rate as indicated by statistically significant change or clinical change at the SCAS-total of children or mothers', several children showed response to treatment. At post treatment half of the group (Erik, Stine and Tom) appears to have responded to treatment, given a ranking of 2, while at the two follow-ups one more child (Mark) fulfilled the criteria. A ranking of 3 indicating statistically significant reduction, or clinical change on the primary diagnosis on SCAS mother $_{\text {or }}$ SCAS $_{\text {child }}$ is granted to four children (Erik, Stine, Niels, 
A "Cool Kids" Cognitive-Behavioral Therapy Group for Youth with Anxiety Disorders:

Part 2, Analysis of the Process and Outcome of Responders Versus Nonresponders

I. Lundkvist-Houndoumadi \& M. Thastum

Pragmatic Case Studies in Psychotherapy, http://pcsp.libraries.rutgers.edu

Volume 9, Module 2, Article 4, pp. 179-274, 06-26-13 [copyright by authors]

Tom) at post-treatment and at the three-month follow-up, with the addition of Mark at the 15month follow-up.

In general, it seems that all rankings include an increasing number of responders over time (with the exception of ranking 1), which may be explained by the fact that the children, possibly with their families' assistance, kept on working on the anxiety issues as they had the needed tools to do so. Nevertheless, explanations regarding treatment outcome and factors that may have contributed to different response rates have to be considered as tentative, since the above findings are all based exclusively on quantitative information obtained from the selfreport scales administered.

\section{$\underline{\text { Diagnoses }}$}

In-depth information about diagnoses was gathered by the ADIS-IV interview, as the families were able to express the difficulties they experienced in their own words, while the clinician assigned the severity ratings. The diagnoses of the six children at the time of referral and at 3-month and at 15-month follow-up is presented in Table 1. As can be see, the four of the six children with a CGI-I rating of 1 or 2 (Erik, Niels, Stine, and Tom) were diagnosis-free at the 3-month follow-up and a fifth child, Mark, at the 15-month follow-up.

All information gathered, both quantitative and qualitative, was taken into consideration when giving the CGI-I ratings to the children 15 months after the end of treatment (see Table 1). Four (Erik, Niels, Stine and Tom) obtained ratings that indicate response to treatment, while two (Mark and Lene) did not. Erik was the only one to obtain a CGI-I rating on 1, which is based in part on the data in Table 3 showing that only Eric had statistically significant reduction and clinical change on the SCAS child $_{\text {and }}$ SCAS $_{\text {mother }}$ at all three time periods: post-treatment, 3month follow-up, and 15-month follow-up. Although Mark was diagnosis free at the 15 month follow-up and showed response to treatment on several response rankings on SCAS, as indicated above, these changes cannot be attributed to the treatment but to the parents providing a new environmental support for reducing Mark's anxiety. Specifically, the parents had arranged for an au pair girl to stay in their house and sleep in a room close to the door of Mark's room, allowing Mark to sleep in his own room. Mark was therefore given a CGI-I rating of 3, indicating non-response. This exemplifies the importance of including qualitative information in the overall evaluation of outcome.

\section{Family Overall Satisfaction With the Treatment}

All the children and their parents were asked to provide an evaluation of the treatment program post therapy as well as 15 months later. As seen from the rating results shown in Table 4, overall the ratings indicate a high level of satisfaction with the Cool Kids Program.

In order to identify variables enhancing or impeding change in the group of responders and non-responders, the therapy process will be examined below on the basis of qualitative data focusing on four elements in therapy: i) motivation and engagement in therapy, ii) therapeutic components of the Cool KidsProgram, iii) changes in parenting behaviors, and iv) group format. 
A "Cool Kids" Cognitive-Behavioral Therapy Group for Youth with Anxiety Disorders:

Part 2, Analysis of the Process and Outcome of Responders Versus Nonresponders

I. Lundkvist-Houndoumadi \& M. Thastum

Pragmatic Case Studies in Psychotherapy, http://pcsp.libraries.rutgers.edu

Volume 9, Module 2, Article 4, pp. 179-274, 06-26-13 [copyright by authors]

\section{Differentiating Responders From Non-Responders: Motivation and Engagement in Therapy}

When children are referred for treatment, they may not necessarily experience their 'problem' as one needing to change (McAdam, 1986; Rubenstein, 2003; Weisz \& Hawley, 2002) and may instead be afraid of giving up previous inappropriate coping strategies (e.g., avoidance), play down or deny the negative consequences of their anxieties, and be reluctant to engage in treatment (Stallard, 2009). Therefore the first, and arguably, the mo

st important goal towards a successful treatment is to get the child motivated for and engaged in the therapy process.

All children in the present study who were classified as responders (except Tom) evaluated therapy as being "fun”, while non-responders said it was merely "ok" (see Table 4.b). What seemed to be enhancing children's motivation for therapy were the practical exercises and rewards, which most children recalled and described 15 months later as challenging but also fun:

The play [role playing in the social skills training] was lots of fun. It was a nice way of learning something." (Erik) "I remember the time we were at the shopping mall and the other girl that was afraid of dogs. It was really nice. I was a bit afraid [of the dog] in the beginning but I ended up sitting with it [the dog]. I thought that was a good idea [to have an in vivo session]...And I remember doing that play, where you had to say different things [assertiveness training]. You had to look the other in the eyes, or be a scared mouse or a mad crocodile. I like doing plays so I thought that was fun.” (Stine). "It was really nice we got stickers. I also think I was the one that got most stickers. I had three and a half rows of them on my workbook... (Niels).

It seems reasonable to assume that in order to enhance children's motivation to practice the treatment components, children need to believe that being engaged in therapy and using the components will help them change and get over their anxiety. Assessing that motivation seems to be elusive as for example children's completion of homework has not been found to predict therapy outcome post therapy or one year later (Hudges and Kendall, 2007). This may be attributed to the fact than an overall measure of homework completion is not a valid indicator, because some of the exercises (e.g., doing exposures systematically) may be more important than others. Kendall and colleagues (1998) found that positive change occurred in the children's treatment group after the exposures sessions, while Chu and Kendall (2004) concluded that therapists' ratings of children's engagement in the middle of the course of CBT, right before the implementation of exposures, but not earlier, was related to a positive treatment outcome.

In addition, Westra, Dozois, and Marcus (2007) have reported findings which suggest that change expectancy might be an important cognitive variable that provides the initial drive and subsequent involvement for therapeutic gains. For the purpose of the present study, information on children's practice of the treatment components in between sessions was obtained primarily from student therapists' journals as the families did not indicate in the workbooks the number of exposure exercises done. 
A "Cool Kids" Cognitive-Behavioral Therapy Group for Youth with Anxiety Disorders:

Part 2, Analysis of the Process and Outcome of Responders Versus Nonresponders

I. Lundkvist-Houndoumadi \& M. Thastum

Pragmatic Case Studies in Psychotherapy, http://pcsp.libraries.rutgers.edu

Volume 9, Module 2, Article 4, pp. 179-274, 06-26-13 [copyright by authors]

\section{Very Much Improved: Erik}

When Erik came to treatment he was tired of psychologists, nevertheless after the first sessions his father described how Erik was motivated for change to happen:

He just really wants to get over his anxiety. For instance, he said the other day: I will never get a girlfriend because I am such a wimp. What motivates him to continue [the program] is that he desperately wants to be able to do the same things as his friends.

Even though Erik was not very engaged during the first sessions that focused on detective thinking, he became motivated to do the exposures because he could directly see the point of practicing that would help him achieve his goal: "being able to do the same things as his friends." His age (12 years and the oldest in the group) might have contributed to this, since peers' opinion is important in pre-adolescence. The relationship identified by Chu and Kendall (2004) between a positive therapy outcome and a high motivation to engage in therapy before the exposures was confirmed also here.

Erik was cognitively mature to be able to see the long-term perspective in practicing and unlike the other children did exposures that were not planned. He wanted to challenge his fears and was not as interested in the material rewards, as for him the reward was to be able to do what he had been afraid of. The motivation observed in Erik's case can be described as intrinsic and functioned possibly as a facilitator of change.

Following the end of treatment, Erik made further progress, because he kept on challenging himself by facing his fears, not needing to do it as part of planned stepladders (steps of gradual exposures). As the mother related:

He told me the other day he really hoped the last part [him being able to take the bus alone] would come soon, so that he could feel completely like the others...I can feel that he really wants to try things on his own.

Erik's motivation to get past his anxiety was related to him wanting to be independent of his mother and part of a peer group and can be seen as possessing the characteristics of what Frank (1982) calls "the good client”. A good client experiences enough distress in order for him to be motivated for the treatment and at the same time has the ego-strength and coping-capacity in order to be able to profit from it. In addition, Erik was supported by his parents in his efforts to change and an important motivation seemed to stem from his wish to make his father proud. One of his student therapists wrote:

During the course of therapy, when the father found out what the program was about, he appeared to become very motivated to be part of it...this support was a help to Erik's motivation and engagement, because it also meant quality time with dad...

\section{Much Improved: Niels, Stine, Tom}

It is possible that not all children who showed progress understood the long-term consequences of their actions, due to their younger age and in those cases extrinsic rewards and 
A "Cool Kids" Cognitive-Behavioral Therapy Group for Youth with Anxiety Disorders:

Part 2, Analysis of the Process and Outcome of Responders Versus Nonresponders

I. Lundkvist-Houndoumadi \& M. Thastum

Pragmatic Case Studies in Psychotherapy, http://pcsp. libraries.rutgers.edu

Volume 9, Module 2, Article 4, pp. 179-274, 06-26-13 [copyright by authors]

praise appeared instrumental in enhancing their motivation to practice the therapeutic components.

Niels. When Niels, who at first was very quiet in therapy, noticed that others received rewards (stickers) and praise for participating, he asked: "If I do this [raise my hand], will I then get a sticker?” and afterwards made great efforts to talk in the group. In order to maintain Niels' motivation parents chose not to pressure him to do homework during therapy.

It wasn't every day we practiced but we talked about it. I think it went very well with talking about the things with him and he looked forward coming here. We could hear from some of the other parents that their child didn't really bother any longer and that is not something we experienced with Niels...

After therapy motivation played a significant role in Niels’ progress according to his parents:

I think that what makes him do something or not has changed. Now it is not anxiety, but whether he wants to do it. He has gotten some new interests that give some new perspectives on it. He is crazy about football and he might go to football although his best friend doesn't. He would never want to do that earlier. But this football is so exciting and then he thinks: ' $\mathrm{I}$ can get past these things [related to social anxiety]'

Stine. It was obvious that Stine liked coming to the Cool Kids Program, always having a hand raised up during sessions and commenting at the evaluation: "There was nothing I didn't like about the program." She was obviously happy about the results, commenting that her student therapist: "should have all the stickers in the world for her help!" Stine's parents were very happy to be included in the therapy program and felt understood in that Stine's specific phobia had a big impact on the family. Parents' appreciation for getting help and their motivation had possibly also a positive influence on Stine's perception of the program and her engagement in the treatment process.

Stine was motivated to stop avoiding situations because of her anxiety and she succeeded this by incorporating the tools she acquired in therapy in the way she handled situations:

I remember in 2nd grade I didn't get to a friend's birthday because she had a dog. And everyone talked about how fun it had been afterwards. Now I go to parties. And I just ask: Where is the dog? How is it? Does it come to you when it sees you? And then I have other thoughts in my head. I think of something else.

Stine would ask questions in order to prepare herself for an encounter with a dog, followed by worry surfing that consisted of transferring attention and concentration from the things that cause worry to other issues, so that she could relax.

Stine enjoyed getting rewards for answering questions, but most of all she smiled and was happy when receiving positive attention for her progress from anyone in the group. Her parents encouraged Stine and when for the first time she succeeded in walking a dog, they took pictures in order for her to show them to the group. When Stine was asked whether she was proud of herself for the progress she had made, she answered: “A lot! And my mother also has kept on her 
A "Cool Kids" Cognitive-Behavioral Therapy Group for Youth with Anxiety Disorders:

Part 2, Analysis of the Process and Outcome of Responders Versus Nonresponders

I. Lundkvist-Houndoumadi \& M. Thastum

Pragmatic Case Studies in Psychotherapy, http://pcsp.libraries.rutgers.edu

Volume 9, Module 2, Article 4, pp. 179-274, 06-26-13 [copyright by authors]

mobile a picture of me walking the dog." Stine felt her parents were proud of her and this motivated her to try further and consequently to progress. It seems that parental engagement in therapy and support enhances children's motivation, while at the same time children's motivation and subsequent engagement and progress in therapy motivates parents to be engaged in the treatment process; child and parents thereby influence each other.

Furthermore, similarly to Erik, Stine was according to the mother motivated to change her anxiety-related behavior in order for her not to feel embarrassed in front of her friends:

It [the anxiety] is not something you automatically grow out of. Our every day has changed and they [Stine and her younger sister] for instance ride to school on their own [with some friends but without parents]. As she gets older she probably does not want to react by standing in the middle of the path crying in front of others if she sees a dog. Earlier she would have done so, no matter what. But she is at an age now, when you start thinking about it. I mean it is not so cool to act like that after a certain age, when with peers.

Even though age in itself may not result in children "growing out" of their anxiety, their motivation to learn relevant techniques is enhanced, as they face more situations they need and want to handle on their own.

Tom. As in Stine's case, the positive role parents may have in enhancing motivation is also apparent in the case of Tom, who responded to treatment, even though he did not seem very motivated in the therapy sessions and in contrast to the other responders rated the program as being merely "ok". The student therapists felt it was difficult to form a connection to him, because he seemed uninterested or tired in the sessions and at times they felt they had to reprimand him to pay attention. They claimed: "we were able to reach Tom through the parents."

Consequently, Tom practiced the therapy components in between sessions, as his parents would encourage him by supporting his efforts and showing him they believed the program was important. They offered to watch a cartoon with a detective when introduced to detective thinking, told him he did not have to complete homework for school at days he would practice a lot for the Cool KidsProgram and showed their own engagement in therapy by spending time on their own homework.

It was our impression that the parents' efforts were the main reason Tom was motivated to practice the components, the father commenting at the interview: "Tom learns very fast and when you tell him to do something, he actually also does it!” According to all student therapists, Tom ended up being the child who understood best the treatment components, easily knowing how to use them if needed. When he experienced problems sleeping alone, he reported that he would do worry surfing: "I lie down and look around and then try to sleep while I think of the things I have seen." At the therapy evaluation he commented: "What was good about it [therapy] was that we learned things in order for us not to be afraid...”

Just as in Stine's case, Tom's father also mentioned how he thought Tom's motivation to face his fears would be enhanced as he grew older and he would want to do the same things as his peers: 
A "Cool Kids" Cognitive-Behavioral Therapy Group for Youth with Anxiety Disorders:

Part 2, Analysis of the Process and Outcome of Responders Versus Nonresponders

I. Lundkvist-Houndoumadi \& M. Thastum

Pragmatic Case Studies in Psychotherapy, http://pcsp.libraries.rutgers.edu

Volume 9, Module 2, Article 4, pp. 179-274, 06-26-13 [copyright by authors]

Also I think the age does something because now for instance he dares do the dragon [a rollercoaster at Legoland] and then there is something from the more wild things he dares to do with his friends. And then we will have to wait and see what the next thing is, because when he gets to be 14-15 he might dare do most of the things. Then he might not feel abnormal or different any longer. Not that I think he thinks so, but he knows there are some things he doesn't dare do with his friends. So there I hope the age will also help him a bit.

\section{Minimally Improved: Mark and Lene}

When looking into the cases of Mark and Lene, who did not respond to treatment, it is obvious that they were not very motivated to get past their anxiety and the parents did not succeed to motivate them to change.

Mark. Mark explained at the interview the reason he was not motivated in therapy: "In the beginning it was boring because it was hard to understand these things [the components]." It was difficult for Mark to understand cognitive restructuring, which was the first component children were introduced to and he was unable to see the long-term perspective of attending therapy, claiming after the first session that it had not helped him and that he no longer wanted to attend the program.

The mother persuaded him not to drop out of therapy, but she needed to bribe him with material goods in order to do so and it is questionable whether this gesture communicated the importance of attending therapy. When the mother heard he had actually participated in the children's group, she commented: "I thought you promised you wouldn't say a word in there," which probably indicated that Mark had agreed to be only physically present, being motivated by external factors to do so. Luckily he had gotten carried away and forgot his "promise" to the mother, but unfortunately the mother did not praise him to reinforce his effort.

During the course of therapy Mark's student therapist tried making suggestions to change the stepladder, so that it would be easier for the family to implement. Mark did not want to and his parents did not argue with him about it. Mark's parents seemed surprised that therapy demanded so much practice and time from them and they had trouble prioritizing the program even though they had put off seeking help, waiting until the mother could find the time for it. The parents seemed also overwhelmed by the demands placed on them in helping Mark get over enuresis "When looking back it has been too hard doing both at the same time."

There were indications of an impaired collaboration which has been found to decrease the treatment outcome (Marder \& Chorpita, 2009), since a parentally imposed secrecy hindered open communication between Mark and the student therapist, the parents commenting: "But that [enuresis] is probably not something you should mention to Mark, as you principally do not know anything about the pad-project...”. Further, attending the clinic was kept a secret and was not an issue openly discussed in the family or school unlike for example in Stine's case.

Mark liked challenging his parents and would question their engagement in therapy. His parents would forget to complete their own homework and it was obvious his impression was that they would not go to great lengths to support him, if it was inconvenient for them. When the 
A "Cool Kids" Cognitive-Behavioral Therapy Group for Youth with Anxiety Disorders:

Part 2, Analysis of the Process and Outcome of Responders Versus Nonresponders

I. Lundkvist-Houndoumadi \& M. Thastum

Pragmatic Case Studies in Psychotherapy, http://pcsp.libraries.rutgers.edu

Volume 9, Module 2, Article 4, pp. 179-274, 06-26-13 [copyright by authors]

student therapist came up with the idea that the father could assist in the implementation of the stepladder, Mark’s reaction was: "He can’t do that! [challenging his father's willingness]" and when asked by the student therapist if he wanted to do something nice with his parents as a reward, he said: “Then she [his mother] has to see me play football!"'exposing his mother's reluctance]. It seemed as if Mark doubted his parents' commitment to devote time to him, while he was preoccupied by what he could get out of them in terms of material goods, for practicing, as he was not really motivated for it. He proudly explained to the student therapist that he easily could persuade his parents into buying him a laptop to do a step on the stepladder.

Mark did not succeed reaching his goal while in therapy, but after the end of treatment he did: "For a while I dared go home alone and I stayed home alone for many hours. So it [therapy] helped me with what I should do there...I used detective thinking.” Mark had reached an age when according to school regulations he was no longer allowed to stay at school until his parents came to pick him up after work, and had to be at a youth club instead, an alternative he disliked because he did not know anyone there. Up until then Mark was not motivated to practice doing the things he feared, as he could stay with his friends at school. His parents were unable to motivate him to use the components either while in therapy, or later when after a frightening incident he relapsed and the parents chose to hire an au-pair girl.

Mark's parents supported his avoidance and would not let him experience the negative consequences of his anxiety, as the responders did. For example his father was willing to lie to another parent and move Mark's bed out of the parents' room, so as to hide his anxiety problem from his friends. The secrecy in the family and the parents' supporting Mark's avoidance contributed to him not facing situations that could be embarrassing sparing him of any negative consequences. This resulted in Mark not being motivated for change, while at the same time receiving the message that there was a reason to be embarrassed of his anxiety. Once more it becomes evident that parents have an essential role to play in children's motivation for change.

Lene. At the beginning of therapy the mother was very motivated for Lene to make progress because her avoidance resulted in the family not doing many things the mother would like them to be able to. Unfortunately, Lene did not appear to be motivated when she should start doing exposures: "If I really wanted to, it would go much faster [moving up the stepladder] but I don't really bother”. This may have contributed to the limited response to treatment, supporting the findings by Chu and Kendall (2004) that children's engagement in therapy right before the implementation of exposures is associated with treatment outcome. Lack of engagement at that point in therapy results in fewer implementations of exposures and impedes change. Lene's lack of progress in turn did not motivate her to be engaged in the treatment process, as she could see that she lagged behind the other children in the group. It is possible that this made her feel uncertain about her capabilities and her claim, "I don't really bother," may actually reflect a denial of her insecurity/low self-efficacy.

As it became more obvious later on, the mother lacked the parental authority to encourage Lene to do the exposures. The mother's parenting fit what Baumrind (1967) has named a permissive parenting style: "I always run around trying to find which course she would like to eat for dinner”, demonstrating inability to persuade the eldest daughter to attend school: "That would 
A "Cool Kids" Cognitive-Behavioral Therapy Group for Youth with Anxiety Disorders:

Part 2, Analysis of the Process and Outcome of Responders Versus Nonresponders

I. Lundkvist-Houndoumadi \& M. Thastum

Pragmatic Case Studies in Psychotherapy, http://pcsp.libraries.rutgers.edu

Volume 9, Module 2, Article 4, pp. 179-274, 06-26-13 [copyright by authors]

be really hard for me to do. It is very difficult to force her. It would be very difficult for me to decide for her". The lack of parental authority became problematic in the implementation of the exposures, as the mother was frustrated with Lene who would not do the exposures, claiming the student therapist had not told her so. This resulted in the mother needing the student therapist as a witness because Lene would otherwise not listen to her.

Permissive parents engage in little control of their children's behavior and most of the times avoid making demands or imposing limits. This may contribute to their children having difficulties controlling their impulses and reacting with disobedience (Baumrind, 1967). This is illustrated in Lene's behaviors, as she rejected doing exposures and was unable to control her impulse to "flee" from an anxiety provoking situation, showing an immature way of thinking based on immediate satisfaction: "I prefer playing with friends".

The mother was unable to communicate to Lene the importance of practicing and ended up being frustrated and feeling helpless. On the rare occasion Lene would do the exposures it was because she did not want to appear childish in front of people she looked up to, the mother not being someone she wanted to make proud. Lene's motivation was clearly extrinsic, she had no wish to use the knowledge obtained in treatment, other than to receive positive attention. It was a wish limited to looking good in a particular situation and not a wish to be able to manage these situations better in the future. As the mother described:

Anxiety for these dogs has been greater compared to the wish to be free from the anxiety. In contrast to many of the others in the group that wanted to practice and get rewarded, Lene didn't have that at all. It was so hard to make her practice. It was hard to find a reward for her and we got to talk about her maybe being spoiled, because we already did the things she wished... She won't do it for my sake but she doesn't want to be this little girl that is afraid of dogs when grownups she looks up to are present. I haven't succeeded in giving her that: 'Lene now I will be really proud of you if you do this.' She will do it more in front of others she doesn’t know well.

Lene was not motivated for change, as she was according to the mother "spoiled", probably as in Mark's case due to parents' lack of setting demands. The mother had trouble persuading Lene to practice, which is possibly related to the fact that children of parents with a permissive parenting style tend to be overly demanding and depend on adults, showing less persistence in tasks than do children of parents who exert more control (Baumrind, 1991).

It was difficult for the mother to function as a coach and therefore the components were not systematically practiced and change could not occur. The mother described at the interview how she was waiting for Lene to become motivated so that they could work on her anxiety and until then, she tried to put up with it. This is in line with the description of permissive parents as having trouble to engage in effective autonomy granting, allowing children to make their own decisions at an age they are not yet capable to do so. Lene was at an age when it was difficult for her to see the long-term consequences of her anxiety, and the mother would let her decide on her own whether she wanted to work on getting over her anxiety:

It [anxiety] is something we have learned to live with and I think I have worked so much with it that I now have chosen to say that now it is [the anxiety] to this degree and that's how 
A "Cool Kids" Cognitive-Behavioral Therapy Group for Youth with Anxiety Disorders:

Part 2, Analysis of the Process and Outcome of Responders Versus Nonresponders

I. Lundkvist-Houndoumadi \& M. Thastum

Pragmatic Case Studies in Psychotherapy, http://pcsp.libraries.rutgers.edu

Volume 9, Module 2, Article 4, pp. 179-274, 06-26-13 [copyright by authors]

things are. The day Lene comes and says that she wants to do something about it then I will be ready again to work on it. But now I won't spend more effort on it, although it stops us from doing things I would like us to.

The parents' role in the treatment process and Lene's lack of motivation to change was summarized by the student therapist:

In my work with the family I found that the parents' effort to work on it was of decisive importance, because Lene from the start was not especially motivated to change anything. It was as if she had difficulties in realizing that her anxiety for dogs was an obstacle preventing her to do a lot of things.

\section{Commentary on Motivation and Engagement in Therapy}

Considering the children studied, the intrinsic motivation seen in Erik's case contributed most effectively in practicing as it was done on his own initiative and did not depend on external rewards. The remaining children who responded to treatment were younger and had difficulties seeing the long-term perspective of practicing in order to get past their anxiety. In those cases, rewards and praise acted as extrinsic motivators and the children's wish to please the parents and make them proud contributed to the children practicing the components that were instrumental in bringing about change. The non-responders lacked motivation to practice the exposures and get over their anxiety and any difficulties in practicing were not counterbalanced by either high parental engagement or effective parenting. What seemed to moderate the degree of children's motivation in treatment and their practice of treatment components was children's age, with associated cognitive developmental level and increasing peer group influence, the parent-child relationship and parental engagement in therapy.

The degree to which parents were engaged in treatment was examined through both quantitative and qualitative data. An overall index (Range=0-80) indicated the extent of parental attendance, the amount of homework completed in the first three sessions, self-reported practice in treatment components and a rating given by student therapists. Findings revealed that parents of the responders were more engaged in the treatment process $\left(M_{R}=55.25\right)$ than those of nonresponders $\left(\mathrm{M}_{\mathrm{NR}}=46.00\right)$.

Parents may have a role in children's motivation and this is supported by a meta-analysis of research findings that has indicated that both youths' and parents' willingness to participate in therapy act as moderating variables in therapy outcome, when applying CBT techniques to childhood anxiety disorders (Karver, Handelsman, Fields \& Bricman, 2006).

\section{Differentiating Responders From Non-Responders: Therapeutic Components of the Cool Kids Program}

When families were asked the open ended question after the end of treatment: "What was good about therapy?" five out of six families highlighted the various treatment components that helped them tackle anxiety. At the 15 month follow-up interview this issue was explored further, in order to examine the different treatment components involved in bringing about change. Children were asked to fill out a questionnaire that assessed the extent to which those components 
A "Cool Kids" Cognitive-Behavioral Therapy Group for Youth with Anxiety Disorders:

Part 2, Analysis of the Process and Outcome of Responders Versus Nonresponders

I. Lundkvist-Houndoumadi \& M. Thastum

Pragmatic Case Studies in Psychotherapy, http://pcsp.libraries.rutgers.edu

Volume 9, Module 2, Article 4, pp. 179-274, 06-26-13 [copyright by authors]

were understood [i.e. were developmentally appropriate], helpful and integrated in their handling of anxiety-provoking situations. The questionnaire had a scale as follows: $0=$ not at all, $1=$ a bit, $2=$ to some degree, $3=$ to a large degree, and 4=very much. In addition, parents were asked to which degree they thought the treatment components had helped their child.

Children had difficulties remembering some of the treatment components and in view of the already limited number of cases it did not seem meaningful to calculate means separately for the group of responders and non-responders. The ratings were evaluated at a group level, in order to draw conclusions on the different components, while qualitative information allowed exploring the ways the different components were adopted by the families of responders versus nonresponders.

Children's ratings showed that overall the treatment components were relatively easy to understand, indicating that they were developmentally appropriate, with stepladders $(\mathrm{M}=3.33)$ and social skills training ( $\mathrm{M}=3.00)$ obtaining highest ratings, followed by worry surfing $(\mathrm{M}=2.80)$, detective thinking $(\mathrm{M}=2.67)$ and problem solving, $(\mathrm{M}=2.50)$.

Social skills training, stepladders and worry surfing involved active exercises that did not demand writing and were therefore not as cognitively demanding. Erik explained: "I generally learn more by doing things instead of sitting down with a piece of paper. More active things in therapy would be a good idea." On the other hand, detective thinking and problem solving involved written exercises and demanded a certain level of self-reflection and consequent thinking, which might have been difficult for some children. This is in line with children mentioning at the interview that what they recalled and enjoyed the most were active exercises, which did not involve writing.

Children and parents rated the two main components of CBT as very helpful: stepladders (exposures; $\mathrm{M}_{\text {children }}=2.67, \mathrm{M}_{\text {parents }}=2.83$ ) and detective thinking (cognitive restructuring; $\mathrm{M}_{\text {children }}=2.60, \mathrm{M}_{\text {parents }}=2.42$ ) obtained the highest ratings, followed by worry surfing $\left(\mathrm{M}_{\text {children }}=2.40, \mathrm{M}_{\text {parents }}=2.0\right)$.

Worry surfing is part of the "third wave" of CBT and may be related to mindfulness practices that are essentially attention-enhancing techniques that have shown promise in treating adult anxiety and depression (Baer, 2003). It is hypothesized that since impaired attention is an important symptom of anxiety, enhancing self-management of attention should contribute to anxiety reduction. However, very few studies have explored the potential benefits of mindfulness in treatment of anxious children. A randomized controlled trial by Semple, Lee, Rosa and Miller (2010) studied the extent to which group mindfulness-based cognitive therapy for children (MBCT-C) increased social-emotional resiliency through enhancement of mindful attention. Findings revealed significant reductions in anxiety problems in children who had reported clinically elevated anxiety at pre-test. This finding and children's reports in the present study indicate that worry surfing (mindfulness exercises) may be contributing to a positive therapy outcome and deserves more attention.

Children and parents gave lower ratings on the degree to which problem solving $\left(\mathrm{M}_{\text {children }}=2, \mathrm{M}_{\text {parents }}=1.83\right)$ and social skills training $\left(\mathrm{M}_{\text {children }}=1.17, \mathrm{M}_{\text {parents }}=1.64\right)$ were helpful. 
A "Cool Kids" Cognitive-Behavioral Therapy Group for Youth with Anxiety Disorders:

Part 2, Analysis of the Process and Outcome of Responders Versus Nonresponders

I. Lundkvist-Houndoumadi \& M. Thastum

Pragmatic Case Studies in Psychotherapy, http://pcsp.libraries.rutgers.edu

Volume 9, Module 2, Article 4, pp. 179-274, 06-26-13 [copyright by authors]

Most likely these components received low ratings because children's responses focused on how much the components had helped them specifically with their anxiety, whereas problem solving and social skills were part of additional training that would be helpful in solving difficulties in their daily lives in general. Although social skills training did not obtain an overall high rating, it proved helpful in some cases, as for example in Erik's, who learned to be more assertive:

Earlier I was one that others overlooked in my class and didn’t care about. Now I have actually gained a lot of respect in my class. Before I would do as they told me to. Then I pulled myself together to answer back and this has given me respect in my class.

Interestingly, when children were asked to rate the extent to which they used the different components, the ratings showed limited use, with worry surfing and detective thinking obtaining the highest ratings ( $M=2.00$ and $M=1.17$, respectively). This may be attributed to the fact that it was difficult for the children to put labels (name the components) on the techniques they actually used as an integrated part of their repertory of behaviors, e.g., they may be facing anxiety provoking situations (doing exposures) without planning stepladders. It is also possible that several children no longer believed they experienced any significant anxiety problems.

\section{Very Much Improved: Erik}

Erik had difficulties in completing the detective thinking exercises: "It is hard for me to know what to write down, when I am not in the [feared] situation," and when his parents tried to assist him in this, they reported that: "He couldn't put words on what it was he was afraid of and then we asked him a lot of questions... where can you feel it?... Then he yelled: 'I don't know!' And he started crying...” This supports Bolton's (2004) concerns that children may find it difficult to answer directly to questions that concern feelings and emotions that are related to problematic situations, especially when they are not experiencing them at that moment.

It has been claimed (e.g. Shirk, 2001) that CBT interventions will be more effective for those functioning at more advanced levels of cognitive development. However, Erik, who had cognitive difficulties, had the best treatment outcome in the group studied and several explanations can be suggested for this finding.

First, the present finding is in line with those of previous studies (e.g. Nakamura et al., 2009) indicating that the cognitive elements of therapy only add very little to the therapy effect. In the case of Erik it was obvious that tremendous progress occurred after he was introduced to stepladders and started doing exposures, demonstrating that exposures were the main mechanism of change. His distorted attributions were challenged through exposures as he came to realize situations he feared were not dangerous and he could master them. As he said after the end of treatment: "Through this thing here [treatment]. I got the push I needed", "the push" referred to him being encouraged during treatment to face his fears through exposures.

Surprisingly, at the 15-month follow-up interview, cognitive restructuring was pointed out by Erik as the most helpful treatment component, indicating it had an important role in the longterm positive effects of treatment shown in his CGI-I rating. It seems that stepladders (exposures) are important while children are still in therapy and they need to get past their anxiety, but when it 
A "Cool Kids" Cognitive-Behavioral Therapy Group for Youth with Anxiety Disorders:

Part 2, Analysis of the Process and Outcome of Responders Versus Nonresponders

I. Lundkvist-Houndoumadi \& M. Thastum

Pragmatic Case Studies in Psychotherapy, http://pcsp.libraries.rutgers.edu

Volume 9, Module 2, Article 4, pp. 179-274, 06-26-13 [copyright by authors]

comes to maintaining gains detective thinking (cognitive restructuring) plays an important role, as it helps children challenge the worrisome thoughts so that they can expose themselves to anxietyprovoking stimuli.

L-H (first author): Which component do you think helped you the most? (The list of therapy components are shown to Erik)

Erik: Detective thinking is what has helped me through most of my life. When I have been in a situation, as for example, alone outside, taking a bus, then I have used it and I have thought: 'What could happen? What is the worst that could happen? Why?' And things like that...And this has helped me a lot. Then I am not at all afraid afterwards. Then I totally relax. I usually remember to use it myself and my parents remind me of it sometimes.

L-H: What about the stepladders?

Erik: No, I don’t really use it. I think I am about to be free of all my problems. I can't actually remember the last time I had an anxiety problem. It is a really long time ago.

Another explanation for Erik's positive response to treatment is related to the role of the mother in the implementation of the treatment components, as the "push" would not have been successful if his mother had kept on overprotecting him as she did before therapy. This maintaining factor was altered during therapy, since the mother was taught during treatment to function as the child's coach. She assisted him in cognitive restructuring by coming up with suggestions of questions he could ask to challenge the worrisome thoughts that characterize GAD. The mother helped Erik for example calm down while sitting in the dentist's waiting room. This illustrates Bolton's (2004) claim that it is possible to address problematic situations with cognitive restructuring, when exposed to the anxiety stimuli and the danger oriented perceptions are closer to the child's experiences.

By gradually introducing cognitive restructuring, Erik was able to integrate it in his way of thinking as he matured. His mother believed that he had made progress in line with his getting older: "I also think that the fact that Erik has gotten more mature has a role in this. I think he is growing out of it. His brain is getting more reasonable.” It appears that besides him getting older, Erik became more "rational" because he had integrated detective thinking in his way of thinking and was therefore able to think more logically and realistically and as a consequence appeared as more mature.

At the interview Erik reported that his parents used detective thinking in order to assist him in situations he got afraid, possibly contributing to the long-term positive therapy outcome:

They help me more [now when compared to before treatment]... Now when I come to them they listen and they help me. They tell me all kinds of things: What could happen if... what is the likelihood that this happens... And that is actually something that really helps me a lot.

Meta-analyses have focused on the age of children or adolescents, considering it to be an approximation of the cognitive-developmental level and a possible moderator of CBT effectiveness (e.g. Weisz, Weiss, Han, Granger, \& Morton, 1995). Erik’s case may be seen as a 
A "Cool Kids" Cognitive-Behavioral Therapy Group for Youth with Anxiety Disorders:

Part 2, Analysis of the Process and Outcome of Responders Versus Nonresponders

I. Lundkvist-Houndoumadi \& M. Thastum

Pragmatic Case Studies in Psychotherapy, http://pcsp.libraries.rutgers.edu

Volume 9, Module 2, Article 4, pp. 179-274, 06-26-13 [copyright by authors]

confirmation of the critique raised by Holmbeck, Greenley and Franks (2003) that age is a weak indicator of the cognitive developmental level that is characterized by a vast heterogeneity and as pointed out by Daleiden and colleagues (1999), the relationships found between age and treatment response may in fact reflect other factors associated with age.

\section{Much improved: Niels, Stine and Tom}

As children and parents classified as responders described the ways different treatment components had been helpful, the heterogeneity in the needs of individual children was made very apparent.

Niels. Niels experienced difficulties in completing detective thinking exercises during the sessions, but was able to do some of them with his parents at home. According to Niels' student therapist: "He did not adopt all methods (e.g., he didn't think he could use detective thinking nor problem solving) but he understood and used the primary technique involving him facing his fears.” At the interview parents mentioned that the in vivo exposures session had been especially good for Niels, because the difficulties he experienced were made more obvious and it gave him a success-experience. His mother described: "I think it helped in that we got faster to some things, maybe that we put some words on what it was. You have this anxiety....and then it might be easier to work on it". After identifying the areas that were anxiety-provoking for Niels, the tools gave the family a common way of handling these:

We got some things, mostly the detective thinking... and the stepladder that we in a concrete way could go and work on something. Words were put on what it was. It is this and there is actually something we can do about it together...It was really good there was focus on the problem and we were given common guidelines to work from. It [therapy] gave us some tools to work on it and this resulted in Niels wanting to try new things and us working with an end goal in mind.

After the end of therapy the mother would ask him to rate his anxiety: "If he is afraid of something I then ask him: 'How would you rate it?' So that he can think a bit about it and turn it around in his head. So he can relate to it." And the father: "I have used the one with problem solving. I mean which options we have to reach that.”

The gradual exposures that involved Niels being more active at school, contributed according to the parents to him changing and being more self-confident, choosing to talk to others, without it having to be pre-arranged as part of a stepladder. Niels' mother explained: “This here has done a lot for Niels. He got to believe in himself, that he could do some things...I definitely think that the fact that he got through this program matured him in many ways.”

It seems as if a promotion of a feeling of self-efficacy was an important mechanism of change in Niels' case. By Niels participating in the group and doing exposures outside the therapy room he got some success-experiences that bolstered his self-esteem and the feeling of being able to manage. It has been hypothesized that high levels of self-efficacy in children will enhance their confidence and this turn will enable them to embrace challenging goals, sustain efforts longer and ultimately succeed (Pajares \& Schunk, 2001). 
A "Cool Kids" Cognitive-Behavioral Therapy Group for Youth with Anxiety Disorders:

Part 2, Analysis of the Process and Outcome of Responders Versus Nonresponders

I. Lundkvist-Houndoumadi \& M. Thastum

Pragmatic Case Studies in Psychotherapy, http://pcsp.libraries.rutgers.edu

Volume 9, Module 2, Article 4, pp. 179-274, 06-26-13 [copyright by authors]

Stine. Similarly to Niels, Stine's report shows that successful mastering of exposures contributes to believing in one's own abilities and to more independent behavior: "It [therapy] helped me a lot. I have gotten more courageous and I believe more in myself [when facing a dog]. Now I tell myself: Now I will do it!” And when asked what she thought had contributed to this, she replied: "I think it was like...Wow, now I can do that! And that! [referring to the steps she succeeded in].”

Stine was able to acknowledge the success-experiences she had had and she learned to trust more in her capabilities, bolstering her self-efficacy and enhancing an internal locus of control, concepts which according to Frank (1982) relate to an enhanced treatment outcome.

Stine described how she would do worry surfing in order to master a situation where she would encounter a dog:

If I see a dog and I am walking together with others, which I often do, then I will talk with them. Otherwise I just talk to myself and in that way I don't look at it [the dog]...it actually helps a lot, so that I can be near a dog.

Stine rated exposures and worry surfing as the most helpful components and Stine's mother emphasized how the treatment components had been helpful as they could be easily implemented in everyday life problems: "The material was easily understood and easy to implement in daily life and describe to others. We learned many good ways to look at problems of everyday life."

Tom. Tom thought all three components of therapy: detective thinking, stepladders and worry surfing, were very helpful. As in Niels' and Erik's case, he found detective thinking to be difficult at first, but ended up using it, initially with the assistance of his parents and later on his own. Just like Erik, Tom had trouble when in therapy sessions to identify the thoughts he had had in situations where he got anxious, but then the parents would do detective thinking with him, when he found himself inside the situations he feared. It was then possible for him to identify the worrisome thoughts and generate alternative ones that were more realistic. Tom also succeeded in using detective thinking on his own initiative as well, for example on an occasion he needed to cross a bridge. In mother's words:

He didn’t really want to cross the bridge, but then he talked his way through it. He used some of the techniques from here. I think it was the one with...Can something happen? And what could happen? And suddenly he had crossed the bridge and everything had gone fine.

Tom's father described how he believed Tom had a great emotional intelligence and was able to put words on his anxiety, which made it easier for them to help him:

Tom is really good in putting it in words, explaining what it is and how he is feeling. We can see something is wrong and ask him and then he can say: 'well this and that'... and then we can try and do some of the things we learned here.

The level of a young person's emotional development, specifically emotion recognition and regulation skills, as seen in Tom's case, is expected to have a considerable impact on CBT 
A "Cool Kids" Cognitive-Behavioral Therapy Group for Youth with Anxiety Disorders:

Part 2, Analysis of the Process and Outcome of Responders Versus Nonresponders

I. Lundkvist-Houndoumadi \& M. Thastum

Pragmatic Case Studies in Psychotherapy, http://pcsp.libraries.rutgers.edu

Volume 9, Module 2, Article 4, pp. 179-274, 06-26-13 [copyright by authors]

participation (Sauter, Heyne, \& Westenberg, 2009). Recognizing and differentiating emotions is essential for understanding and applying the cognitive model, while better developed emotion regulation may allow a more quick adoption of adaptive coping strategies learned in CBT (Bailey 2001; Kingery et al. 2006; Suveg et al. 2009).

Tom progressed a lot during therapy because of the exposures: "The stepladder was very good, it helped a lot, because I could do more things afterwards.” What contributed to change according to the mother was the homework that they would work on; even at times Tom had gotten tired of it:

We worked hard with the homework. Exposures were the ones that really made a difference for us, and did that we got so far as we have gotten today. It was hard and uphill, sometimes Tom was ready to explode, but it is also a big reward that he is where he has gotten today.

Parents' engagement and homework completion have had a great impact on the mechanisms of change operating in the case of Tom, who succeeded in integrating the tools in his everyday life as reported by parents: “Those good tools are now an integrated part of Tom's everyday life and help him in small and big things”.

\section{Minimally Improved (Nonresponders): Mark and Lene}

The non-responders did not practice the treatment components as systematically as the responders and did not succeed in incorporating them in the way they approached situations.

Mark. Mark rated detective thinking as the component that helped him the most. After some initial difficulties Mark was able to do the exercises but he did not feel it helped him with his anxiety. Even though he was able to logically understand that the chance there would be burglars in the house was very small, he had trouble convincing himself, when in the fearful situation. He explained: "I know there are no burglars, but it is hard to believe it". In order for Mark to learn a new meaning for the anxiety-provoking situation (being alone in the house), the old response to the feared stimuli had to be extinguished through exposures. Unfortunately, several factors prevented this from taking place.

First, the parents had trouble prioritizing the program and practicing systematically the exposures with Mark. The student therapist was often frustrated by the parents, who often would practice only once during a whole week, as it was not viewed as a joint responsibility: “The father appears not to know about the homework and it seems to be the mother's responsibility to do it. During most of the program it seems to be Mark's mother that is the primus motor in the family".

Too much time would pass in between the exposures for systematic desensitization to occur and as a consequence Mark responded with intense anxiety and had trouble believing that "no burglars are in the house".

Second, Mark had trouble understanding and using components that could have helped him endure the intense anxiety that characterizes specific phobias. As the father commented: "He didn't understand worry surfing and it is difficult talking with him about it...He can't explain which strategies he uses, it's just something that has to be done.” Unlike Stine, Mark was not able 
A "Cool Kids" Cognitive-Behavioral Therapy Group for Youth with Anxiety Disorders:

Part 2, Analysis of the Process and Outcome of Responders Versus Nonresponders

I. Lundkvist-Houndoumadi \& M. Thastum

Pragmatic Case Studies in Psychotherapy, http://pcsp.libraries.rutgers.edu

Volume 9, Module 2, Article 4, pp. 179-274, 06-26-13 [copyright by authors]

to use a treatment component in order to enter a more relaxed state when in the feared situation and classical conditioning did not occur because the situation in which Mark experienced intense fear could not become associated with a new meaning. Mark's difficulties in putting words on issues related to his anxiety are in contrast to Tom and may be related to his inability to adopt the cognitively based coping strategies he was taught.

Nevertheless, Mark's mother believed the treatment components had been helpful for her: "Before I didn't know what I should do about it and how we should go on from there and now I do because of the tools..." It seemed therefore odd that the parents would not refer to the components when Mark would get anxious, but chose instead to support his avoidance. After hearing about how Mark 15 months after the end of treatment was still afraid of the possibility that burglars were in the house, I (first author) tried to confront them:

$\mathrm{L}-\mathrm{H}$ : The things he is afraid of, for example you mention he calls you in the night when wanting to go to the bathroom so you can accompany him. Have you tried doing something about them?

Father: No, we haven't. And it might be that we should try to.... But he feels safe with having the mobile. If he didn't have it, I don't know what we would do. But he is fine with the phone. So that is fine. It's fine and we can live with that with no problem. And then of course we hope that things at some point will stabilize when he gets older.

Mother: We are just glad that we can sleep in our own bed. [laughing a bit]. But the anxiety isn't gone. We haven't worked on it in that way.

Father: It is not a big hurdle, but there are maybe some situations where we don't do something because it is more convenient. It is something we can live with. On the other hand we could say: 'ok, should we come a bit further now?'

Mother: I also think there is more peace now, also because we have gotten the tools, both we and he. So we can take them out of the drawer and use them. That's how I think mostly. So if the problems do not solve themselves when Ann [the au-pair girl] isn't here any longer, then we will just start over again.

L-H: So you believe you have the tools if you decide to work on it?

Both of them: yes, we definitely think so.

Mother: I believe something from the program has stayed with us, although we haven't talked about it. But I think although he doesn’t consciously use it, it is still there.

L-H: Yes, Mark mentioned that at times he might use detective thinking...

Mother: Did he?? Because when we have tried to, he has totally rejected it. We might as well forget about that. I think it is hard because he refuses. We have trouble moving on from the situation we are in now. But I have the technique. I have the tools, but I don't think that we will succeed in using it, not right now. But that's of course also because it is done sporadically. It's not like we make a stepladder and make a plan. 
A "Cool Kids" Cognitive-Behavioral Therapy Group for Youth with Anxiety Disorders:

Part 2, Analysis of the Process and Outcome of Responders Versus Nonresponders

I. Lundkvist-Houndoumadi \& M. Thastum

Pragmatic Case Studies in Psychotherapy, http://pcsp.libraries.rutgers.edu

Volume 9, Module 2, Article 4, pp. 179-274, 06-26-13 [copyright by authors]

Mark's parents believe they have the tools to help him, but they hope for better days in the future, without doing much about it in the present. The parents were not engaged in helping Mark overcome his anxiety, as it was no longer problematic for them and it was more "convenient" to support Mark's avoidance than to try and work on it systematically. The important element of motivation discussed earlier was absent. The mother was happy they could "sleep in their own bed" (prior to treatment Mark would sleep with them) and the father could not see any problem with the situation as it was, commenting that everything was "fine" even though it was obvious Mark would still experience intense anxiety.

The mother thought it was very hard to work with Mark, because he would reject using the components when she mentioned them, being as she claimed "stubborn". The mother acknowledged that they did not use the components systematically and it is not surprising that Mark preferred persuading his parents to let him have his way, than trying to face his fears. Unfortunately this meant that he did not show any significant progress.

At the interview Mark described what made it difficult for him to stay home alone after the setback he had had:

I thought that someone was in there [in the house]. I started believing more that someone was there. I believed that, even though I knew that no one was there...I think it is because I thought about the burglars that had gotten in the house.

The experience had been very traumatic for Mark and even though he was able to logically conclude that no burglars would be in the house (cognitive restructuring), he would still be anxious and remember the incident he had experienced (no extinction).

An additional element that could have impeded change was the fact that even though Mark was able to make some progress that resulted in him being able to sleep in his own bed, the father told us Mark was able to sleep in his own room because: "He feels safe with having the mobile...” It seems that it was a safety-behavior, which maintained Mark's anxiety, as the erroneous attributions were not challenged (Salkovski, 1991). Mark did not succeed to sleep in his own bed based entirely on his own capabilities, but rested on the circumstances that allowed him to call his parents whenever he got anxious.

According to Hedtke, Kendall and Tiwari (2009) who investigated children's behaviors during exposure exercises, children's use of safety behaviors, but not coping behaviors during the exposures was significantly predictive for a bad treatment outcome. The non-responders in the present study used substantially more safety behaviors than the responders, while the opposite was the case for the observed coping behaviors.

Another issue that ought to be considered in Mark's case is whether his perfectionism influenced negatively the implementation of the treatment components. According to Dunkley and colleagues the tendency to evaluate one's self critically and the concern about the critique and expectations of others is related to maladaptive perfectionism (Dunkley, Blankstein, Masheb \& Grilo, 2006), something that is apparent in Mark's case. As the mother informed us: "He is afraid 
A "Cool Kids" Cognitive-Behavioral Therapy Group for Youth with Anxiety Disorders:

Part 2, Analysis of the Process and Outcome of Responders Versus Nonresponders

I. Lundkvist-Houndoumadi \& M. Thastum

Pragmatic Case Studies in Psychotherapy, http://pcsp.libraries.rutgers.edu

Volume 9, Module 2, Article 4, pp. 179-274, 06-26-13 [copyright by authors]

of answering incorrectly [at school] and he is afraid of everything unknown and of what others will think of him.”

Mark’s perfectionism made it hard for him to accept that the first stepladder was too difficult for him and he did not want to revise it, which probably resulted in him not making as much progress while in therapy. He wanted to practice only his goal of "entering the house alone" and when unable to reach the high standards he had set, he blamed himself: “It's my fault". His perfectionism may have also made it difficult for him to see the completion of a step as a success, because it wasn't "good enough” for his high standards. This resulted in him neither being motivated for further progress nor developing self-efficacy. Unfortunately, no research studies of childhood anxiety treatment that relate perfectionism to treatment outcome could be located. Nevertheless, in depression research a high degree of perfectionism in short-term treatment has been found to predict a worse treatment outcome (Blatt et al., 1995).

Lene. Contrary to the responders, Lene was not able to receive as much effective help from her parents in practicing the components. She was annoyed by her mother when asked detective thinking questions and her father was annoying because he would propose exposures that were too difficult for her. Lene's tendency to react with anger was also evident in the pretreatment scores on the BYI that had shown an elevated anger score and can be related to the mother's permissive parenting, described earlier, and the father's lack of sensitivity to Lene's capabilities.

Similarly to Mark, Lene's anxiety would subside a bit after doing detective thinking, but the next time she stood in front of a dog, she became again extremely anxious. Extinction of the anxiety response to the feared stimulus was needed to occur through systematic exposures by practicing in between therapy sessions, but several family characteristics prevented this from happening.

Family dysfunction as revealed in communication problems between the parents was evident repeatedly during the course of treatment. In the planning of stepladders the parents' conflictual relationship was problematic for the therapy process, as the mother would reject all of the father's ideas about possible steps and parents seemed unable to collaborate in order to help Lene. In addition, Lene's lack of motivation and negative reactions contributed to the parents not being able to function as collaborators during the course of therapy.

The father's working hours together with his lack of engagement in the therapy process resulted in the mother having the responsibility to practice with Lene, as was the case with Mark, and this proved to be too much for the mother. She had trouble getting Lene engaged in systematically practicing exposures so that change could occur via extinction of the anxiety response to the feared stimuli. The mother commented:

The stepladders have demanded HARD work to practice! It has been unbearable. They demanded a great deal of time. To make arrangements with dog owners...We made some agreements now and then but I think there was too little progress for me and Lene to be able to keep up the good spirit. 
A "Cool Kids" Cognitive-Behavioral Therapy Group for Youth with Anxiety Disorders:

Part 2, Analysis of the Process and Outcome of Responders Versus Nonresponders

I. Lundkvist-Houndoumadi \& M. Thastum

Pragmatic Case Studies in Psychotherapy, http://pcsp.libraries.rutgers.edu

Volume 9, Module 2, Article 4, pp. 179-274, 06-26-13 [copyright by authors]

Lene rated the stepladders as the most important component and on the occasion she did the exposures with other adults present, she made progress. This became apparent at the in-vivo exposure session. Unfortunately there were no more sessions that consisted of doing exposures and as Lene's parents were not able to practice constructively with her in between sessions, she still feared dogs and would still try avoiding them after the end of treatment:

I am still afraid of dogs. When I manage something I afterwards forget it quickly again. I forgot the things we did here very fast. We practised a bit in between sessions but often forgot it. I am now better in doing some things. I for instance go home alone. But if it is possible I generally choose the easy way out.

This is in contrast to Stine's case who remembered her success-experiences and all the treatment components. This may be partly explained by the fact that Stine claimed to have a good memory and her parents reminded her of the times she was able to tackle her fear. It is possible that some children may not show a positive long-term response to treatment when parents do not remind them of their successes and the components taught to them, resulting in quicker forgetting, as they are not readily incorporated in autobiographic memory.

The mother explained how she had gotten some strategies to tackle situations where Lene would encounter a dog, but Lene would not follow her mother's instructions:

When I say we have gotten some strategies I mainly think of worry surfing: Try and feel how the anxiety subsides again. Try and endure staying in the anxiety...She doesn't like worry surfing, to stay in the anxiety provoking situation and can be totally hysterical when I tell her to do so and first relaxes when she has lost sight of the dog.

Interestingly, as was the case with Mark’s parents, Lene’s mother believed the tools they received during therapy were very good:

It is a pity the program didn't really help Lene but we got some tools. We analyze the situation and choose a way out...I think we also use them in other difficult situations in everyday life when Lene becomes worried or is sad about something. And Lene has also used some of it, without her being conscious that that is what she is doing for example she made a stepladder in order for her to gradually sleep in her own bed. Things that we think are minor. But that is also something she couldn't do before, so I think we both have gotten some tools from this program that we can use when we need them.

Although Lene did not make progress in overcoming her specific phobia for dogs, the components had been helpful in other everyday issues. It seems impressive how Lene made a stepladder on her own in order to be able to sleep in her bed, while her mother's comment that it was a minor thing sounded dismissing. This can be seen as one more indication of the mother having difficulties being supportive of Lene.

Another sign of the family being disorganized and not engaged, was that they were the only family that did not complete the questionnaires 3 months post treatment and they were unable to find their workbooks at the 15 month-follow-up interview. It could be argued that this indicates their dissatisfaction with the program, but this is not supported neither by the fact they 
A "Cool Kids" Cognitive-Behavioral Therapy Group for Youth with Anxiety Disorders:

Part 2, Analysis of the Process and Outcome of Responders Versus Nonresponders

I. Lundkvist-Houndoumadi \& M. Thastum

Pragmatic Case Studies in Psychotherapy, http://pcsp.libraries.rutgers.edu

Volume 9, Module 2, Article 4, pp. 179-274, 06-26-13 [copyright by authors]

agreed to participate in an interview or by what they reported. The mother asked me whether Lene had completed the questionnaires, commenting she had told her to do so a hundred times and hoped she would do it because someone else had the expectation she would. Once more the lack of parental authority was evident.

\section{Commentary on the Therapeutic Components}

There are many cognitive capacities implicated in the CBT approach to treatment. Metacognitive and social-perspective taking skills are most frequently mentioned (e.g., Grave and Blissett 2004; Holmbeck et al., 2006; Oetzel \& Scherer, 2003; Quakley et al., 2004; Weisz \& Hawley, 2002; Weisz \& Weersing, 1999), but there still remains little consensus in the clinical and research literature regarding the age at which young people acquire the 'minimum' level of cognitive skills needed to participate in CBT. Some researchers claim that even very young children are able to engage in 'basic' CBT techniques (e.g., Grave \& Blissett, 2004; Quakley et al., 2004; Reynolds et al., 2006; Stallard, 2009), while others have argued that CBT may be more appropriate for young people aged 11 years and older (e.g., Durlak et al., 1991).

The present study included children that were under the age of 11, except Erik, and it became apparent how parents were able to “compensate” for children's cognitive difficulties in doing cognitive restructuring by assisting them in it and reminding them of it. Even if a child has developed the skills taught in therapy, he/she may still be relatively 'inexperienced' in applying them and the use of such skills may be context-dependent (Werner-Wilson, 2001). As it was seen in the group of responders, parents were able to assist with the application of therapeutic skills outside of the clinical setting, conforming to what has been already referred to as the 'transfer of control’ model (Silverman \& Kurtines, 1996).

The children who responded to treatment, other than Erik, rated the stepladders (exposures) as more helpful than cognitive restructuring. This is in line with previous studies indicating that younger children may be more responsive to behaviorally oriented treatment techniques like exposures (O’Connor \& Creswell, 2005), as cognitive restructuring may prove to be difficult for them. Exposures, proved to be very important in providing children that responded to treatment with an experience of mastering situations. The children acquired a sense of selfefficacy that appears to arise from an increasing belief in their own competences and an understanding that anxiety problems are no longer beyond control.

The way perceived control may be related to childhood anxiety is seen in a study by Weems et al. (2003) where anxious children and adolescents displayed lower levels of perceived control over anxiety-related events than their non-anxious counterparts. In addition, findings of Muris, Mayer, den Adel, et al. (2009) indicated that the reduction of anxiety disorders symptoms observed after a CBT intervention was significantly associated with a decrease in negative automatic thoughts as well as an increase of anxiety control. During CBT children are taught various techniques for coping more adequately with their anxious cognitions and feelings and as such it is well conceivable that perceptions of control over anxiety-related events are significantly enhanced by such an intervention. 
A "Cool Kids" Cognitive-Behavioral Therapy Group for Youth with Anxiety Disorders:

Part 2, Analysis of the Process and Outcome of Responders Versus Nonresponders

I. Lundkvist-Houndoumadi \& M. Thastum

Pragmatic Case Studies in Psychotherapy, http://pcsp.libraries.rutgers.edu

Volume 9, Module 2, Article 4, pp. 179-274, 06-26-13 [copyright by authors]

When considering the non-responders, even though the components were believed to be helpful by children and their parents, they did not contribute to change. This may be explained by the fact that exposures were not practiced systematically, since the mothers were solely responsible for practicing and children were not motivated to change. In addition, Mark and Lene experienced some difficulties in understanding the components, since they lacked the parental assistance received by the responders and did not practice systematically so that desensitisation would take place.

Furthermore, a success-experience or self-efficacy is related to an individual's experience of being able to master a current situation, which emerges as a result of an evaluation of different relevant sources of information (Bandura 1988 and 1997; Muris 2002). Non-responders did not receive positive feedback and encouragement from their parents when doing exposures, as was the case for the responders. Lene's mother was not able to communicate that she was proud of her and Mark might have related his success in therapy to the safety behaviors, contributing to low levels of self-efficacy.

\section{Differentiating Responders From Non-Responders: Parenting Behaviors}

We have already discussed the important role engaged parents can play in motivating children and coaching them in using acquired techniques of handling anxiety. Several studies are pointing to the existence of a reliable relationship between parenting styles and childhood anxiety (e.g. Rapee, 1997), while parental beliefs regarding children's capabilities have been found to be related to parental behaviors (e.g. Rubin et al, 1999). It is therefore relevant to investigate whether parental beliefs and behaviors related to childhood anxiety change during the treatment process and whether this was related to practicing the treatment components with their children and contributed to therapy outcome.

In some cases, as it can be seen in the case formulations in Appendix B, children's anxiety was maintained due to factors inherent in their families. Changes in parental beliefs and behaviors are especially relevant in case parents have psychological problems themselves, as those parents are more likely to react to their children with rejection, overprotection or control, which may increase the probability of psychopathology in the child. Many of the parents in the group have suffered from depression (Niels' parents and Tom's mother), have had severe problems due to stress (Tom's father) or have suffered from anxiety while in therapy (Erik's mother and Lene's parents). Parental anxiety is especially relevant to explore in the group studied, because it was evident while the families attended treatment.

\section{Very Much Improved: Erik}

Rapee's (2001) model (see Figure 1 in the Part 1 article, "The Case of Erik") describes how parental anxiety may be related to childhood anxiety, because in addition to genetic factors it influences parents' behavior, which becomes overprotective, and it interferes with parents' ability to cope in difficult situations. These issues are relevant in Erik's case whose mother suffered from anxiety. During the first sessions it was observed that her anxiety interfered with teaching Erik coping skills; she would model anxious behaviors and reinforce these by assisting avoidant 
A "Cool Kids" Cognitive-Behavioral Therapy Group for Youth with Anxiety Disorders:

Part 2, Analysis of the Process and Outcome of Responders Versus Nonresponders

I. Lundkvist-Houndoumadi \& M. Thastum

Pragmatic Case Studies in Psychotherapy, http://pcsp.libraries.rutgers.edu

Volume 9, Module 2, Article 4, pp. 179-274, 06-26-13 [copyright by authors]

behaviors. These are two of the pathways that according to learning theory (Rachman, 1977) lead to the development of childhood fears.

Erik’s main anxiety related difficulty was his inability to go to places alone. When he told his mother he wanted to go home alone, she responded by saying: "Then you can call me when you get there and I can call you, when I finish from work". When asked why she said this, she explained that she wanted to be certain he would not change his mind and not go. Then the psychologist confronted her: "So you have the expectation that he will not manage to do it?" and a discussion started about how instead of helping Erik, she communicated that the situation was dangerous and that he would not be able to handle it on his own. After it was pointed out how her behavior could impact negatively Erik and his ability to do things that were difficult for him, the mother became motivated to try to manage her own anxiety and alter her behavior. As she saw Erik's progress in therapy and started doing cognitive restructuring on her own anxious thoughts, her expectations for what Erik was capable of were challenged:

I read this list of all the things they would do at the camp trip and I thought: 'My God!' But instead of coming with all that crap: 'You can do it...everything will go fine...' Then I thought: 'Come on. He will just manage fine these things, because I have now also seen all the things he can manage and he has said I should just relax...' So instead I told him: 'Try and look here at all the exciting things you will do on this camp trip!' I haven't stopped worrying completely but it has gotten better and better. I think differently now.

During therapy Erik started telling his mother to stop worrying in an assertive way and showed increased self-confidence (seen also in post therapy ratings on self-concept subscale of BYI), while the mother learned to stop reassuring him that everything will go well with things that she perceived as dangerous due to her anxiety. At the same time the mothers' expectations changed after getting tools she could use as coping skills she lacked earlier:

I think my expectations have changed. Our expectations were probably not so high before we started therapy. He can do many more things than before he started therapy and both we and he have gotten some tools now in order to tackle anxiety.

Fifteen months after therapy, Erik's mother still thought about what she had learned in therapy and implemented it in practice in order to both help Erik with his anxiety and become able to think more "rationally", challenging her erroneous attributions:

After therapy one should remind one's self and think not to go back to the same patterns. If you are a bit stressed... It doesn't take any time to say to the child: 'Stop what you are doing!' [being worried about something] or 'I'll do it for you'. But you should instead try and help the child the right way; have the time to talk with him. We have used that thing with saying: 'What would the detective do? Try and do some detective thinking on it'. We have changed in the way that we got here some tools on how we should talk with Erik. I also think I use it [detective thinking] on myself ...that more rational way of thinking.

The above citation illustrates how Erik's mother changed from being either dismissing: 'Stop what you are doing!' or supporting his avoidance by being over-controlling: 'I'll do it for you'. These two ways of reacting are in line with the two parenting styles: lack of acceptance and 
A "Cool Kids" Cognitive-Behavioral Therapy Group for Youth with Anxiety Disorders:

Part 2, Analysis of the Process and Outcome of Responders Versus Nonresponders

I. Lundkvist-Houndoumadi \& M. Thastum

Pragmatic Case Studies in Psychotherapy, http://pcsp.libraries.rutgers.edu

Volume 9, Module 2, Article 4, pp. 179-274, 06-26-13 [copyright by authors]

parental over-control that have been related to childhood anxiety (Rapee, 1997). Cognitive factors such as the children's locus of control and threat appraisal are hypothesized to be the mediating factors between parenting styles and childhood anxiety (Bögels \& Brechman-Toussaint, 2006). When Erik was assisted in doing detective thinking these factors were targeted, as he learned he could handle the situation (acquired an internal locus of control) and thought of the situation in more realistic terms (the threat appraisal was altered through cognitive restructuring). As the student therapists noted:

The mother worked hard with Erik and she was very engaged. It was my impression that she also realized some dysfunctional patterns in her behavior and pressured herself to change them, although it was not necessarily to her advantage, understood in the way that Erik had had a big influence on her everyday life and with our actions he became more independent of his mother.

The strong bond between Erik and the mother had left the father, who did not suffer from anxiety, out of the picture. According to the student therapists:

In the first sessions the father had trouble seeing why he should do homework possibly because he did not believe it was relevant for him, since he did not suffer from anxiety, and the mother had pointed out: 'You don't have anxiety so you cannot know what Erik is experiencing'. Nevertheless, during the course of therapy, when the father found out what the program was about, he appeared to become very motivated to be part of it. I saw a big difference in his attitude after the day he had come alone to the session. There he might have gotten more space and his engagement was required...His support was helpful for Erik's motivation and engagement, because it also meant quality time with dad. I also think he had a big part in that Erik got to ride his bike and he was not as worried about Erik, as the mother was, which I believe was a big support for Erik.

Erik clearly preferred doing exposures with his father, enjoying the positive attention and encouragement he would receive from him. It is interesting how the absence of the mother in one of the sessions facilitated the process since she was not there to take over and consequently the father got more engaged. The father realized he could function as a positive role model when practicing exposures with Erik and the mother mentioned she felt supported by her husband during the course of the treatment, something that possibly contributed to her acquiring the strength to change.

As Erik’s mother learned how to manage her anxiety she transferred control to Erik:

I have thought a lot about my anxiety and that I shouldn't transfer it to him and I have generally gotten a better understanding of anxiety. What it does to children, what parents should say and what they shouldn't. I learned how I should tackle my own anxiety and how I shouldn't overprotect Erik. I don't do that [overprotect] any more.

\section{Much Improved: Niels, Stine and Tom}

The remaining children who responded to treatment did not have parents with psychological difficulties present when they attended therapy. Nevertheless, all parents were characterised by helplessness, as they had been struggling with their children's anxiety for many 
A "Cool Kids" Cognitive-Behavioral Therapy Group for Youth with Anxiety Disorders:

Part 2, Analysis of the Process and Outcome of Responders Versus Nonresponders

I. Lundkvist-Houndoumadi \& M. Thastum

Pragmatic Case Studies in Psychotherapy, http://pcsp.libraries.rutgers.edu

Volume 9, Module 2, Article 4, pp. 179-274, 06-26-13 [copyright by authors]

years, without being able to help them. During the course of treatment parents got more aware of the way they reacted and got some skills in order to be better able to help, something which is claimed to have enhanced the families' sense of self-efficacy and thereby contributed to change.

Niels. In the case of Niels, the student therapist described how the parents: "were very interested and paid attention in the sessions...they were very engaged in Niels' getting better." The family got a common language when talking about Niels' anxiety and learned how to assist him in analyzing a situation in order to explore and identify the thoughts which provoked anxiety feelings. Erroneous attributions could then be challenged and solutions found regarding how a situation should be handled. The mother described:

We are better talking about it. Sitting down and talking about what it is that makes this so dangerous. And that is probably something we learned here. The one with: 'how should we tackle this thing?

The mother's low expectations about Niels' capabilities and the way they were challenged at the in vivo exposure session, surfaced at the interview: “At the time I heard we would go to the shopping mall I was very skeptical about it. But it was really really good for Niels.” When asked why she was initially skeptical, she answered:

I couldn't really imagine what we would get out of it. I probably didn't have any expectation that he would do it. Because when we have been to such places and I have said: 'you should do this and that', then he didn't want to. He would not want to buy things, but there he just did it. And he has also done this again.

When parents are integrated in the therapy process their expectations can be challenged by observing the positive changes in their children's behavior that make them realize how their children gradually become able to master situations they used to fear. This may influence positively the treatment process, as we know form literature with adult clients since more positive expectancies produce greater involvement or engagement in treatment, leading to better outcomes (Arnkoff et al., 2002; Chambless, Tran, \& Glass, 1997; Ilardi \& Craighead, 1994).

According to Frank (1973; Frank \& Frank, 1991) the facilitation of change by positive expectancies, particularly early in treatment, is a critical pathway through which psychotherapy exerts its positive effects. It is likely that positive expectations on the part of the parents have contributed to Niels' positive outcome, since as suggested by Alloy (2001) children's cognitions tend to be influenced by the feedback they receive regarding their competencies from significant others.

Niels’ father described how he had gotten important knowledge concerning parenting skills that had contributed to him changing his behavior in a way that had helped Niels: "I have gotten better at praising Niels and I have learned I should not give him ways out [alternatives so he can avoid a feared situation]". The student therapist also had the impression that Niels' father had changed his attitudes and behavior:

The father was very open to change his way of being towards Niels, e.g., by improving the way he would be together with him, being there on his son's conditions. 
A "Cool Kids" Cognitive-Behavioral Therapy Group for Youth with Anxiety Disorders:

Part 2, Analysis of the Process and Outcome of Responders Versus Nonresponders

I. Lundkvist-Houndoumadi \& M. Thastum

Pragmatic Case Studies in Psychotherapy, http://pcsp.libraries.rutgers.edu

Volume 9, Module 2, Article 4, pp. 179-274, 06-26-13 [copyright by authors]

In addition, during the course of treatment the father learned to expect that Niels could face social situations he avoided earlier and therefore tried to encourage him using components taught in therapy. A new independent behavior was seen in Niels, which in turn challenged the father's beliefs concerning his role as a parent:

I think I have learned to have expectations. That thing with meeting other people I always try to push him and see if that is something that has changed...Then we talk about what he would achieve at some point by going there and talking to someone. It is mostly problem solving that we use and we talk about what it is that he would like to achieve...One of the first times I brought him to football practice, he told me: 'Good. Now dad you can just drive home.' Then I stood there and thought: 'Now, he doesn't need me anymore. He can now take care of himself'...And that was a great feeling.

Changes in Niels reinforced the new narrative that was created concerning him being independent and "able to take care of himself". The bi-directionality of influences between parent and child is evident. The changes in Niels' parents can be viewed in relationship to a longitudinal study by Rubin and colleagues (1999) where it was demonstrated how parental perception of the child's temperament and not objective observations of the child's shyness predicted future parenting behavior. Parents will encourage their children to do things when they expect them to manage and thereby have a positive influence on children overcoming their anxiety. Evaluating the effects of FCBT, Bögels and Siqueland (2006) found that large improvements in parents' dysfunctional beliefs regarding the child's anxiety and their role as parents, were related to large effect sizes in post-treatment improvement for children's fears, dysfunctional beliefs, and interpretations of ambiguous situations.

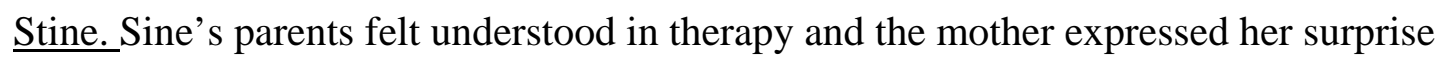
about how the simple knowledge they had obtained concerning the consequences of avoidance, had contributed to tremendous changes:

Before we did not know what to do, so we tried different things and sometimes I would get mad, while other times I would choose to take a detour [in order to avoid dogs]. I didn't really know what we should do about it...Now I think was it just that?! I mean why the hell did we not think of this before? I mean we have fought with these dogs in so many years...For us it has been really important to have gotten some tools, but also that we realised what we should do, instead of trying out different things. It is great knowing this is it! This is what works.

Stine's mother changed from feeling helpless to feeling more secure, knowing the answer to the problem they had been fighting with: "We had ended up thinking it was easier to have them keep their dogs away. So it was definitely an eye opener that it was the wrong thing to do."

Similarly to what was observed in Niels' case, Stine's mother saw the impressive progress made during the course of therapy and came to believe more in Stine's capability of handling alone an encounter with a dog. This contributed to the mother encouraging Stine to face more situations than earlier: 
A "Cool Kids" Cognitive-Behavioral Therapy Group for Youth with Anxiety Disorders:

Part 2, Analysis of the Process and Outcome of Responders Versus Nonresponders

I. Lundkvist-Houndoumadi \& M. Thastum

Pragmatic Case Studies in Psychotherapy, http://pcsp.libraries.rutgers.edu

Volume 9, Module 2, Article 4, pp. 179-274, 06-26-13 [copyright by authors]

I feel completely safe with her being alone and me not accompanying her to school, which is something I wouldn't do before. Then [before treatment] Stine could panic and run out on the street if she saw a dog, without checking if there was any car around... Now we have also been to some parks we hadn't been earlier, because we didn't want to be bothered by all that screaming when she would spot a dog.

Fifteen months post treatment the family was better able to talk about what they could do to help Stine, having acquired a common way of handling anxiety in order for progress to occur:

It could be that unconsciously we have used some of these things, although we haven't talked about it. We talk about the things that Stine might be afraid of [mostly dogs] and what it takes to get it work...In the situations [where Stine encounters a dog] we use surfing. We have a common way to talk about things. Stine can surf and I can surf and we can talk about some other things in a way we couldn't before.

Stine's father claimed: "The fact that both we and Stine attended the program helped us help Stine." And the mother commented: "Half of it [what they got out of the treatment] is that we have learned what is the right thing to do." Stine had noticed how her parents had changed their behavior in a positive way and would successfully communicate to her that she was able to master a fearful situation:

When we are going to go to my grandfather [that has a dog], I am only allowed to call him before we drive to them and ask if he will have the dog on a leash. They tell me: 'We wait till we have to leave. Then we will see how things are and what you want to do.' And when we get there, they don't go in first, in front of me...And before, when I got afraid, because I saw a dog, I would always hold their hand and try to stand behind them. When I try to do that now, they just stand aside, because they know I have gotten better in it now... That's ok. Then I can also move on. If I just kept on doing the same, then I would never have moved on.

Overall, there seemed to be a healthy hierarchy in the family, where parents supported Stine but did not allow her to employ as many safety behaviors, unlike Mark's parents who did. At the same time, Stine's family seemed to be high in cohesion and the parents were cooperative and accepting of her difficulties, indicating the presence of emotional bonding among the family members. When parents are included in the treatment process high family cohesion has been found to be related to significantly greater reduction in children's anxiety after therapy (Victor, Bernat, Bernstein \& Layne, 2007), which as seen in Stine's case may be related to the fact that warm, involved parents who are secure in the standards they set for their children are likely to be more effective reinforcing agents.

Tom. Tom's mother provided a good description of how difficult it is for a parent to see her/his child in distress and why parents normally overprotect their children when they are anxious:

It is always hard to see your child being afraid or sad. You get to have a lot of feelings in one second. Do I set unreasonable demands? Is there something I can do differently? Am I saying the right thing to him? You also get a bit sad yourself inside. 
A "Cool Kids" Cognitive-Behavioral Therapy Group for Youth with Anxiety Disorders:

Part 2, Analysis of the Process and Outcome of Responders Versus Nonresponders

I. Lundkvist-Houndoumadi \& M. Thastum

Pragmatic Case Studies in Psychotherapy, http://pcsp.libraries.rutgers.edu

Volume 9, Module 2, Article 4, pp. 179-274, 06-26-13 [copyright by authors]

All of the parents in the group of responders were relieved to know what they could do to help their children overcome anxiety and felt safe knowing they were doing the right thing, when "pressuring" their children to do things they avoided. This knowledge together with the tools acquired most likely contributed to them not becoming as easily emotionally overwhelmed as earlier, so they could handle the anxiety-provoking situation and function as coaches.

Treatment contributed to positive changes in Tom's family as a whole and empowered the parents so they no longer felt helpless, since they were able to help their child constructively:

I don't think Tom's anxiety has its origins in our behavior towards him. And because of this we also haven't changed our behavior towards him, but we have changed in that we do not let anxiety define the context of our family life. Now we also have some tools to control the anxiety and ease it out...This program has brought noticeable changes in our family life. First of all we can DO something to help Tom and we can personally plan and do things that would not have been possible three months ago...We have all gotten better in tackling the anxiety, and for me it also means I feel safer in my expectation that we will also manage this situation. I have always tried not to let the anxiety control our lives totally and I have pressured Tom in situations, he certainly did not like, if I assessed they wouldn't hurt him. It is probably both good and bad, but now we have the tools to do it as constructively as possible.

The statement "we have all gotten better in tackling the anxiety" shows that parental behaviors were changed after all and this agrees with Mendlowitz and colleagues (1999) who found that a parent training program was especially effective in enhancing coping strategies. In the parents' words:

This program has given us a better understanding and tools we were missing. I think most of the families that come here have ended up in a dead end. So it is great to get some input about what you can try and do. And then you make an effort so you can make it happen.

Tom's father described an incident where it becomes apparent how parents may have a positive influence in the maintenance of treatment gains, by encouraging children to do things they may be afraid of at first:

We told him: 'It is now you have the chance, you will not have it again' and then we can push him a bit. But then it is the thing with whether we should push him or not, because we also don't want to force him into something. But we know that if he has tried it first, then he usually thinks it's good. And then he said: 'You know what mum and dad, I would like to do it on my own...' It was really impressive because he was terrified of it. And then he said it by himself and then he did it! So he can, but he needs to be pushed to get there...

Tom listened to his parents and gained experiences that gave him courage to try out new things:

He does it because we say he has to and he doesn't get to choose... Then he is good in convincing himself about it...'ok, then that is what will happen'. And then he tries all these things he learned here...” 
A "Cool Kids" Cognitive-Behavioral Therapy Group for Youth with Anxiety Disorders:

Part 2, Analysis of the Process and Outcome of Responders Versus Nonresponders

I. Lundkvist-Houndoumadi \& M. Thastum

Pragmatic Case Studies in Psychotherapy, http://pcsp.libraries.rutgers.edu

Volume 9, Module 2, Article 4, pp. 179-274, 06-26-13 [copyright by authors]

And the father added:

And I think that as a parent you should also not signal that it is dangerous, or you might teach them to be afraid of something. For instance when he told me about this badmintonnight I was like: 'Wow! This really sounds exciting! Would you like to try that?' And then...yeah, he would. And he had a great time and received a lot of praise. So I hope that I can influence him in that way to find out things are not as bad.

Communicating to the child that a situation is not dangerous, as Tom's father did, can be quite effective in view of earlier reported findings, which show how children's responses to ambiguous scenarios are influenced by the information they receive and discussions they have with family members (Barrett, Rapee, Dadds \& Ryan, 1996).

The expectations and behavior of Tom's parents, similarly to Stine's, facilitated the treatment process. Their parenting style could be characterized as authoritative (Baumrind, 1967), as they were warm and patient, attending to Tom's needs, while at the same time setting some reasonable demands and giving reasons for their expectations. This kind of parents let children know they are competent individuals, who can do things successfully by themselves and therefore contribute to the development of self-control, task persistence, cooperativeness and emotional intelligence, as shown in what the father reports below:

Tom is sensitive to the feelings of others and aware of his own, so we could talk to him about what he was anxious about and what we could do about it, while some of the other children had difficulties in doing this. This is an advantage, you can say, because you get some information that some of the other parents didn't get.

\section{Minimally Improved (Nonresponders): Mark and Lene}

The parents of the non-responders obtained important knowledge regarding parenting an anxious child and they were to some degree able to change their behaviors, but characteristics related to children, parents and the nature of interactions between them, prevented children from getting over their anxiety.

Mark. During the assessment interview there were indications of problems in Mark's family, which needed to be addressed in therapy. The parents mentioned that there were some conflicts at home, because Mark would rather be with his mother, who had a tendency to let him have his way for the "sake of peace" and did not pressure him as much as the father to do things he avoided. The parents' disagreement about how they should tackle Mark’s anxiety may have contributed to its maintenance, as Mark could have felt he was the cause of those conflicts and therefore experienced negative affect in the form of anxiety.

Similar to the parents in the group of responders, Mark's parents became more aware of their role in maintaining Mark’s anxiety. His mother commented at post-treatment: "I have become more conscious about the way I relate towards my son in the situations where he gets anxious” And his father added: 
A "Cool Kids" Cognitive-Behavioral Therapy Group for Youth with Anxiety Disorders:

Part 2, Analysis of the Process and Outcome of Responders Versus Nonresponders

I. Lundkvist-Houndoumadi \& M. Thastum

Pragmatic Case Studies in Psychotherapy, http://pcsp.libraries.rutgers.edu

Volume 9, Module 2, Article 4, pp. 179-274, 06-26-13 [copyright by authors]

I got new knowledge about what you should do as a parent of a child with anxiety. I wasn't sure if I should pressure him or not. It was good to be reassured it was OK to pressure him and learn that what I would do [protecting him] is actually no favor at all.

At the 15 month follow-up interview I asked the mother whether they used some of the therapy components they were taught, to which she answered:

We do not use any of these things now. But now we know that it is not the right thing to do, this with protecting him. And then we do it anyway...but I must say we try and pressure him.

Even though the parents had obtained new knowledge on how they should change their behaviors in order to help Mark, they had difficulties transferring this knowledge into practice, which can be explained by a number of factors.

An important factor seemed to be that, as parents admitted, it was easier and more convenient for them to regress to the old patterns after therapy. The father described:

We choose maybe not to take that battle. An evening when we come home late and are tired and he wants to sleep in our room, then we say it is ok he sleeps with us. We do it [Mark sleeping in his own room] on another occasion when he has more energy.

Unfortunately the parents did not communicate clearly to Mark their expectation that he was able to handle the situation and Mark did not know how his parents would react to him when anxious. An inconsistent parenting style did not give Mark a feeling of control over the situation, contributing to the maintenance of his anxiety. This is further illustrated in the following:

Father: The other day I was probably a bit harder on him when he asked me to call a friend of his, telling him it was something he should do. But then he usually gets really stubborn and chooses not to do it.

Mother: yes, and then I thought that there were other things that I would rather do on Sunday, so I called and made the arrangements for him. So there I would rather call and take the consequences of it. I think also now that I am conscious about what it is that happens if I call. Then it is a clear choice I make and I know the consequences of it.

As it was pointed out in an earlier section, parents were not very motivated to help Mark overcome his anxiety. This was further manifested in the way they reacted to Mark's setback after therapy, when on a stormy day he thought he heard people in the house and was afterwards afraid of being in the house alone. When asked about whether they tried using the treatment components to get past this incident, the mother responded: "He is really hard to influence", indicating, as in Lene's case, that the mother had trouble using her parental authority and that Mark was not motivated to change. The family "resolved" the problem by getting an au-pair girl to stay at home with Mark: "We haven’t worked on it because it wasn't necessary.” And the father added:

Well you can say that getting Ann [the au-pair] was an easy way out...But then we haven't done much about it because he no longer had to come home to an empty house and he can sleep in his own room. So the big hurdles we got over and then there were of course some 
A "Cool Kids" Cognitive-Behavioral Therapy Group for Youth with Anxiety Disorders:

Part 2, Analysis of the Process and Outcome of Responders Versus Nonresponders

I. Lundkvist-Houndoumadi \& M. Thastum

Pragmatic Case Studies in Psychotherapy, http://pcsp.libraries.rutgers.edu

Volume 9, Module 2, Article 4, pp. 179-274, 06-26-13 [copyright by authors]

minor still...It [Mark's anxiety] is not a big problem today. If Ann hadn't been here we would have had to work goal oriented with it and then he might not have been so anxious. It might be so.

Besides maintaining factors inherent in the parents' behaviors, Mark was, as all of the children, influenced by multiple contexts, which may have acted as additional maintaining factors. Thus, it is possible that the setbacks Mark had experienced during treatment (e.g. after their relatives' house got robbed and there was a fire in the house across the street) discouraged the family and made them doubt that the implementation of therapy elements would contribute to Mark overcoming his anxiety. The mother believed that the stepladder was helpful but:

"Sometimes you suddenly fall totally back again." It is obvious that there are multiple and diverse factors which are not limited to either the client or the form of treatment as such and which nevertheless can influence therapy outcome, and cause setbacks. According to Frank (1982) things that happen to the life of clients in between sessions in some occasions have greater importance for the therapy outcome than the therapy in itself, and those unfortunately cannot be foreseen.

Lene. In the case of the presence of parental psychopathology it becomes especially relevant to examine how parental behaviors may maintain children's anxiety and influence treatment. Study findings regarding the relationship between parental psychopathology and Family CBT treatment outcome in children have been inconclusive. Toren and colleagues (2000) found that anxious children of mothers with an anxiety disorder improved more than children of non-anxious mothers (as was found in Erik's case), while Southam-Gerow and colleagues (2001) reported a relationship between parental psychopathology and poor treatment outcome in anxious children (as found in Lene's case). Those studies focused on treatment outcome, while the present study is trying to explore the impact of treatment on parental expectations and behaviors.

The fact that Lene had a different therapy outcome than Erik can be partly attributed to parenting stress and problematic family functioning, which were not present in Erik's family. Erik's father, who did not suffer from anxiety, was able to support the mother, while in Lene's family both parents suffered from anxiety and the father seemed to be both physically and mentally absent in the family life. It has been suggested (Messer \& Beidel, 1994) that parental psychopathology may affect the family environment, while offspring of depressed or anxious parents are at risk for developing anxiety or depression, especially when both parents suffer from a disorder (Nauta, 2005).

Crawford and Manassis (2001) have found that therapists’ perceived parental frustration with the child's behavior and children's perception of problems in the family were related to a less favorable outcome for the child. These same issues were evident in Lene's case. She would complain about her parents being annoying, while her mother was clearly frustrated with Lene's anxiety problem, commenting at the beginning of therapy: "I would like that all dogs in [the name of their town] would be shot!” Further, family conflicts (as those present in Lene's family) can lead to negative parental behavior, because parents do not show as much warmth and acceptance in stressful situations, acting as maintaining factors of childhood anxiety. 
A "Cool Kids" Cognitive-Behavioral Therapy Group for Youth with Anxiety Disorders:

Part 2, Analysis of the Process and Outcome of Responders Versus Nonresponders

I. Lundkvist-Houndoumadi \& M. Thastum

Pragmatic Case Studies in Psychotherapy, http://pcsp.libraries.rutgers.edu

Volume 9, Module 2, Article 4, pp. 179-274, 06-26-13 [copyright by authors]

On the basis of the observations made during treatment, it seemed as if the anxiety problems of Lene's mother resulted in her being less warm and positive when Lene became anxious, because she herself was overwhelmed by the situation. She did not challenge Lene's avoidance and this contributed to Lene becoming dependent of her mother's help, as she did not learn to handle the situation on her own. This description of the behavior of Lene's mother matches those observed in the interactions of anxious mothers and their children in a study by Whaley, Pinto, and Sigman (1999) and which are believed to contribute to children's anxiety.

In the same study (Whaley et al., 1999) it was observed how anxious parents transfer negative information to their children by communicating messages regarding situations with potential harm in an irresolvable or dangerous manner, which results in children learning to perceive the world in a catastrophic manner. This is actually a good description of the way that the father's anxiety in Lene's case interfered with his ability to be a positive role model. During treatment he often came with long stories about how some dangerous dogs had attacked him. Both of Lene's parents were therefore behaving in ways that maintained Lene's anxiety and it becomes apparent that in cases where parental psychopathology is present, the therapy should also target parents' behaviors.

Lene's mother was able to make some progress in therapy and described how her expectations changed because she saw her daughter being able to endure anxiety. She was able to stay in the situation with Lene by using worry surfing, instead of trying to protect her. During treatment the mother became aware of how Lene's anxiety had influenced her negatively and that she had been actually supporting Lene's anxiety:

The expectations that changed in me was that: 'She can manage this. She can endure the anxiety.' I changed in how long I would let her be in these situations. Before I would comfort her earlier, I got affected by her anxiety and thought: 'I might be pressuring her too much', while now [with worry surfing] I can be in the situation in a completely different way than I could before. Now I can be much calmer and tell her: 'Lene we know from experience that it will go over again and we will stay in the situation until it does.' I have gotten these tools. I have learned this is how things are and people have tried this and it works...Before I got to think the devil created dogs. I had almost ended up hating animals. My attitude changed then during the program here and I could say: 'Look how cute it looks.' I have supported her in avoidance behavior in the past. I thought: 'How do we get easiest through our day around your dog phobia? We do that in this way: we go on the other side of the street instead of you panicking.' Now it is her choice if she goes on the other side of the street. I do not comment on it. I've had enough. It has cost me so much energy. Lene also has an older sister with problems. So now we try to have a completely normal everyday...I can still become irritated. It depends on how much energy and time I have. Sometimes I can be caring, but I think it is hard to help her. I can't. That's a fact. I am no longer frustrated about it. I have been and that is why I also contacted you.

Following treatment, the mother would still at times become irritated, because Lene kept reacting intensely and she was aware that she was unable to help her, which is in contrast to the other parents who felt empowered through treatment. Although the mother claimed she no longer was frustrated, it must have been a big defeat for her, as she noticed how the other families made progress and how she was unable to fulfill her role as a coach. 
A "Cool Kids" Cognitive-Behavioral Therapy Group for Youth with Anxiety Disorders:

Part 2, Analysis of the Process and Outcome of Responders Versus Nonresponders

I. Lundkvist-Houndoumadi \& M. Thastum

Pragmatic Case Studies in Psychotherapy, http://pcsp. libraries.rutgers.edu

Volume 9, Module 2, Article 4, pp. 179-274, 06-26-13 [copyright by authors]

Even though the mother made some progress in therapy, not supporting Lene's avoidance, as she did earlier, she did not have the energy and felt unable to alter Lene's behavior. This might be related to her permissive parenting style, Lene's lack of motivation and cooperativeness and the lack of support from her husband. Lene's student therapist commented: "There was a big difference between the father's and the mother's engagement in the project, the mother being much more engaged in therapy in comparison to the father." When I asked the father at the interview if he had tried practicing with Lene, the mother told her husband:

There I think you got away. It is hard work to practice...make arrangements, motivate... and you let me therefore do it. Because I have tried to encourage you a couple of times but nothing came out of it. And it is me that took the initiative to seek help...I believe it has been too much my project. Well, I also ended up being tired of it.

At the interview the mother acknowledged how she had been unable to help Lene and related this to her daughter's lack of response to treatment, claiming that Lene would have made progress if she had done the exposures with the student therapist, because instead of reacting with anger Lene would want to impress her:

When I think back about it now, I think it would have been better for her to have someone else to practice with than me. She was for example very happy for her student therapist and wanted to perform for her. The biggest motivation for her was that she could come to the next session and tell the student therapist: 'In this week, I practiced four times.' And the day we were at the shopping mall it went really well. And I think that was due to the fact that there were some other people that have different expectations that haven't seen her with the old eyes that I have. I almost see her reactions before they come. I have really thought if there was something I could have done differently. But I really couldn't. We had gotten so much in this pattern with her reacting: 'Mum I don't want to! I can't!' that I think it was really hard for me, although I had these tools with me so I could be calm in the situation. But she got angry at me. She has also practiced with her cousin and it went much better...I don't feel she wants the help I have to give. Her wish is that I flee with her from danger. And I know that is not a help in a long term perspective.

Surprisingly, Lene described the situation very differently than the mother:

My mother makes me calm down by saying: 'Take it easy. Think about something else. Focus on something else!' When she says things like that, I know what she means and I automatically focus on something else. Afterwards I feel better than avoiding the dog, because it was cool that I managed, even though it was more difficult.

Lene's description of being able to worry surf without any problem seems to be related to her wish to look good, which was a motivating factor in therapy. Her response is attributed to social desirability, as it was obvious from other descriptions that she would still react with panic, avoided encounters with dogs and would react with anger to her mother, when she attempted to assist her in using the tools.

The father was not very talkative at the interview and when I asked him whether he had noticed changes in his behavior towards Lene, the mother commented: 
A "Cool Kids" Cognitive-Behavioral Therapy Group for Youth with Anxiety Disorders:

Part 2, Analysis of the Process and Outcome of Responders Versus Nonresponders

I. Lundkvist-Houndoumadi \& M. Thastum

Pragmatic Case Studies in Psychotherapy, http://pcsp.libraries.rutgers.edu

Volume 9, Module 2, Article 4, pp. 179-274, 06-26-13 [copyright by authors]

I think it has made a big difference that he doesn't tell the dog stories any more. It was horrible to listen to. There couldn't be a dog on TV before you had to hear about it. [And the father added:] I do not tell dog stories any longer. Not at all. I don't even think about a dog that might be across the street. I am now much much much more calm. I don't even believe Lene has a problem.”

An important change was reported to have occurred in the father, although he did not believe it was related to attending therapy, and the fact that he repeated the word "much" three times, concerning how calm he had gotten underlines that this was not the case earlier. At the interview the father would only talk if he was directly addressed and he usually had difficulties answering the questions. The parents' responses were very different and it was obvious it was not a topic they talked about. They had a very different view of Lene, the father's impression being that there was not any significant anxiety problem present.

Lene's father changed his behaviors, no longer transmitting negative information about dogs to Lene and the mother was better able to handle her own emotions and model positive responses to anxiety provoking situations. Those issues are successfully targeted in some FCBT family components (e.g. Barrett et al, 1996; Bodden, Bögels, Nauta et al, 2008; Cobham, Dadds \& Spence, 1998); however in Lene's case several negative factors prevented change from occurring.

Lene's parents, similar to Mark's, did not appear to be in agreement and had communication problems, issues that have been related to the maintenance of childhood anxiety (Crawford \& Manassis 2001; Ginsburg \& Schlossberg 2002). In addition, permissive parenting patterns may maintain problematic behavior patterns, because children are not given enough guidance. Furthermore, parents who deny their role in contributing to the resolution of a problem, seen in Lene's father, or family members who believe that they are not competent to solve the problem, seen in Lene's mother, may be contributing to the maintenance of childhood anxiety as well.

There are great variations in the degree of parental inclusion in CBT and it is possible that a component which would facilitate better communication in the family (e.g. Barrett et al., 1996; Bodden et al., 2008) and address the parent-child relationship could have contributed to Lene showing a better response to treatment.

\section{Commentary on Parenting Behaviors}

Parental inclusion in treatment rests on the assumption that it will contribute to additional improvements, as well as the maintenance and generalizability of the treatment results after the end of treatment (Nauta et al. 2003). The qualitative information presented illustrated how parenting behaviors may differentially influence the therapy process as well as children's anxiety after the end of treatment. This was supported by additional quantitative information that was collected but will not be reviewed here.

Overall, it appears that changes in parents' expectations and behaviors were more evident in parents of the responders who would no longer support their children's avoidance, but would 
A "Cool Kids" Cognitive-Behavioral Therapy Group for Youth with Anxiety Disorders:

Part 2, Analysis of the Process and Outcome of Responders Versus Nonresponders

I. Lundkvist-Houndoumadi \& M. Thastum

Pragmatic Case Studies in Psychotherapy, http://pcsp.libraries.rutgers.edu

Volume 9, Module 2, Article 4, pp. 179-274, 06-26-13 [copyright by authors]

refer to the treatment components, coaching their children and enhancing coping behaviors. Those parents expected their children to be able to tackle anxiety and their beliefs concerning their role as parents were altered. The changes in parents can be related to the children gradually acquiring an internal locus of control and gaining a feeling of self-efficacy that helped them face more situations than before the treatment and discover, as their erroneous attributions were challenged, that situations were not dangerous but manageable.

Barmish and Kendall (2005) have reported that parental behaviors related to childhood anxiety are commonly targeted in the treatment of childhood anxiety in the expectation that improvement in those behaviors would be associated with improvement in children's anxiety (e.g., Barrett et al., 1996; Ginsburg et al., 1995). The possibility that reciprocal or bidirectional influences exist between child anxiety and parent variables has been rarely acknowledged in the youth anxiety treatment literature (Silverman, Kurtines, Jaccard \& Pinas, 2009). Such dynamics are plausible since children that respond to treatment show a decrease in anxiety and this may contribute to a decrease in parents' own anxieties and a subsequent improvement in their behavior toward their children. At the same time, parents may act more positively toward their children as a result of children showing less adverse reactions to anxiety provoking situations. Another possibility is that both dynamics operate simultaneously so that reduction in children's anxiety results from improvement in the parenting variables and vice versa.

In a randomized controlled clinical trial by Silverman, Kurtines, Jaccard and Pinas (2009) findings indicated that a youth to parent influence was somewhat stronger than either the parentto-child influence or the bidirectional influence. Even though the current study has not explored this issue systematically, it hopes to contribute to an understanding of the therapy process in CBT for childhood anxiety. Advancing theory about directionality of change has the potential of informing the field about the variables that are most critical to target for improvement in treatment.

\section{Differentiating Responders From Non-Responders: Group Format and Processes}

In addition to the components related to CBT and the inclusion of parents in therapy, a third aspect that appeared equally important in the treatment process and was raised by the families themselves at the treatment evaluation was the group format. Four out of six families mentioned it as a very good aspect of therapy: “It was very good we were a group” (Mark’s father), "a nice division of children and adults teaching” (Stine’s mother), "we liked that children and parents were together and separately" (Tom's father). At the 15-month interview parents agreed that: "The way in which the therapy was structured, was good for my child's problems" (mean rating $=3.00$, with a range of $0-4.00$ ).

Parents appreciated the group format, which recent research indicates to be efficacious in the treatment of childhood anxiety disorders (Barrett, 1998; Silverman, Kurtines et al. (1999); Flannery-Schroeder \& Kendall, 2000; Manassis, Mendlowitz, Scapillato et al., 2002), even though the mechanisms underlying the effects of group therapy are not yet very clear (Davies, Burlingame, Johnson, et al 2008). In the following section issues related to the therapy format are examined as they may have contributed to changes observed in parents and children. 
A "Cool Kids" Cognitive-Behavioral Therapy Group for Youth with Anxiety Disorders:

Part 2, Analysis of the Process and Outcome of Responders Versus Nonresponders

I. Lundkvist-Houndoumadi \& M. Thastum

Pragmatic Case Studies in Psychotherapy, http://pcsp.libraries.rutgers.edu

Volume 9, Module 2, Article 4, pp. 179-274, 06-26-13 [copyright by authors]

\section{Very Much Improved: Erik}

Erik's mother was successful in altering her behavior because she was supported not only by her husband but also by the parents' group. As recorded in the student therapists' journal Erik's mother eagerly contributed to the discussions in the parents' group and shared her worries concerning her tendency to overprotect Erik. Later on she enjoyed the positive attention she received from others when informing them about her progress exclaiming: "I think I am really good!"

At the 15 month follow-up she mentioned how Erik's brother still suffered from encopresis and had anxiety problems and she had therefore contacted the Anxiety Clinic. When asked why she did not use some of the principles she had already learned from the program, among other things she said: "It has been hard for me to have suddenly two children with anxiety. I think if we come here, it will also keep me going so I don't get tired of it.” It was important for her to be supported in order to be engaged in the therapy process. The parents' group would be checking up on each other's progress and this was often a motivating factor. As Erik's father mentioned, they might have pushed Erik to practice, because: "we wanted to be good and active and have something to present to the group”.

On the other hand, Erik did not feel comfortable in the children's group because he was the eldest, in the mother's words: "The only negative thing about the program for us was that Erik was in a group of children that were younger than him.” He thought he was not taken seriously, when the psychologist at times talked to the children as if they were very young and believed the reward system to be "childish". He was at an age, when it was important for him to be thought of as mature. This need was also evident in the mother's description of what he told her about the visit to the dentist, “Erik told me that the next time he will tell the dentist: 'you don't have to talk to me as if I am a child’ [providing him with detailed explanations on what he would do]”.

When later the psychologist altered the way he talked to him, explaining it was not on purpose he was placed in a group with younger children it ceased being a problem. It is possible that he even started enjoying a little the role of being the eldest in the group. Although we told him it was not his responsibility, he often participated in the other children's games and tried to keep them quiet.

Erik might have felt pressured to progress in therapy in order to show to the other children he was older than they and more courageous. For instance, Erik was overheard, when talking to one of the children, saying he would go wind-surfing:

Mark: Are you not afraid?

Erik: No

Mark: And what if you fall in the water? Can you swim?

Erik: Well no, but I'll just learn it on my way out to the shore.

On the other hand, the fact that Erik was in a group with other children who also had various 
A "Cool Kids" Cognitive-Behavioral Therapy Group for Youth with Anxiety Disorders:

Part 2, Analysis of the Process and Outcome of Responders Versus Nonresponders

I. Lundkvist-Houndoumadi \& M. Thastum

Pragmatic Case Studies in Psychotherapy, http://pcsp.libraries.rutgers.edu

Volume 9, Module 2, Article 4, pp. 179-274, 06-26-13 [copyright by authors]

anxiety disorders, may have had an additional positive influence on Erik, as his anxieties were normalised and accepted, his self-esteem being bolstered because he experienced how he could do things the other children could not. Through therapy, Erik's beliefs about himself changed as he possibly started to compare himself to other children instead of how he was before therapy (i.e., a child with anxiety) and commented: “That's nothing. That's normal!” when praised for his progress in therapy.

\section{Much improved: Niels, Stine and Tom}

Overall for these families, the therapy format offered encouragement, support, modeling and relationships with other group members who were working on overcoming similar difficulties; all issues that have been considered by CBT researchers to be the advantages of group therapy (Johnson, 2010). The group format provided parents with feedback from others and ideas on what they should do and the children with consensual validation, models of coping, and a feeling of control through active participation in helping one's self and others.

Niels. According to Niels’ parents it was very helpful to talk with other families facing similar problems:

We heard other families talk about their problems and being together with other parents and children we got to talk about some of the things that have preoccupied us a lot...

The mother further explained how they would share experiences and ideas and she felt supported so that change could occur:

I think it was healthy to talk with the other parents. The way we sat and talked about it. Hearing what other children were afraid of: 'Ok, we also have these problems...ok, you do this and that?'...it both [helped us and] gave us some options in order to help Niels go on. We heard a bit of theory and we heard the other parents and got ideas on what we could do. It's not only us that have this problem...I definitely also got something out of it for myself. I got some tools in order to help Niels and I managed to open up myself more.

Kaul and Bednar (1994) refer to feedback received from others of the type described by Niels' mother as a critical therapeutic factor in group treatment. Prior to treatment Niels had trouble being with other children and would avoid talking to people he did not know. Although at first he would not talk in the children's group and would not want to participate in the others' play, after the first sessions he became more open. His father described how the therapy format was helpful for Niels, who got to be in a context with other children:

The structure with us being together and then parents and children alone, that structure was really good. It seemed to be good for him and he felt safe being there [with the other children]...For Niels this meant he realized he is not the only one that is afraid of these things. Niels got success-experiences and crossed some limits.

Niels also described: "It was nice that more children were there. Then we could play when you [student therapists] were with our parents. And it was nice our parents also were with us."

His mother described Niels as becoming more open in social situations: 
A "Cool Kids" Cognitive-Behavioral Therapy Group for Youth with Anxiety Disorders:

Part 2, Analysis of the Process and Outcome of Responders Versus Nonresponders

I. Lundkvist-Houndoumadi \& M. Thastum

Pragmatic Case Studies in Psychotherapy, http://pcsp.libraries.rutgers.edu

Volume 9, Module 2, Article 4, pp. 179-274, 06-26-13 [copyright by authors]

I think he has gotten more open in a group than he was. You cannot know if it would have happened anyway but the things that were worked on... He tried some things and found out that 'ok, this I dared do'. I think that has had an influence. If not anything else it has helped speed up some things and he got the courage to do things...He tried different things with some other children and showed that he could be there.

Finding himself in a safe context Niels would try and interact with other children that had similar difficulties as him and this contributed to some positive experiences that gave him courage to open up in other social situations.

Stine. Stine’s mother believed that parents' inclusion in treatment was important:

Being there gave a signal that WE are interested to solve this problem. It is not just something you [the child] have a problem with that you need to solve, but it is something we should do together.

Furthermore, the mother thought it was positive that the group consisted of children with different anxiety disorders, because it contributed to different discussions that made her think about her role as a parent and of her behaviors:

I think it was good that it was a mixed group. There were many issues that we talked about, and although we might not have had the problem you get to think about some of the things and can see some other things too that some of the others said. It is first when you sit down and talk about it that you realize that you actually have some problems. How much space it actually takes up [the anxiety problem]...As a parent you automatically have this protectortrait where you think: 'children should of course not be confronted by the things they are afraid of.' So I have thought about it many times.

Stine was happy to meet another child [Lene] who was also afraid of dogs and that contributed to her accepting her anxiety and normalizing it: "I think it was very nice that there was one more that had the same anxiety as me. That made me think: 'it is ok, then it is not just me who is afraid'." The in-vivo exposures session was a positive experience for Stine who had the role of a helper in an anxiety provoking situation instead of the one needing help and she enjoyed being a positive role model for Lene. In addition, Stine liked that the treatment format included individual student therapists and that there were social arrangements in the group:

Another thing that was good, was that we had an adult for ourselves...it was nice that someone sat right next to you and helped all the time...I also thought it was really cozy to eat dinner together.

Tom. Tom's parents often took initiatives in order to contribute to a positive atmosphere in the group, which they believed was important in order to create a safe space, where parents and children would want to open up. At the interview 15 months after treatment the father provided with an interesting insight on the parents' group:

I thought it was really nice that it was like that [therapy format] so we could discuss things and that can be very different from one group to another, but we quickly got some nice talks in our group. I think that was very very fruitful. I also think it was so for most of the others, 
A "Cool Kids" Cognitive-Behavioral Therapy Group for Youth with Anxiety Disorders:

Part 2, Analysis of the Process and Outcome of Responders Versus Nonresponders

I. Lundkvist-Houndoumadi \& M. Thastum

Pragmatic Case Studies in Psychotherapy, http://pcsp.libraries.rutgers.edu

Volume 9, Module 2, Article 4, pp. 179-274, 06-26-13 [copyright by authors]

because you felt that it is not just us that stand with this problem and we have tried everything and we just can't manage anymore...or yes we can but it doesn't help. So we can say the same thing and do the same one more time, but it doesn't change anything....Me and Tom's mother we just talk a lot. And some of them looked a bit hesitant at first but then they also contributed in the talks. So you need someone to start the talking and then usually the rest follows. Otherwise it can also end up being so that no one dares say something....If you get there and...like the father of Lene...he was very quiet at first, sitting there...but he got more and more involved. And then it is very different with parents; what they think is taboo or what they like to share and talk about.

As Tom's father describes it can be very different how a group turns out to function and it seems to be important they do not believe it is a taboo to talk about their frustrations and concerns related to parenting their children. In therapy parents got new knowledge on how to help their children, felt less isolated and were encouraged by the other parents to change their behaviors. As a result they kept on being engaged in the treatment process. In addition, the parents had a forum where they could air their frustrations, so they would not take them out on their child, while they became aware of how their children's anxiety had been taking too much space in the family life:

Earlier the usual reaction when I was stressed and Tom would not calm down was: 'Oh, just stop it! There is nothing to be afraid of! Why don't you understand it?' I could get really irritated about it. I think again that this thing with being in a group was good. You got some ideas from the others and we could pass some ideas on to the others. That's why I liked that children were alone, parents were also alone and then all of us were together. I thought that was very good. It was very good that the parents could have theirs and the children too without their parents and then together, to say that this here is a common project. We fight together...We in the parents' group realized how much time was spent every day on anxiety...And that is what was so great about sitting with the other parents and talking about...how much time do we actually spend on this? You don't think of it in your everyday in the beginning, because it has always been like that. Tom is like that, his sister isn't. But when we then realized, we actually spent 1.5-2 hours every day to get him to sleep. And we hadn't been in the cinema in many years. There are many things when you then realize... And that is what was so great about this here. It helps both him and us parents.

Parents received help and got to prioritize their time as a couple because they no longer overprotected their children. It is believed that this alleviated the stress parents often experienced due to their child's anxiety problems and possibly contributed to a positive family atmosphere that indirectly also had a positive influence on children. It is reported that in a warm and considerate marital relationship mothers and fathers praise and stimulate their children more than when they experience tension and tend to be less responsive to their children's needs (Cox, Paley \& Harter, 2001; Erel \& Burman, 1995). Tom's mother also described how she felt supported and understood in the parents' group:

To have a forum with other parents in the same situation was very good. You felt that it is not just us that stand with this problem. The [therapy] form was very good for us. My husband and I needed the parents' group, both to support us in it, meet others in the same situation that understand the problem, but also come to see ourselves in it, obtain selfknowledge. It is very rewarding to share experiences and see the 'mirror' the parents hold up in front of us. 
A "Cool Kids" Cognitive-Behavioral Therapy Group for Youth with Anxiety Disorders:

Part 2, Analysis of the Process and Outcome of Responders Versus Nonresponders

I. Lundkvist-Houndoumadi \& M. Thastum

Pragmatic Case Studies in Psychotherapy, http://pcsp.libraries.rutgers.edu

Volume 9, Module 2, Article 4, pp. 179-274, 06-26-13 [copyright by authors]

Besides the positive effects on Tom's parents, the therapy format also contributed to Tom feeling supported, his anxiety being normalized, just like in Niels' case:

Tom was very supported by meeting other children, who were in the same situation, and experienced that anxiety is legitimate and not something you should be embarrassed about.

At the last therapy session Tom's parents had arranged to buy gifts for the psychologist and the student therapists that contributed to a very joyous atmosphere, where the mother gave the following speech:

It has been a pleasure to be part of this community. Because our children have been brought together in this 'shared destiny' and we also share our children's destiny and this has brought us together. And we have had great pleasure out of this, great joy. And that is something that has made all of us happy. And even though this program has been for free, we have not felt less committed, on the contrary actually.

\section{Minimally Improved (Nonresponders): Mark and Lene}

In contrast to the responders, non-responders did not describe the therapy format as positively, indicating that it did not give them the support and encouragement they needed in order to be engaged in the treatment process; ironically they were the ones that needed it the most.

Mark. Even though Mark’s father reported: "It was rewarding with the group of parents", when asked about what had made it rewarding he replied vaguely: "We had some nice talks. That was what we had come for." The mother disagreed with him:

I don't think it gave that much. It was cozy, but it could have been more structured. The first time you [psychologist and student therapists] disappeared and we sat there and giggled all of us. What would happen now? What was the purpose of it?

It was difficult for the mother to see how parents' alone-time could be helpful and preferred a structured program, where a psychologist would bring up different topics they could discuss. Nevertheless, the father described how he believed it was helpful to talk with others:

We have been uncertain what we should do and if we should pressure him. But it was good to talk with you and the parents and be reassured that it is ok [that they as parents pressure their children a bit in order for them to progress]...It was very good we parents also took part in this. The fact that children and adults have had this together I think also contributed to say: 'OK, there are also others that are on the same boat as I...And it was good Mark was in a context where we weren’t with him.

Even though Mark's father felt reassured that it was ok not to overprotect Mark, he did not engage in that behavior consistently. It appears that the fact that Mark's parents did not stop supporting his avoidance was not due to a lack of understanding of the consequences, but a lack of motivation and those maintaining factors remained uninfluenced by the group. The mother could not see the purpose of the parents' talking freely, which may be related to her admitting being a perfectionist, needing clear guidelines on what is expected of her, feeling uncertain in unstructured settings. 
A "Cool Kids" Cognitive-Behavioral Therapy Group for Youth with Anxiety Disorders:

Part 2, Analysis of the Process and Outcome of Responders Versus Nonresponders

I. Lundkvist-Houndoumadi \& M. Thastum

Pragmatic Case Studies in Psychotherapy, http://pcsp.libraries.rutgers.edu

Volume 9, Module 2, Article 4, pp. 179-274, 06-26-13 [copyright by authors]

Lene. Similar to Mark's mother, Lene's mother believed it was positive that parents were included in therapy, but she wanted the parents' alone time to be more structured:

I think a big part of this program is that both we parents [and the children] get the same background knowledge, understanding and line of thinking. But I have all along thought the structuring of the parent time should be different. We spent the first many times to sit there and small talk. I believe someone should have sat with us and lead it and then maybe later on could have given us a subject to talk about.

According to the first author's observations the other parents showed their support and understanding to Lene's mother, as illustrated in the following exchange:

Lene's mother: I can see Lene is afraid, but she will not admit it and says that she is not afraid and I feel I should try and show her I accept it is OK to be afraid instead of pushing her. It is almost unbearable to see how she is lying to herself and me...

Tom's mother: I understand exactly what you mean; I also have similar difficulties with Tom...

Nevertheless it seems that the parents' group did not have the positive influence it had on the parents of the responders. It is possible that Lene's mother and Lene were discouraged by the fact that the other children in the group were progressing, while Lene made very little progress. As related by the mother, Lene told her on their way to one of the sessions: "I am sure that Stine will no longer be afraid of dogs." At that point the mother's impression was that Lene was jealous and thought: "Why couldn't it be me?", but the mother herself nurtured similar feelings "I don't feel like there is any progress".

\section{Commentary on the Group Format}

The families of the children responding to treatment described several advantages related to therapy conducted in a group format and it has been shown that a perception of the group climate as positive is associated with positive patient outcome (Hoberman, Lewinsohn, \& Tilson, 1988; Davies, Burlingame, Johnson, et al., 2008). The group contributed to normalizing children's anxiety, provided with modeling, prompting, reinforcement and heightened mastery, as well as increased opportunities for social experience. These same issues have been stressed by Heimberg and colleagues (1990) in the case of group CBT and have been presented as theoretical advantages of group treatment by Yalom and colleagues (1993).

On the other hand, potential disadvantages of group treatment have also been suggested (Groot, Cobham, Leong, McDermott, 2007). Those are related to parental skepticism regarding the effectiveness of group treatment and the more limited opportunities for therapists to tailor the treatment to individual families needs. These disadvantages were not voiced in the group investigated. All parents were happy to participate in a group (though the mothers of nonresponders would have liked a more structured approach) and the manual-based treatment was implemented flexibly with the student therapists following closely the needs of the individual families. 
A "Cool Kids" Cognitive-Behavioral Therapy Group for Youth with Anxiety Disorders:

Part 2, Analysis of the Process and Outcome of Responders Versus Nonresponders

I. Lundkvist-Houndoumadi \& M. Thastum

Pragmatic Case Studies in Psychotherapy, http://pcsp.libraries.rutgers.edu

Volume 9, Module 2, Article 4, pp. 179-274, 06-26-13 [copyright by authors]

Within the parents' subgroup, parents became more aware of their role as parents and of their parenting style by talking with other families. The parents discussed about striking a balance between the parental duty of protecting children, versus an inefficient over-protectiveness and setting rules and limits that are not over-controlling. They used examples from their daily life and the therapist focused on enabling the discussions to be mostly inquiring and non-judgmental. Tom's mother explained how the others would: "hold up a mirror in front of us". The heightened awareness of the parents regarding their own behaviors contributed to changes in the case of parents of responders, for example when they realized how anxiety had been taking too much space in family life.

In addition, parents of the responders, in contrast to the non-responders, appreciated the independence and autonomous functioning encouraged by the psychologist as seen in their comments concerning how they enjoyed having talks in parents' alone-time. They had gotten a forum where they could express thoughts and feelings without needing guidance from the psychologist and there was room for many initiatives. These group experiences could have contributed to positive changes in parents, and indirectly the children and is in agreement with Oei and Browne's (2006) conclusions that mood and anxiety disordered patients' perception that the group and its leader fosters independence and expressiveness is a good prognostic indicator in CBT based psychoeducational groups.

The parents of the non-responders did not comment that they felt supported or encouraged by other parents and being part of the group did not seem to affect their self-reflection as parents and consequently the behaviors that were related to the maintenance of their children's anxiety. More specifically, although Lene's mother was encouraged to reclaim her parental authority, she claimed she could not do it. For example, when she presented her problem persuading Lene's sister to go to school, one of the parents suggested that she told her daughter: "If you don't go to school there will be consequences" to which the mother replied: "That would be really hard for me to do.” Similarly, Mark's parents had trouble to set limits for what they would not do for Mark, supporting his avoidance. Unfortunately, the parents were not able to see how this practice was paradoxically trapping their son in a vicious cycle of anxiety and lack of confidence that did not allow Mark to gradually become more independent of his parents.

In addition, it is important to keep in mind that since non-responders progressed very slowly in therapy, both parents and the children could have become demoralized when comparing themselves to the other families and this may provide a partial explanation of why they did not profit as much from the group format.

In contrast, children that responded to treatment became more independent of their parents during therapy, as they believed more in themselves and they were able to handle anxietyprovoking situations without their parents' reassurance and protection. Promoted by the group format, children's identification with each other seemed to empower them and to facilitate their differentiation from their parents, since they felt accepted and understood. Children became gradually more active and involved as the sessions progressed and they began interacting with each other, shared their experiences of dealing with anxiety-provoking situations, in some cases giving each other advice. We suggest that these group processes contributed to a positive change, 
A "Cool Kids" Cognitive-Behavioral Therapy Group for Youth with Anxiety Disorders:

Part 2, Analysis of the Process and Outcome of Responders Versus Nonresponders

I. Lundkvist-Houndoumadi \& M. Thastum

Pragmatic Case Studies in Psychotherapy, http://pcsp.libraries.rutgers.edu

Volume 9, Module 2, Article 4, pp. 179-274, 06-26-13 [copyright by authors]

which is in line with the finding of a study with adults (Taube-Schiff et al., 2007) indicating that an increase in perceived group cohesion from mid-group to termination significantly predicted better improvement in anxiety and depressive symptoms. Cognitive-behavior group therapists are increasingly attending to the nonspecific group processes operating in the group (Bieling, McCabe, \& Antony, 2006) and this is important in order to gain a more holistic view of the possible mechanisms of change.

\section{Therapy Process and Response to Treatment: Overall Commentary}

In order to understand why some children responded to treatment and others did not, it is reasonable to raise the question "why did change come about?" The treatment process was examined to provide an answer by exploring the four treatment elements studied and considering their contribution as possible mechanisms of change. An attempt is made to summarize below the complex interplay of variables found to be related to the child, the parents and the therapy setting and appear to have influenced children's differential response to treatment.

\section{i) Responders}

The therapeutic elements focused upon in the present study as facilitators of the use of treatment components, along with client characteristics and therapeutic outcomes as they relate to responders and non-responders are shown in Figure 1. The characteristics of children (box 1) and parents (box 2) and the nature of the relationship between them in terms of communication, parenting style and family cohesion provides the clients' background that is brought into therapy and which interacts with the different treatment components they are exposed to (box 3). Overall, the children who responded to treatment were motivated (box 4) and their parents were engaged (box 5), supporting and transferring skills to their children (box 6), while at the same time, the group format context (box 7) encouraged and supported both children and parents. In turn, the support provided by parents reinforced children's motivation, while the positive parenting style and good relations within the family facilitated the practice and use of the treatment components. Thereby children integrated anxiety coping skills (box 8) and enhanced their self-efficacy (box 9), while their anxiety was gradually lowered (box 10). The parents changed their expectations about their children's ability to deal with anxiety (box 11), altered their behavior (e.g., no longer overprotecting them) (box 12), and acquired skills becoming more confident about handling future anxiety in their children (box 13). Those parental changes contributed to the maintenance of changes in children.

Given the multiplicity of bidirectional influences, an attempt to capture the flow of therapeutic effects is quite elusive and the above description may give a rather static and hence false representation. Thus for example, not only do parents change their expectations and behavior as a result of skills training and/or discussions in the group, but their children's increasing coping skills make parents change their expectations and behavior as well. Additionally the figure may at points give the impression of the existence of a linear progression in time, which does not fully capture the process. While the client characteristics was something brought into therapy and the selected therapeutic elements studied preceded the outcomes, in terms of their initial introduction, later they were in constant dialogue influencing each other, so that the changed parental behaviors (outcome) directly affected the use of treatment components 
A "Cool Kids" Cognitive-Behavioral Therapy Group for Youth with Anxiety Disorders:

Part 2, Analysis of the Process and Outcome of Responders Versus Nonresponders

I. Lundkvist-Houndoumadi \& M. Thastum

Pragmatic Case Studies in Psychotherapy, http://pcsp.libraries.rutgers.edu

Volume 9, Module 2, Article 4, pp. 179-274, 06-26-13 [copyright by authors]

(process). In order to get a glimpse of the difficulties in drawing any firm conclusions concerning the direction of influences in therapy, the motivational aspects involved in the case of Tom will be briefly presented as an example below.

Tom was not as motivated for therapy as the other responders, possibly due to his inhibited temperament that made it difficult for the student therapists to form a connection to him and make him feel comfortable in therapy, while his friends were fond of him as he was, so he did not feel the need to get past his anxiety to get their approval. Nevertheless, his at times diminished motivation was counterbalanced by the fact that the parents were extremely engaged in the therapy process and did a lot of homework as a family. The father described Tom as having great emotional intelligence, which made it easier for them to help him. In addition, practicing seemed to be facilitated by the authoritative parenting style and positive parent-child relationships. On the other hand, it is possible to see Tom's relatively lower motivation, when compared against other responders, as a result of the parents pressuring him too much at home in doing a lot of homework. If parents had not emphasized as much doing homework, Tom might have been more motivated in therapy sessions (as seen in Niels' case), but on the other hand, this may have resulted in Tom not having incorporated in his behavior the treatment components to the degree he did.

\section{ii) Non-Responders}

When examining the cases of non-responders it is important to identify moderating factors that impeded the treatment elements from contributing to a positive therapy outcome. The non-responders were overall not motivated to practice while in therapy and this could be related to different issues. The children did not seem to be aware of the negative consequences of their anxiety when they came for treatment, since their parents had up until then supported their avoidance. In addition, while they experienced difficulties in using the treatment components (found them difficult to understand or were impatient and defensive), the parents were unable to support them in their practicing, the families being characterized by a number of hindering factors: lack of parental (especially paternal) engagement, permissive and inconsistent parenting style, parental stress and frustration with children's anxiety, problematic parent-child relations and impaired mother-father communication. We suggest that all of these factors in combination with certain children's characteristics (e.g. low self-efficacy and cognitive immaturity) interfered with the successful practice of treatment components. Since exposures did not occur as often as needed in order for extinction to occur, the children experienced very intense anxiety when doing the exposures, and progressed very slowly in therapy, both parents and the children being demoralized when comparing themselves to the other families.

The non-responders of the study deserve attention, since they may provide us with some knowledge concerning what can be done if we were to optimize therapeutic change. The treatment components were evaluated as very useful by all families, indicating that it was not due to the components of the Cool Kids Program that those children did not respond to treatment. Nevertheless, in order to reach children and engage all of them, it is important to apply the therapeutic manual flexibly and creatively, with clinicians taking developmental principles and the particular needs of each case into consideration (Kendall \& Choudhury, 2003; Kendall, Chu, 
A "Cool Kids" Cognitive-Behavioral Therapy Group for Youth with Anxiety Disorders:

Part 2, Analysis of the Process and Outcome of Responders Versus Nonresponders

I. Lundkvist-Houndoumadi \& M. Thastum

Pragmatic Case Studies in Psychotherapy, http://pcsp.libraries.rutgers.edu

Volume 9, Module 2, Article 4, pp. 179-274, 06-26-13 [copyright by authors]

Gifford, Haynes \& Nauta, 1998). Clinicians need to try and understand a particular child's level of cognitive, social and emotional development, since these skills can have a great impact on each child's ability to participate and ultimately respond to treatment. Kingery, Roblek, Suveg, Grover, Joel and Bergman (2006) provide suggestions on how clinicians may implement creative strategies for engaging children in treatment and modifying CBT components to fit children's developmental level.

Besides children's and parents' characteristics, an important element for children not responding to treatment was the family's lack of engagement throughout the treatment process. Empirical literature suggests that early prognostic beliefs about change or anticipation of relief (either positive or negative) play a key role in subsequent response to treatment across different disorders and different treatments (e.g., Arnkoff, Glass \& Shapiro, 2002; Dozois \& Westra, 2005; Greenberg, Constantino, \& Bruce, 2006). It therefore seems reasonable to argue that the treatment gains of those children could be enhanced if these issues were targeted and altered through a motivational enhancement approach. Those approaches address the whole family and focus on building motivation to change by highlighting the discrepancy between present behavior and desired outcomes, subsequently strengthening the commitment to change by supporting the individual's sense of self-efficacy (see Nock, 2005). Children have to be made aware of the short-term and long-term consequences of their anxiety problems and the gains connected to getting over them, realizing and believing that they have the power to change. A lot of the work that has been done with adults could be easily adapted to children, while parents could also be targeted through for example the Participation Enhancement Intervention designed by Nock (2005), which focuses on enhancing parent attendance and adherence to child therapy.

\section{Conclusions}

We want to conclude by highlighting several issues that are related to the treatment elements that were revealed in the present study and deserve further research attention.

Children's motivation. The influence of children's age needs to be considered in association with the identified important aspects of advancing cognitive development and increasing peer influence, while the age differences among participating children in a therapeutic group context may be an additional potentially enhancing or impeding factor mobilizing children's involvement. The close interrelationship found between parental engagement and children's motivation deserves further attention, with a special emphasis on fathers' engagement.

Children's use and implementation of treatment components. Children's use of different treatment components should be explored in relationship to a variety of factors. These include: (a) the degree of assistance needed (e.g., cognitive restructuring was found to be cognitively demanding for children, but it was easier when parents assisted and when children were closer to the frightening situation); (b) family dysfunction as revealed in communication problems between parents and secrecy in the family, patterns identified here in the non-responders' families; (c) the differential helpfulness of the various components (e.g., exposures were very helpful in gradually decreasing children's anxiety in therapy and providing them with a feeling of self-efficacy, a notion that deserves more attention in the treatment of childhood anxiety (see Gade, 2011), while cognitive restructuring facilitated the implementation of exposures and 
A "Cool Kids" Cognitive-Behavioral Therapy Group for Youth with Anxiety Disorders:

Part 2, Analysis of the Process and Outcome of Responders Versus Nonresponders

I. Lundkvist-Houndoumadi \& M. Thastum

Pragmatic Case Studies in Psychotherapy, http://pcsp.libraries.rutgers.edu

Volume 9, Module 2, Article 4, pp. 179-274, 06-26-13 [copyright by authors]

contributed to the maintenance of treatment gains); d) a consideration of techniques that are based on mindfulness principles deserve more attention (e.g., worry surfing was incorporated the most in children's use of coping skills after the end of therapy and seemed especially helpful in the treatment of specific phobias).

Parenting behaviors and expectations. The interrelationships among variables related to family functioning and communication need more systematic exploration in order to identify the multiple paths through which they influence parenting expectations and behaviors that help maintain or reduce children's anxiety by implementing the newly obtained coping skills and transferring control from parents to children. Several facilitating aspects that were identified here as candidates for that more systematic research include open communication and high family cohesion as well as an authoritative parenting style and fathers' involvement. Some of the impeding aspects include: parental overprotective behavior, inconsistent parenting, lack of support from the spouse, and permissive parenting style. In addition, future studies on the directionality of change between parent and child hold promise for informing the field about the variables that are most critical to target for improvement in treatment.

Group format. The ways in which a group format may contribute to a positive therapeutic outcome need to be studied more systematically in order to enhance its facilitating potential. The positive atmosphere that was evident in the present group and supported by parents taking initiatives for social arrangements facilitated the treatment process. Parents had the opportunity to talk openly about their frustrations and challenges stemming from parenting an anxious child and their joys and pride from witnessing progress. Nevertheless, not all parents viewed the group equally positively; responders perceived it as a "community with shared destinies" while nonresponders wanted a more structured setting. We plan in our future therapy work to pay particular attention to this factor.

\section{$\underline{\text { Promising Results }}$}

Since the present research involved only one pilot study group involving only six children, and since as in any such study there were limitations in our data-e.g., the self-report nature of much of the quantitative material - the conclusions to be drawn from this research have to be qualified. Nevertheless, we believe we have presented sufficient evidence to conclude that this particular Cool Kids Program group, as implemented at the Anxiety Disorder Clinic for Children and Adolescents of Aarhus University, was evaluated positively by the families, who were especially happy that (a) both parents and children had acquired useful tools they could turn to in case these were needed, even after the completion of treatment; (b) parents were included in therapy; and (c) they had the opportunity to meet and share with other families facing similar problems.

These affirmative experiences by the families were complemented by the fact thatbased on data derived from standardized diagnostic standardized interviews, self-report measures, and qualitative interview material-four out of the six children obtained CGI-I ratings that classified them as responders at the 15-month follow-up. 
An additional finding was that the methodology of the study—an embedded case study combining quantitative with qualitative data and having multiple informants—-proved successful in capturing the multiplicity of influences and the interrelations among variables influencing therapy process and outcome, albeit limited by the small number of subjects, as mentioned above.

Overall, we deem our pilot group successful and will use it to plan what is needed for the next research step: conducting larger and more controlled studies of the group-based Cool Kids Program in the future. 
A "Cool Kids" Cognitive-Behavioral Therapy Group for Youth with Anxiety Disorders:

Part 2, Analysis of the Process and Outcome of Responders Versus Nonresponders

I. Lundkvist-Houndoumadi \& M. Thastum

Pragmatic Case Studies in Psychotherapy, http://pcsp.libraries.rutgers.edu

Volume 9, Module 2, Article 4, pp. 179-274, 06-26-13 [copyright by authors]

\section{REFERENCES}

Albano, A.M. \& Silverman, W.K. (1996). Anxiety Disorders Interview Schedule for DSM - IV. Child version. Oxford: Oxford University Press.

Alloy, L.B. (2001). The developmental origins of cognitive vulnerability to depression: Negative interpersonal context leads to personal vulnerability. Cognitive Therapy and Research, 25, 349-351.

Arnkoff, D.B., Glass, C.R., \& Shapiro, S.J. (2002). Expectations and preferences. In J. C. Norcross (Ed.), Psychotherapy relationships that work: Therapist contributions and responsiveness to patients (pp. 335- 356). London: Oxford University Press.

Baer, R. A. (2003). Mindfulness training as a clinical intervention: A conceptual and empirical review. Clinical Psychology: Science \& Practice, 10, 125-143.

Bailey, V. (2001). Cognitive-behavioral therapies for children and adolescents. Advances in Psychiatric Treatment, 7(3), 224-232.

Bandura, A. (1988). Self-efficacy conception of anxiety. Anxiety Research No. 1, pp. 77-98.

Bandura, A. (1997). Self-efficacy: The exercise of control. W. H. Freeman.

Barmish, A., \& Kendall, P. C. (2005). Should parents be co-clients in cognitive-behavioral therapy for anxious youth? Journal of Clinical Child and Adolescent Psychology, 34, 569-581.

Barrett P.M. (1998). Evaluation of cognitive-behavioral group treatments for childhood anxiety disorders. Journal of Clinical Child Psychology, 27, 459-468.

Barrett, P.M., Rapee, R.M., Dadds M.R. \& Ryan, S.M. (1996). Family enhancement of cognitive style in anxious and aggressive children. Journal of Abnormal Child Psychology, 24, 187-203.

Baumrind, D. (1967). Child care practices anteceding three patterns of preschool behavior. Genetic Psychology Monographs, 76, 43-88.

Baumrind, D. (1991). The influence of parenting style on adolescent competence and substance use. Journal of Early Adolescence, 11, 56-95.

Beck, J. S., Beck, A. T., \& Jolly, J. (2001). Beck Youth Inventories ${ }^{\mathrm{TM}}$ of Emotional and Social Impairment. The Psychological Corporation.

Bieling, P.J., McCabe, R.E., \& Antony, M.M. (2006). Cognitive-behavioral therapy in groups. New York: Guilford.

Blatt, S.J., Quinlan, D.M., Pikonis, P.A. \& Shea, T.A. (1995): Impact of perfectionism and need for approval on the brief treatment of depression: the national institute of mental health treatment of depression. Collaborative research program revisited. Journal of Consulting and Clinical Psychology, 63, 125-132.

Bodden, D.H.M., Bögels, S.M., Nauta, M.H., De Haan, E., Ringrose, J., Appelboom, C., Brinkman, A.G. \& Appelboom-Geerts, K.C.M.M.J. (2008).Child versus family cognitive-behavioral therapy in clinically anxious youth: An efficacy an partial effectiveness study. American Academy of Child and Adolescent Psychiatry, 47, 13841394.

Bögels, S.M., \& Brechman-Toussaint, M. (2006). Family issues in child anxiety: Attachment, family functioning, parental rearing and beliefs. Clinical Psychology Review, 26, 834856. 
A "Cool Kids" Cognitive-Behavioral Therapy Group for Youth with Anxiety Disorders:

Part 2, Analysis of the Process and Outcome of Responders Versus Nonresponders

I. Lundkvist-Houndoumadi \& M. Thastum

Pragmatic Case Studies in Psychotherapy, http://pcsp.libraries.rutgers.edu

Volume 9, Module 2, Article 4, pp. 179-274, 06-26-13 [copyright by authors]

Bögels, S. M., \& Siqueland, L. (2006). Family cognitive behavioral therapy for children and adolescents with clinical anxiety disorders. Journal of the American Academy of Child \& Adolescent Psychiatry, 45, 134-141.

Bolton, D. (2004). Cognitive behavior therapy for children and adolescents: Some theoretical and developmental issues. In P.J. Graham (Ed.), Cognitive Behavior Therapy for Children and Families (pp. 9-24). Cambridge: Cambridge University Press.

Bowlby, J. (1982). Attachment and loss: Volume 1, Attachment. $2^{\text {nd }}$ ed. New York: Basic Books.

Carr, A. (1999). The handbook of child and adolescent clinical psychology: A Contextual Approach. New York: Routledge.

Chambless, D. L., Tran, G. Q., \& Glass, C. R. (1997). Predictors of response to cognitivebehavioral group therapy for social phobia. Journal of Anxiety Disorders, 11, 221-240.

Chu, B.C. \& Kendall, P.C. (2004). Positive association of child involvement and treatment outcome within a manual-based cognitive-behavioral treatment for children with anxiety. Journal of Consulting and Clinical Psychology, 72, 821-829.

Cobham, V.E., Dadds, M.R. \& Spence, S.H. (1998). The role of parental anxiety in the treatment of childhood anxiety.Journal of Consulting and Clinical Psychology, 66, 893-905.

Conger, R.D., Patterson, G.R., \& Ge, X. (1995). It takes two to replicate: A meditational model for the impact of parents' stress on adolescent adjustment. Child Development, 66, 80-97.

Cox, M.J., Paley, B., \& Harter, K. (2001). Interparental conflict and parent-child relationships. In J.H. Grych \& F.D, Fincham (Eds.), Interparental conflict and child development: Theory, research, and applications (pp. 249-272). New York: Cambridge University Press.

Crawford, A. M., \& Manassis, K. (2001). Familial predictors of treatment outcome in childhood anxiety disorders. Journal of the American Academy of Child \& Adolescent Psychiatry, 40, 1182-1189.

Daleiden, E. L., Vasey, M. W., \& Brown, L. M. (1999). Internalizing disorders. In W. K. Silverman \& T. H. Ollendick (Eds.), Developmental issues in the clinical treatment of children (pp.261-278). Needham Heights, MA: Allyn \& Bacon.

Davies, D. R., Burlingame, G. M., Johnson, J. E., Gleave, R. L., Barlow, S. H. (2008). The Effects of a Feedback Intervention on Group Process and Outcome. Group Dynamics: Theory, Research, and Practice. 12,141-154.

Dozois, D. J., \& Westra, H. A. (2005). Development of the Anxiety Change Expectancy Scale (ACES) and validation in college, community, and clinical samples. Behavior Research and Therapy, 43, 1655-1672.

Dunkley, D.M., Blankstein K.R., Masheb, R.M. \& Grilo, C.M. (2006). Personal standards and evaluative concerns dimensions of "clinical” perfectionism: A reply to Shafran et al. (2002, 2003) and Hewitt et al. (2003). Behavior Research and Therapy, 44, 63-84.

Durlak, J.A., Fuhrman, T., \& Lampman, C. (1991). Effectiveness of cognitive-behavior therapy for maladapting children: A meta-analysis. Psychological Bulletin, 110, 204-214.

Erel, O., \& Burman, B. (1995). Interrelatedness of marital relations and parent-child relations: A meta-analytic review. Psychological Bulletin, 118, 108-132.

Flannery-Schroeder, E. C. \& Kendall, P. C. (2000). Group and individual cognitive-behavioral treatments for youth with anxiety disorders: A randomized clinical trial. Cognitive Therapy and Research, 24, 251-278.

Frank, J. D. (1973). Persuasion and healing: A comparative study of psychotherapy. Baltimore: Johns Hopkins University Press. 
A "Cool Kids" Cognitive-Behavioral Therapy Group for Youth with Anxiety Disorders:

Part 2, Analysis of the Process and Outcome of Responders Versus Nonresponders

I. Lundkvist-Houndoumadi \& M. Thastum

Pragmatic Case Studies in Psychotherapy, http://pcsp.libraries.rutgers.edu

Volume 9, Module 2, Article 4, pp. 179-274, 06-26-13 [copyright by authors]

Frank, J.D. (1982). Therapeutic components shared by all psychotherapies. In: J.H. Harvey \& M.M. Parts (eds.), The Master Lecture Series. Vol. 1.Psychotherapy Research and Behavior Change. (pp. 5-37).Washington: American Psychological Association.

Frank, J. D., \& Frank, J. B. (1991). Persuasion and healing: A comparative study of psychotherapy (3rd ed.). Baltimore: Johns Hopkins University Press.

Gade, A. (2011). Self-efficacy: A key mechanism of change in The Cool Kids Program. Thesis in preparation to be submitted, Aarhus University, Aarhus, Denmark.

Ginsburg, G. S., \& Schlossberg, M. C. (2002). Family-based treatment of childhood anxiety disorders. International Review of Psychiatry, 14, 143-154.

Ginsburg, G. S., Silverman, W. K., \& Kurtines, W. M. (1995). Family involvement in treating children with phobic and anxiety disorders: A look ahead. Clinical Psychology Review, 15, 457-473.

Goodman, R. \& Scott, S. (1999) Comparing the Strengths and Difficulties Questionnaire and the Child Behavior Checklist: Is small beautiful? Journal of Abnormal Child Psychology, 27, 17-24.

Grave, J., \& Blissett, J. (2004). Is cognitive behavior therapy developmentally appropriate for young children? A critical review of the evidence. Clinical Psychology Review, 24, 399420.

Greenberg, R. P., Constantino, M. J., \& Bruce, N. (2006). Are patient expectations still relevant for psychotherapy process and outcome? Clinical Psychology Review, 26, 657-678.

Groot, J. D., Cobham, V. Leong, J. \& McDermott, B. (2007). Individual versus group familyfocused cognitive behavior therapy for childhood anxiety: A pilot randomized controlled trial. Australian and New Zealand Journal of Psychiatry, 41, 990-997.

Hedtke, K.A., Kendall, P.C. \& Tiwari, S. (2009). Safety-seeking and coping behavior during exposure tasks with anxious youth. Journal of Clinical Child and Adolescent Psychology, 38, 1-15.

Heimberg, R.G., Dodge, C.S., Hope, D.A., Kennedy, C.R., Zollo, L.J. \& Becker, R.E. (1990). Cognitive-behavioral group treatment for social phobia: comparison with a credible placebo control. Cognitive Therapy and Research, 14, 1-23.

Hirshfeld, D. R., Rosenbaum, J. F., Biederman, J., \& Bolduc, E. A. (1992). Stable behavioral inhibition and its association with anxiety disorder. Journal of the American Academy of Child and Adolescent Psychiatry, 31, 103-111.

Hoberman, H. M., Lewinsohn, P. M., \& Tilson, M. (1988). Group treatment of depression: Individual predictors of outcome. Journal of Consulting and Clinical Psychology, 56, 393-398.

Holmbeck, G.N., Greenley, R.N. \& Franks, E.A. (2003). Developmental Issues and Considerations in Research and Practice. In A.E. Kazdin \& J.R. Weisz (Eds.) EvidenceBased Psychotherapies for Children and Adolescents, pp. 21-41. New York: The Guilford Press.

Holmbeck, G. N., O’Mahar, K., Abad, M., Colder, C., \& Updegrove, A. (2006). Cognitivebehavior therapy with adolescents: Guides from developmental psychology. In P. C. Kendall (Ed.), Child and adolescent therapy: Cognitive-behavioral procedures (pp. 419464). New York: Guilford. 
A "Cool Kids" Cognitive-Behavioral Therapy Group for Youth with Anxiety Disorders:

Part 2, Analysis of the Process and Outcome of Responders Versus Nonresponders

I. Lundkvist-Houndoumadi \& M. Thastum

Pragmatic Case Studies in Psychotherapy, http://pcsp.libraries.rutgers.edu

Volume 9, Module 2, Article 4, pp. 179-274, 06-26-13 [copyright by authors]

Hudges, A.A., \& Kendall, P.C. (2007). Prediction of cognitive behavior treatment outcome for children with anxiety disorders: Therapeutic relationship and homework compliance.

BehaviorBehavioral and Cognitive Psychotherapy, 35, 487-494.

Hudson, J.L., \& Rapee, R.M. (2009). Familial and social environments in the etiology and maintenance of anxiety disorders. In M. M. Antony, \& M. B. Stein (Eds.), Oxford handbook of anxiety and related disorders. (pp. 173-189). New York, NY, US: Oxford University Press.

Ilardi, S. S., \& Craighead, W. E. (1994). The role of nonspecific factors in cognitive-behavior therapy for depression. Clinical Psychology: Science and Practice, 1, 138-156.

Ishikawa, S., Okajima, I., Matsuoka, H., \& Sakano, Y. (2007). Cognitive behavioral therapy for anxiety disorders in children and adolescents: A meta-analysis. Child and Adolescent Mental Health, 12, 164-172.

Karver, M.S., Handelsman, J.B., Fields, S. \& Bickman, L. (2006). Meta-analysis of therapeutic relationship variables in youth and family therapy: The evidence for different relationship variables in the child and adolescent treatment outcome literature. Clinical Psychology Review, 26, 50-65.

Kaul, T. J., \& Bednar, R. L. (1994). Pretraining and structure: Parallel lines yet to meet. In A. Fuhriman \& G. M. Burlingame (Eds.), Handbook of group psychotherapy: An empirical and clinical synthesis. New York: Wiley.

Kendall, P. G., Chu, B., Gifford, A., Hayes, G., \& Nauta, M. (1998). Breathing life into a manual: Flexibility and creativity with manual-based treatments. Cognitive and Behavioral Practice, 5, 177-198

Kendall, P. G., \& Choudhury, M. S. (2003). Children and adolescents in cognitive-behavioral therapy: Some past efforts and current advances, and the challenges of our future. Cognitive Therapy and Research, 27, 89-104.

Lundkvist-Houndoumadi, I., \& Thastum, M. (2011). An embedded case study: Therapy process and outcome in an application of the Cool Kids Program on six children with anxiety disorders: Responders versus non-responders. Unpublished paper, Department of Clinical Psychology, University of Aarhus, Aarhus, Denmark.

Lundkvist-Houndoumadi, I., \& Thastum, M. (2013). A "Cool Kids" cognitive-behavioral therapy group for youth with anxiety disorders: Part 1, The case of Erik.

Pragmatic Case Studies in Psychotherapy, http://pcsp.libraries.rutgers.edu. Vol 9 (2), Article 3, pp. 122-178.

Lyneham, H.J., Abbott, M.J., Rapee, R.M., Tolin, D.F., Carlson, S.E., \& Hudson, J.L. (in preparation). Psychometric properties of the Child Anxiety Life Interference Scale (CALIS). Retrieved from: http://www.psy.mq.edu.au/CEH/CALIS.html (CALIS Scoring, pdffile).

Manassis, K., Mendlowitz, S. L., Scapillato, D., Avery, D., Fiksenbaum, L., Freire, M., Monga, S. \& Owens, M. (2002). Journal of the American Academy of Child \& Adolescent Psychiatry, 41, 1423-1430.

Manassis, K., Tannock, R. \& Monga, S. (2009). Anxious by maternal- versus self-report: Are they the same children? Journal of the Canadian Academy of Child and Adolescent Psychiatry, 18, 103-109.

Marder, A.M., \& Chorpita, B.F. (2009). Adjustment in treatment for limited of nonresponding cases on contemporary cognitive-behavioral therapy with youth. In D. McKay \& E.A. 
A "Cool Kids" Cognitive-Behavioral Therapy Group for Youth with Anxiety Disorders:

Part 2, Analysis of the Process and Outcome of Responders Versus Nonresponders

I. Lundkvist-Houndoumadi \& M. Thastum

Pragmatic Case Studies in Psychotherapy, http://pcsp.libraries.rutgers.edu

Volume 9, Module 2, Article 4, pp. 179-274, 06-26-13 [copyright by authors]

Storch (Eds.), Cognitive-behavior therapy for children (pp. 9-46). New York: Springer Publishing Company.

McAdam, E. (1986). Cognitive behavior therapy and its application with adolescents. Journal of Adolescence, 9, 1-15.

Mendlowitz, S.L., Manassis, K., Bradley, S., Scapillato, D., Miezitis, S. \& Shaw, B. (1999). Cognitive-behavioral group treatments in childhood anxiety disorders: The role of parental involvement. Journal of the American Academy of Child and Adolescent Psychiatry, 38, 1223-1229.

Messer, S. C., \& Beidel, D. C. (1994). Psychosocial correlates of childhood anxiety disorders. Journal of the American Academy of Child \& Adolescent Psychiatry, 33, 975-983.

Muris, P. (2002). Relationships between self-efficacy and symptoms of anxiety disorders and depression in a normal adolescent sample. Personality and Individual Differences, 32, 337-348.

Muris, P., Mayer, B., den Adel, M., Roos, T., \& van Wamelen, J. (2009). Predictors of change following cognitive-behavioral treatment of children with anxiety problems: A Preliminary investigation on negative automatic thoughts and anxiety control. Child Psychiatry and Human Development, 40,139- 151.

Muris, P., Meesters, C., Merckelbach, H., \& Huelsenbeck, P. (2000). Worry in children is related to perceived parental rearing and attachment. Behavior Research and Therapy, 38, 487497.

Murray, L., Sinclair, D., Cooper, P., Ducournau, P., \& Turner, P. (1999). The socioemotional development of 5-year-old children of postnatally depressed mothers. Journal of Child Psychology and Psychiatry, 8, 1259-1271.

Nakamura, B.J., Pestle, S.L., \& Chorpita, B.F. (2009). Differential sequencing of cognitivebehavioral techniques for reducing child and adolescent anxiety. Journal of Cognitive Psychotherapy: An International Quarterly, 23,114-135.

Nauta, M.H. (2005). Anxiety disorders in children and adolescents: Assessment, cognitive behavioral therapy, and predictors of outcome. Groningen: University Library Groningen.

Nauta, M. H., Scholing, A., Emmelkamp, P.M.G., \& Minderaa, R.B. (2003). Cognitivebehavioral therapy for children with anxiety disorders in a clinical setting: no additional effect of a cognitive parent training. Journal of American Academy of Child and Adolescent Psychiatry, 42, 1270-1278.

Nauta, M.H., Scholing, A., Rapee, R.M., Abbott, M., Spence, S.H., \& Waters, A. (2004). A parent-report measure of children's anxiety: Psychometric properties and comparison with child-report in a clinical and nonclinical sample. Behavior Research and Therapy, 42, 813-839.

Nock, M.K. (2005). Participation enhancement intervention: A brief manual for a brief intervention. Unpublished manuscript. Harvard University, Cambridge, MA.

O’Connor, T., \& Creswell, C. (2005). Cognitive behavioral therapy in developmental perspective. In P. J. Graham (Ed.), Cognitive behavior therapy for children and families, 2nd ed. (pp. 25-47). Cambridge: Cambridge University Press.

Oetzel, K. B., \& Scherer, D. G. (2003). Therapeutic engagement with adolescents in psychotherapy. Psychotherapy: Theory, Research, Practice, Training, 40, 215-225. 
A "Cool Kids" Cognitive-Behavioral Therapy Group for Youth with Anxiety Disorders:

Part 2, Analysis of the Process and Outcome of Responders Versus Nonresponders

I. Lundkvist-Houndoumadi \& M. Thastum

Pragmatic Case Studies in Psychotherapy, http://pcsp.libraries.rutgers.edu

Volume 9, Module 2, Article 4, pp. 179-274, 06-26-13 [copyright by authors]

Oei, T.P.S., \& Browne, A. (2006). Components of group processes: Have they contributed to the outcome of mood and anxiety disorder patients in a group cognitive-behavior therapy program? American Journal of Psychotherapy, 60, 53-70.

Quakley, S., Reynolds, S., \& Coker, S. (2004). Visual cues and age improve children's abilities to distinguish amongst thoughts, feelings and behaviors. Behavior Research and Therapy, 42, 343-356.

Rapee, R.M. (1997). Potential role of childrearing practices in the development of anxiety and depression. Clinical Psychology Review, 17, 47-67.

Rapee, R.M. (2001). The development of generalized anxiety. In M.W. Vasey \& M.R. Dadds (Eds.), The developmental psychopathology of anxiety (pp. 481-503). New York: Oxford University Press.

Rapee, R.M., Schniering, C.A., \& Hudson, J.L. (2009).Anxiety disorders during childhood and adolescence: Origins and treatment. Annual Review of Clinical Psychology, 5, 311-341.

Reynolds, S., Girling, E., Coker, S., \& Eastwood, L. (2006). The effect of mental health problems on children's ability to discriminate amongst thoughts, feelings and behaviors. Cognitive Therapy and Research, 30, 599-607.

Rosenbaum, J., Biederman, J., Hirshfeld-Becker, D.R., Kagan, J., Snidman, et al. (2000). A controlled study of behavioral inhibition in children of parents with panic disorder and depression. The American Journal of Psychiatry, 157, 2002-2010.

Rubenstein, A. K. (2003). Adolescent psychotherapy: An introduction. Journal of Clinical Psychology, 59, 1169-1175.

Rubin, K.H., Nelson, L.J., Hastings, P.D., \& Asendorpf, J.B. (1999). The transaction between parents' perceptions of their children's shyness and their parenting styles. International Journal of Behavioral Development, 23, 937-957.

Sakkovski, P.M. (1991). The importance of behavior in the maintenance of anxiety and panic: A cognitive account. Behavioral Psychotherapy, 19, 6-19.

Sauter, F.M., Heyne D., \& Westenberg, P. M. (2009). Cognitive behavior therapy for anxious adolescents: Developmental influences on treatment design and delivery. Clinical Child and Family Psychology Review, 12, 310-335.

Semple, R., Lee, J., Rosa, D., \& Miller, L. (2010). A randomized trial of mindfulness-based cognitive therapy for children: Promoting mindful attention to enhance social-emotional resiliency in children. Journal of Child \& Family Studies, 19, (2), 218-229.

Shirk, S. R. (2001). Developmental therapy. In W.K. Silverman \& T. H. Ollendick (Eds.), Developmental issues in the clinical treatment of children (pp. 60-73). Boston: Allyn \& Bacon.

Silverman, W. K., \& Kurtines, W. M. (1996). Anxiety and phobic disorders: A pragmatic approach. New York: Plenum Press.

Silverman, W.K., Kurtines, W.M., Ginsburg, G.S., Weems, C.F., Lumpkin, P.W., \& Carmichael, D.H. (1999). Treating anxiety disorders in children with group cognitive behavioral therapy: A randomized clinical trial. Journal of Consulting and Clinical Psychology, 67, 675-687.

Silverman, W.K., Kurtines, W.M., Jaccard, J., \& Pinas A. (2009). Directionality of change in youth anxiety treatment involving parents: An initial examination. Journal of Consulting and Clinical Psychology, 77, 474-485. 
A "Cool Kids" Cognitive-Behavioral Therapy Group for Youth with Anxiety Disorders:

Part 2, Analysis of the Process and Outcome of Responders Versus Nonresponders

I. Lundkvist-Houndoumadi \& M. Thastum

Pragmatic Case Studies in Psychotherapy, http://pcsp.libraries.rutgers.edu

Volume 9, Module 2, Article 4, pp. 179-274, 06-26-13 [copyright by authors]

Spence, S. H. (1998). A measure of anxiety symptoms among children. Behavior Research and Therapy, 36, 545-566.

Stallard, P. (2009). Anxiety: Cognitive behavior therapy with children and young people. East Sussex: Routledge.

Suveg, C., \& Zeman, J. (2004). Emotion regulation in children with anxiety disorders. Journal of Clinical Child and Adolescent Psychology, 33, 750-759.

Suveg, C., Sood, E., Comer, J. S., \& Kendall, P. C. (2009). Changes in emotion regulation following cognitive-behavioral therapy for anxious youth. Journal of Clinical Child and Adolescent Psychology, 38, 390-401.

Taube-Schiff, M., Suvak, M. K., Antony, M. M., Bieling, P. J., \& McCabe, R. E. (2007). Group cohesion in cognitive-behavioral group therapy for social phobia. Behavior Research and Therapy, 45, 687-698.

Vasey, M. W., \& Dadds, M. R. (2001). An introduction to the developmental psychopathology of anxiety. In Vasey, M. W., \& Dadds, M. R. (2001). The developmental psychopathology of anxiety. New York: Oxford University Press. pp. 3-26.

Victor, A. M., Bernat, D. H., Bernstein G. A., \& Layne A. E. (2007). Effects of parent and family characteristics on treatment outcome of anxious children. Journal of Anxiety Disorders, 21, 835-848.

Whaley, S. E., Pinto, A., \& Sigman, M. (1999). Characterizing interactions between anxious mothers and their children. Journal of Consulting and Clinical Psychology, 67, 826-836.

Weems, C.F., Silverman, W.K., Rapee, R.M. \& Pina, A.A. (2003) The role of control in childhood anxiety disorders. Cognitive Therapy Research, 27, 557-568.

Weisz, J. R., \& Hawley, K. M. (2002). Developmental factors in the treatment of adolescents. Journal of Consulting and Clinical Psychology, 70, 21-43.

Weisz, J. R., \& Weersing, V. R. (1999). Psychotherapy with children and adolescents: Efficacy, effectiveness, and developmental concerns. In D. Cicchetti \& S. L. Toth (Eds.), Rochester symposium on developmental psychopathology (Vol.9): Developmental approaches to prevention and intervention (pp. 341-386). Rochester, NY: University of Rochester Press.

Weisz, J.R., Weiss,B., Han,S.S., Granger, D. A., \& Morton, T. (1995). Effects of psychotherapy with children and adolescents revisited: A meta-analysis of treatment outcome studies. Psychological Bulletin, 117, 450-468.

Werner-Wilson, R. J. (2001). Developmental-systemic family therapy with adolescents. New York: The Haworth Clinical Practice Press.

Westra, H.A., Dozois, D.J.A., \& Marcus, M. (2007). Expectancy, homework compliance, and initial change in cognitive-behavioral therapy for anxiety. Journal of Consulting and Clinical Psychology, 75, 363-373.

Wood, J., McLeod, B. D., Sigman, M., Hwang, W. C., \& Chu, B. C. (2003). Parenting and childhood anxiety: Theory, empirical findings and future directions. Journal of Child Psychology \& Psychiatry \& Allied Disciplines, 44, 134-151.

Yalom, V.J., Vinogradov, S., O’Hearne, J.J., et al. (1993). Group psychotherapy derived from schools of psychology and philosophy. In: H.I. Kaplan \& B.J. Sadock (Eds.), Comprehensive group psychotherapy, 3rd ed. Baltimore: Williams \& Wilkins. 
Table 1. Demographic Characteristics at Referral, Diagnoses Over Time, and CGI-I Rating at 15 Months

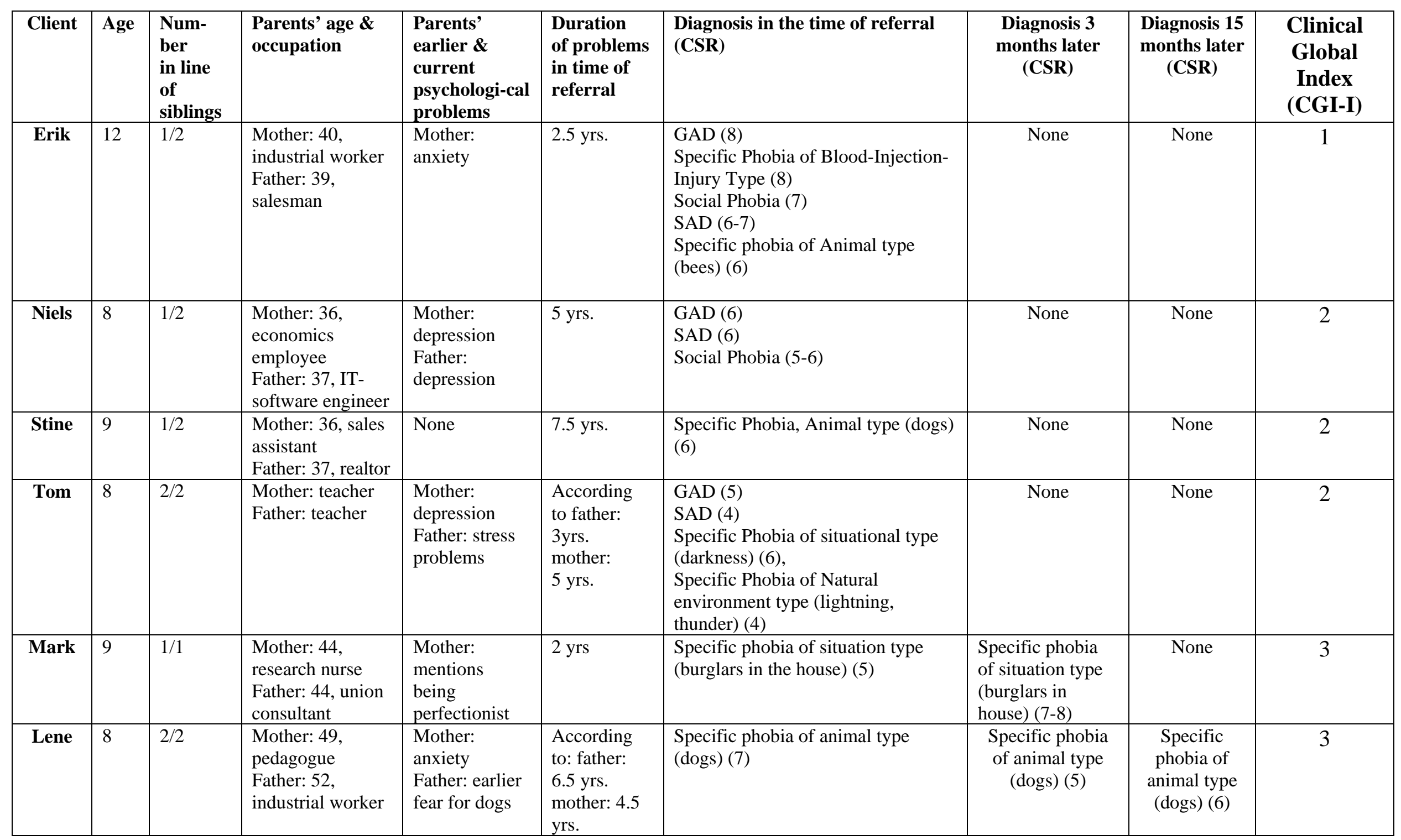


Table 2. Mean and Effect Sizes on SCAS and CALIS for the Group

\begin{tabular}{|c|c|c|c|c|c|c|c|c|c|}
\hline & \multirow[t]{3}{*}{ Scales } & \multicolumn{2}{|c|}{ Pre-treatment } & \multicolumn{2}{|c|}{ Post-treatment $^{a}$} & \multicolumn{2}{|c|}{ 3-month follow-up ${ }^{a}$} & \multicolumn{2}{|c|}{ 15-month follow-up ${ }^{a}$} \\
\hline & & mother & child & mother & child & mother & child & mother & child \\
\hline & & $\begin{array}{ll}M & (\mathrm{~N})\end{array}$ & $\begin{array}{ll}M & (\mathrm{~N})\end{array}$ & 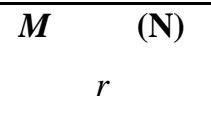 & $\begin{array}{lll}M & & (\mathbf{N}) \\
& & \\
& r & \end{array}$ & \begin{tabular}{|lll} 
& & (N) \\
& & \\
& &
\end{tabular} & $\begin{array}{lll}\mathbf{M} & & (\mathbf{N}) \\
& r & \end{array}$ & 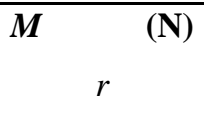 & $\begin{array}{ll}\text { M } & \text { (N) } \\
& r\end{array}$ \\
\hline \multirow{2}{*}{$\begin{array}{c}\text { Disorder } \\
\text { specific } \\
\text { measures: }\end{array}$} & $\begin{array}{l}\text { SCAS } \\
\text { (total) }\end{array}$ & $24.5 \quad(6)$ & $27.7 \quad(6)$ & $\begin{array}{c}21.17 \quad(6) \\
0.34\end{array}$ & $\begin{array}{c}24.3 \quad(6) \\
0.38\end{array}$ & $\begin{array}{c}15.8 \quad\left(5^{\mathrm{b}}\right) \\
0.82^{* *}\end{array}$ & $\begin{array}{c}15 \quad \text { (5) } \\
0.78^{*}\end{array}$ & $\begin{array}{c}16.7 \quad(6) \\
0.82^{* *}\end{array}$ & $\begin{array}{c}18.3 \quad(6) \\
0.47\end{array}$ \\
\hline & $\begin{array}{l}\text { SCAS } \\
\text { (Prim. Diagnosis) }\end{array}$ & \begin{tabular}{|ll}
7.33 & $(6)$
\end{tabular} & $6.17 \quad(6)$ & $\begin{array}{c}5.33 \quad(6) \\
0.91^{* *}\end{array}$ & $\begin{array}{c}5.17 \quad(6) \\
0.44\end{array}$ & \begin{tabular}{|lll}
4.6 & & (5) \\
& 0.17 &
\end{tabular} & $\begin{array}{l}3.42 \\
\end{array}$ & $\begin{array}{c}5.17 \quad(6) \\
0.75^{*}\end{array}$ & 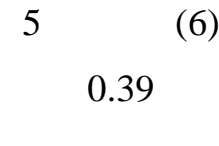 \\
\hline \multirow[t]{2}{*}{\begin{tabular}{|c} 
Life \\
interference \\
measures:
\end{tabular}} & \begin{tabular}{|l} 
CALIS \\
(Ch. Interference)
\end{tabular} & $11.3 \quad(6)$ & $7.6 \quad(6)$ & $\begin{array}{ll}9 \quad(6) \\
& 0.38\end{array}$ & 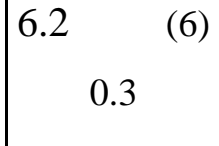 & $0.65^{(5)}$ & $\begin{array}{l}7.2 \quad(5) \\
0.31\end{array}$ & $\begin{array}{c}5.8 \quad(6) \\
0.64^{*}\end{array}$ & $\begin{array}{ll}4.7 \quad(6) \\
0.44\end{array}$ \\
\hline & $\begin{array}{l}\text { CALIS } \\
\text { (Fam. Interference) }\end{array}$ & $11.17 \quad(6)$ & & $\begin{array}{c}7.5 \quad(6) \\
0.90^{* *}\end{array}$ & & $\begin{array}{c}6.6 \quad \text { (5) } \\
0.54 *\end{array}$ & & $\begin{array}{c}6.2 \quad(6) \\
0.90^{* *}\end{array}$ & \\
\hline
\end{tabular}

${ }^{\mathrm{a}}$ All comparisons are in relationship to pre-treatment. ${ }^{\mathrm{b}}$ Lene and her parents did not complete the measures at the first follow-up.

* represents a medium effect size, ** represents a large effect size 
Table 3. Response on the Disorder Specific Measures of Treatment Outcome

\begin{tabular}{|c|c|c|c|}
\hline \multirow[b]{2}{*}{ Ranking of outcome } & \multicolumn{3}{|c|}{ Number (percent) of clients who responded to treatment } \\
\hline & Post treatment $^{\mathrm{a}}$ & 3 month follow-up ${ }^{a}$ & 15 month follow-up ${ }^{a}$ \\
\hline $\begin{array}{l}\text { 1. Statistically significant } \\
\text { reduction and clinical } \\
\text { change on SCAS } \\
\text { SCASild }_{\text {mother }} \text { and }\end{array}$ & $\begin{array}{l}1 \text { out of } 6(16.7 \%) \\
\text { Erik }\end{array}$ & $\begin{array}{l}3 \text { out of } 5^{b}(60 \%) \\
\text { Erik, Tom, Mark }\end{array}$ & $\begin{array}{l}2 \text { out of } 6(33.3 \%) \\
\text { Erik, Mark }\end{array}$ \\
\hline $\begin{array}{l}\text { 2. Statistically significant } \\
\text { reduction or clinical } \\
\text { change on Total SCAS } \\
\text { and SCAS } \\
\text { another, }\end{array}$ & $\begin{array}{l}3 \text { out of } 6(50 \%) \\
\text { Erik, Stine, Tom }\end{array}$ & $\begin{array}{l}5 \text { out of } 5(100 \%) \\
\text { Erik, Stine, Niels, } \\
\text { Tom, Mark }\end{array}$ & $\begin{array}{l}5 \text { out of } 6(83.3 \%) \\
\text { Erik, Stine, Niels, } \\
\text { Tom, Mark }\end{array}$ \\
\hline $\begin{array}{l}\text { 3. Statistically significant } \\
\text { reduction or clinical } \\
\text { change on the primary } \\
\text { diagnosis on SCAS }_{\text {mother }} \mathrm{O} \\
\text { SCAS }_{\text {child }}\end{array}$ & $\begin{array}{l}4 \text { out of } 6(66.7 \%) \\
\text { Erik, Stine, Niels, } \\
\text { Tom }\end{array}$ & $\begin{array}{l}4 \text { out of } 5(80 \%) \\
\text { Erik, Stine, Niels, } \\
\text { Tom }\end{array}$ & $\begin{array}{l}5 \text { out of } 6(83.3 \%) \\
\text { Erik, Stine, Niels, } \\
\text { Tom, Mark }\end{array}$ \\
\hline
\end{tabular}

${ }^{\text {a }}$ All comparisons are in relationship to pre-treatment.

${ }^{\mathrm{b}}$ Lene and her parents did not complete the measures at the first follow-up. 
Table 4. Families' Evaluation of Therapy at 15-Month Follow-Up

a. Overall evaluation of treatment programme as assessed by the children

Overall what did you think of the program?

\begin{tabular}{|l|c|c|c|c|c|c|c|}
\hline & Erik & Stine & Tom & Niels & Mark & Lene & Group Mean \\
\hline It helped me* & 4 & 3 & 3 & 3 & 3 & 2 & 3 \\
\hline It was** & 2 & 2 & 1 & 2 & 1 & 1 & 1.5 \\
\hline
\end{tabular}

${ }^{*} 0=$ not at all, $1=$ a bit, $2=$ to some degree, $3=$ to a large degree, $4=$ very much

** $0=$ boring, $1=$ ok, $2=$ fun

b. Overall evaluation of treatment programme and outcome as assessed by parents

\begin{tabular}{|c|c|c|c|c|c|c|c|c|c|c|c|c|c|c|c|}
\hline & \multicolumn{2}{|c|}{ Erik } & \multicolumn{2}{|c|}{ Stine } & \multicolumn{2}{|c|}{ Tom } & \multicolumn{2}{|c|}{ Niels } & \multicolumn{2}{|c|}{ Mark } & \multicolumn{2}{|c|}{ Lene } & \multicolumn{3}{|c|}{ Group Mean } \\
\hline & $\mathrm{M}$ & $\mathrm{F}$ & $\mathrm{M}$ & $\mathrm{F}$ & $\mathrm{M}$ & $\mathrm{F}$ & $\mathrm{M}$ & $\mathrm{F}$ & $\mathrm{M}$ & $\mathrm{F}$ & $\mathrm{M}$ & $\mathrm{F}$ & MF & $\mathrm{M}$ & $\mathrm{F}$ \\
\hline $\begin{array}{l}\text { Anxiety is something } \\
\text { that takes up space in } \\
\text { the family at the } \\
\text { present moment }\end{array}$ & 1 & 1 & 1 & 1 & 1 & 2 & 1 & 1 & 1 & 1 & 2 & 1 & 1.2 & 1.2 & 1.2 \\
\hline $\begin{array}{l}\text { My child experiences } \\
\text { anxiety }\end{array}$ & 1 & 1 & 2 & 2 & 2 & 2 & 0.5 & 2 & 2 & 2 & 3 & 1 & 1.8 & 1.8 & 1.7 \\
\hline $\begin{array}{l}\text { Overall I am at the } \\
\text { present moment } \\
\text { satisfied with the } \\
\text { therapy }\end{array}$ & 3 & 4 & 3 & 3 & 4 & 4 & 3 & 3 & 3 & 3 & 3 & 2 & 3.2 & 3.2 & 3.2 \\
\hline $\begin{array}{l}\text { If a friend had a child } \\
\text { with similar problems } \\
\text { I would recommend } \\
\text { this form of treatment }\end{array}$ & 4 & 4 & 3 & 3 & 4 & 4 & 3 & 4 & 3 & 3 & 3 & 3 & 3.4 & 3.3 & 3.5 \\
\hline $\begin{array}{l}\text { The way in which the } \\
\text { therapy was structured, } \\
\text { was good for my } \\
\text { child's problems }\end{array}$ & 3 & 3 & 3 & 3 & 4 & 3 & 3 & 2 & 3 & 3 & 2 & 3 & 2.9 & 3 & 2.8 \\
\hline $\begin{array}{l}\text { Therapy demanded a } \\
\text { lot of time }\end{array}$ & 2 & 1 & 2 & 1 & 3 & 3 & 2 & 0 & 3 & 2 & 3 & 2 & 2 & 2.5 & 1.5 \\
\hline
\end{tabular}

$0=$ not at all, $1=$ a bit, 2 = to some degree, 3=to a large degree, 4=very much 


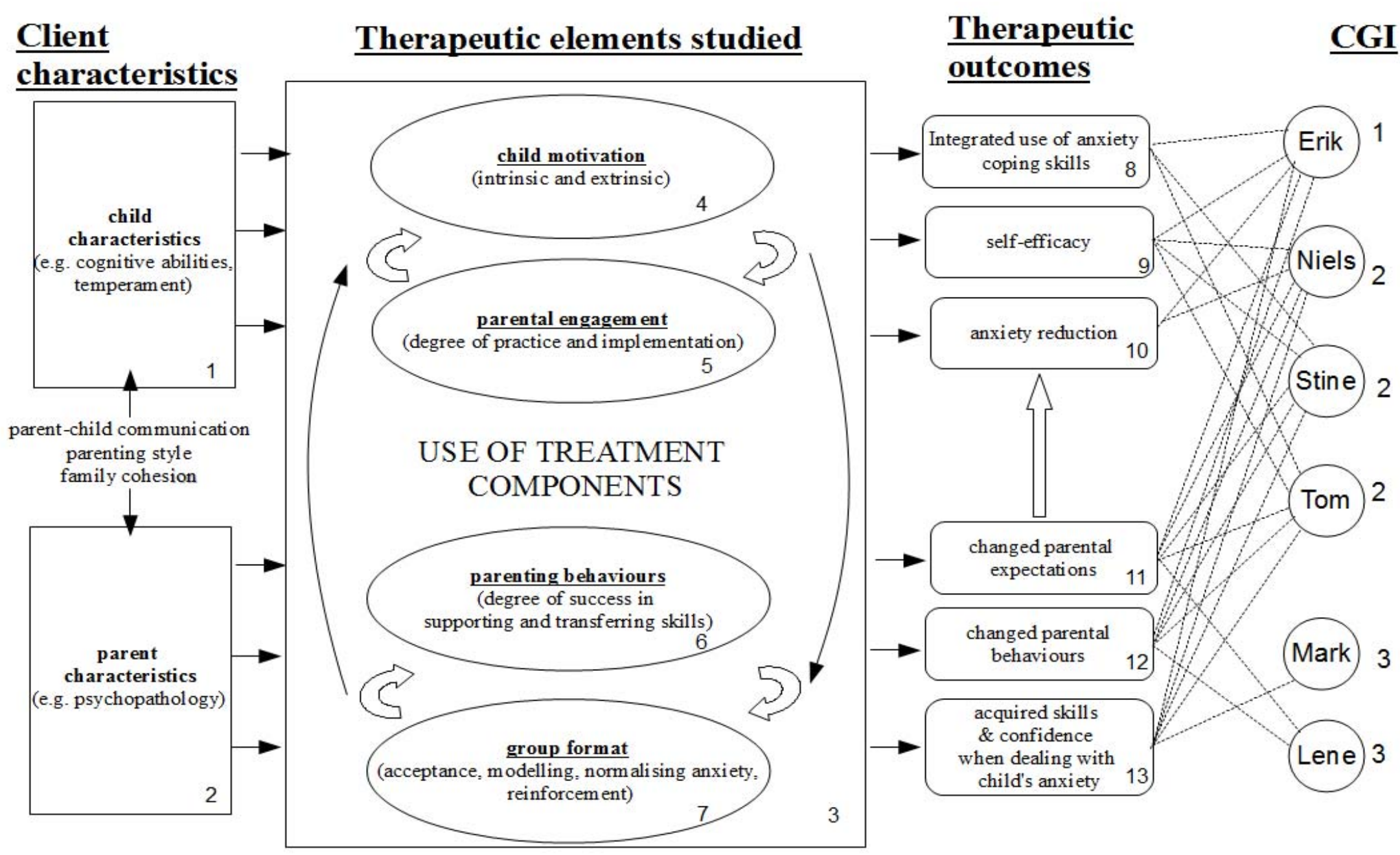

Figure 1. A Graphic Representation of the Therapy Process and Outcome 
Pragmatic Case Studies in Psychotherapy, http://pcsp.libraries.rutgers.edu

Volume 9, Module 2, Article 4, pp. 179-274, 06-26-13 [copyright by authors]

Appendix A. Quantitative Data at Four Points in Time: 1. ERIK

\begin{tabular}{|c|c|c|c|c|c|c|c|c|c|c|c|c|}
\hline \multirow[b]{2}{*}{ Scale } & \multicolumn{3}{|c|}{ Pre-treatment } & \multicolumn{3}{|c|}{ Post-treatment } & \multicolumn{3}{|c|}{ 3-month follow-up } & \multicolumn{3}{|c|}{ 15-month follow-up } \\
\hline & Mother & Father & Child & Mother & Father & Child & Mother & Father & Child & Mother & Father & Child \\
\hline \multicolumn{13}{|l|}{ SDQ } \\
\hline Emotional sympt. & $6^{*}$ & & $7 *$ & $2 \# a$ & $3 \# a$ & & $1 \#^{a} a^{a}$ & $1 \#^{a} a^{a b}$ & $9 a^{a}$ & 1 & $0 \mathbf{a}^{b}$ & $1 \#^{C} a^{C}$ \\
\hline Hyperactivity & 5 & & 2 & 3 & 3 & & 3 & 3 & 1 & 2 & 3 & $5 \#^{C} a^{C}$ \\
\hline Conduct pbs & 3 & & 3 & $1 a$ & $1 a$ & & $1 a^{a}$ & $1 a^{a}$ & $5 a^{a}$ & 2 & 0 & $2 a^{c}$ \\
\hline Prblms with peers & 3 & & 3 & 3 & 4 & & $1 a^{a b}$ & $1 \#^{b} a^{a b}$ & $1 a^{a}$ & 2 & $0 \#^{b} a^{b}$ & 0 \\
\hline TOTAL & $17^{*}$ & & 15 & $9 a$ & $11 a$ & & $6 \#^{a} a^{a}$ & $6 \#^{a} a^{a}$ & 16 & 7 & $3 a^{b}$ & $8 \#^{C} a^{c}$ \\
\hline Prosocial bhvr. & 9 & & 10 & 10 & 8 & & 10 & 8 & $2 \#^{a} a^{a}$ & $7 \#^{\mathrm{bc}} \mathbf{a}^{\mathrm{bc}}$ & 8 & $9 \#^{\mathrm{c}}$ \\
\hline \multicolumn{13}{|l|}{ BYI } \\
\hline Self-concept & 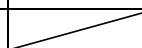 & 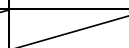 & $34+$ & 2 & 2 & $34+$ & 2 & 2 & $44 \#^{\mathrm{ab}} a^{\mathrm{ab}}$ & 2 & 2 & $36+\#^{C} a^{c}$ \\
\hline Anxiety & 2 & 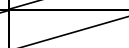 & 11 & 2 & 2 & $14+$ & 2 & 2 & $8 \#^{b}$ & 2 & 2 & $13+$ \\
\hline Depression & 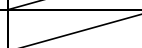 & 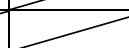 & 9 & $\infty$ & 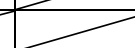 & $1 \# a$ & 2 & 2 & $8 \#^{b} a^{b}$ & 2 & 2 & 7 \\
\hline Anger & 2 & 1 & 12 & 2 & 1 & $16+$ & 2 & 2 & $10 \#^{b}$ & 2 & 2 & $9 \#^{b} a^{b}$ \\
\hline Disruptive behvr & & & 4 & 2 & & 6 & 2 & 2 & - & 2 & 2 & - \\
\hline & & & & & & & & & & & & \\
\hline \multicolumn{13}{|l|}{ SCAS } \\
\hline Panic/agoraphobia & 1 & 0 & 2 & 0 & 0 & 2 & 0 & 0 & 1 & 1 & 0 & 0 \\
\hline Generalised anx. & $6^{*}$ & 5 & $8^{*}$ & $3 \# \mathbf{a}$ & $2 \# \mathbf{a}$ & $4 \# \mathbf{a}$ & $2 \#^{a} a^{a}$ & $2 \#^{a} a^{a}$ & $4 \#^{a} a^{a}$ & $3 \#^{a} a^{a}$ & 3 & $5 a^{a}$ \\
\hline Social phobia & 7 & $8^{\star}$ & $7^{*}$ & $2 \# a$ & $4 \#$ & $4 a$ & $4 a^{a}$ & $4 \#^{a} a^{a}$ & $3 \#^{a} a^{a}$ & $2 \#^{a} a^{a}$ & $3 \#^{a} a^{a}$ & $4 a^{a}$ \\
\hline Anx. Phys. Injury & 2 & 3 & 4 & 3 & 3 & $5 *$ & 1 & 1 & $2 a^{b}$ & 1 & $0 a^{a b}$ & $2 a^{b}$ \\
\hline OCD & 0 & $5^{*}$ & 4 & 0 & $0 \# \mathbf{a}$ & $0 \# \mathbf{a}$ & 0 & $0 \#^{a} a^{a}$ & $0 \#^{a} a^{a}$ & 0 & $0 \#^{a} a^{a}$ & $0 \#^{a} a^{a}$ \\
\hline Separation anxiety & 2 & 4 & 3 & 2 & 2 & 2 & 2 & $5 \#^{b} a^{b}$ & 3 & 1 & $1 \#^{\mathrm{ac}} \mathbf{a}^{\mathrm{ac}}$ & 1 \\
\hline TOTAL & 18 & 25 & $28 *$ & $10 \#$ & $11 \# \mathbf{a}$ & $17 \#$ & $9 \#^{a} a^{a}$ & $12 \#^{\mathrm{a}} \mathrm{a}^{\mathrm{a}}$ & $13 \#^{\mathrm{a}} \mathrm{a}^{\mathrm{a}}$ & $8 \#^{a} a^{a}$ & $7 \#^{a} a^{a}$ & $12 \#^{\mathrm{a}} \mathrm{a}^{\mathrm{a}}$ \\
\hline \multicolumn{13}{|l|}{ CALIS } \\
\hline Child interference & 15 & 8 & 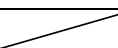 & $6 \# a$ & 7 & & $2 \#^{\mathrm{a}}$ & 5 & 2 & $2 \#^{a} a^{a}$ & 2 & 2 \\
\hline Fam. Interference & 13 & 5 & 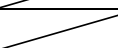 & $3 \# a$ & 3 & 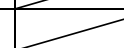 & $0 \#^{\mathrm{a}}$ & 2 & N & 6 & 0 & 2 \\
\hline Child reported & 2 & 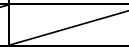 & 4 & $\infty$ & 2 & 3 & 2 & 2 & $29+\#^{b} a^{b}$ & 2 & 2 & $10 \#^{C} a^{c}$ \\
\hline
\end{tabular}

NATURE OR SIZE OF CHANGE: *clinical population level; \#statistically significant change; alarge effect (positive change more than one SD of the scale); clinical change (going from a clinical to a non-clinical level on a scale); negative change

POINTS OF CHANGE: compared to ${ }^{\mathrm{a}}$ : pre-treatment. ${ }^{\mathrm{b}}$ : post-treatment ${ }^{\mathrm{c}}$ : 3 -month follow-up 


\section{Appendix A. Quantitative Data at Four Points in Time: 2. NIELS}

\begin{tabular}{|c|c|c|c|c|c|c|c|c|c|c|c|c|}
\hline \multirow[b]{2}{*}{ Scale } & \multicolumn{3}{|c|}{ Pre-treatment } & \multicolumn{3}{|c|}{ Post-treatment } & \multicolumn{3}{|c|}{ 3-month follow-up } & \multicolumn{3}{|c|}{ 15-month follow-up } \\
\hline & Mother & Father & Child & Mother & Father & Child & Mother & Father & Child & Mother & Father & Child \\
\hline \multicolumn{13}{|l|}{ SDQ } \\
\hline Emotional sympt. & $9 *$ & & & $6 * a$ & $5 * \# a$ & & $6 a^{a}$ & $7 a^{a}$ & & $4 a^{b c}$ & $5^{\star} a^{c}$ & 5 \\
\hline Hyperactivity & $8^{*}$ & & & 6 & $5 a$ & & $9 *$ & $8 *$ & & $3 \#^{c} a^{b c}$ & $7 *$ & 3 \\
\hline Conduct pbs & 1 & & & 2 & 2 & & 2 & $4^{*} a^{a}$ & & 1 & $2 a^{c}$ & 2 \\
\hline Prblms with peers & 1 & & & 2 & 1 & & 0 & $3 a^{a}$ & & 1 & $0 \#^{C} a^{c}$ & 3 \\
\hline TOTAL & $19 *$ & & & 16 & $13 a$ & & $17^{*}$ & $22^{*} \#^{b}$ & & $9 a^{b c}$ & $14 a^{C}$ & 13 \\
\hline Prosocial bhr & 3 & & & $7 \# a$ & 3 & & $6 \#^{a} a^{a}$ & 3 & & 6 & $2^{*}$ & 6 \\
\hline & & & & & & & & & & & & \\
\hline \multicolumn{13}{|l|}{ BYI } \\
\hline Self-concept & 1 & 2 & $33+$ & 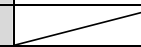 & 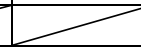 & $31+$ & 2 & 2 & $30+$ & 2 & 2 & $41+\#^{b c} a^{b c}$ \\
\hline Anxiety & 2 & 2 & 10 & 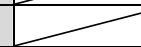 & 1 & 10 & 2 & 2 & 12 & 2 & 2 & 9 \\
\hline Depression & 2 & & $13+$ & 2 & 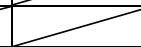 & $11+$ & 2 & 2 & $17+$ & 2 & 2 & $10=$ \\
\hline Anger & 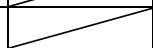 & 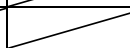 & 7 & 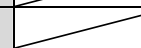 & 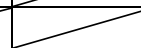 & 8 & 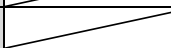 & 2 & $12=$ & 2 & 2 & 10 \\
\hline Disruptive behvr & 1 & & 2 & 2 & 1 & 2 & 2 & 2 & - & 2 & 2 & - \\
\hline & & & & & & & & & & & & \\
\hline \multicolumn{13}{|l|}{ SCAS } \\
\hline Panic/agoraphobia & $4^{*}$ & & 4 & $4^{*}$ & $0 \# a$ & 2 & $2 \#^{a b} a^{a b}$ & $3^{*} \#^{b} a^{b}$ & 1 & $2 \#^{\mathrm{ab}} a^{\mathrm{ab}}$ & $3 *$ & 2 \\
\hline Generalised anx. & $6^{*}$ & & 5 & 5 & $3 \# a$ & 4 & $6^{*}$ & $6^{*} \#^{b} a^{b}$ & 4 & $6^{\star}$ & 5 & $7 * a^{b c}$ \\
\hline Social phobia & 8* & & 3 & $8^{*}$ & $4 a$ & 3 & $5 a^{a}$ & $7 * a^{b}$ & 5 & $3 \#^{a b} a^{a b}$ & 6 & $6 * a^{a b}$ \\
\hline Anx. Phys. Injury & 0 & & 4 & $4 a$ & 0 & 3 & 2 & 1 & 4 & $1 a^{b}$ & 1 & 4 \\
\hline OCD & 1 & & 0 & 2 & 0 & $3 a$ & $0 a^{b}$ & 1 & $5^{*} a^{a}$ & $0 a^{b}$ & 0 & $4 \#^{a} a^{a}$ \\
\hline Separation anxiety & 6 & & $5^{*}$ & $9 *$ & 5 & $5^{\star}$ & $8^{*}$ & $8^{*}$ & 4 & $7 *$ & $4 a^{c}$ & $7 * a^{c}$ \\
\hline TOTAL & 25 & & 21 & $32 *$ & $12 \# a$ & 20 & 23 & $26 \#^{b} a^{b}$ & 23 & $19 \#^{b} a^{b}$ & 19 & $30 *$ \\
\hline \multicolumn{13}{|l|}{ CALIS } \\
\hline Child interference & $18+$ & & 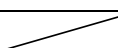 & $19+$ & $8 \# a$ & 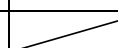 & $21+$ & $19+\#^{a} a^{b}$ & 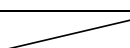 & $9 \#^{\mathrm{abc}} a^{\mathrm{abc}}$ & $10 \#^{\mathrm{c}} \mathrm{a}^{\mathrm{ac}}$ & 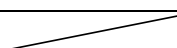 \\
\hline Fam. Interference & 12 & & 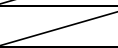 & 9 & $3 \# a$ & 1 & $20+\#^{a} a^{a b}$ & $11+\#^{a} a^{b}$ & & $10 \#^{C} a^{C}$ & $2 \#^{\mathrm{ac}} \mathrm{a}^{\mathrm{ac}}$ & 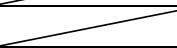 \\
\hline Child reported & 2 & & $15+$ & 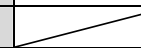 & $>$ & $4 \# a$ & 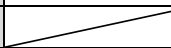 & 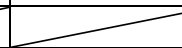 & $1 \#^{a} a^{a}$ & 2 & 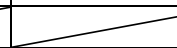 & $1 \#^{a} a^{a}$ \\
\hline
\end{tabular}

NATURE OR SIZE OF CHANGE: *clinical population level; \#statistically significant change; alarge effect (positive change more than one SD of the scale); clinical change (going from a clinical to a non-clinical level on a scale); negative change

POINTS OF CHANGE: compared to ${ }^{\text {a }}$ : pre-treatment. ${ }^{\text {b }}$ : post-treatment ${ }^{c}$ : 3 -month follow-up 
Appendix A. Quantitative Data at Four Points in Time: 3. STINE

\begin{tabular}{|c|c|c|c|c|c|c|c|c|c|c|c|c|}
\hline & \multicolumn{3}{|c|}{ Pre-treatment } & \multicolumn{3}{|c|}{ Post-treatment } & \multicolumn{3}{|c|}{ 3-month follow-up } & \multicolumn{3}{|c|}{ 15-month follow-up } \\
\hline & Mother & Father & Child & Mother & Father & Child & Mother & Father & Child & Mother & Father & Child \\
\hline \multicolumn{13}{|l|}{ SDQ } \\
\hline Emotional sympt. & 1 & & & 0 & 0 & & 0 & 0 & & $2 a^{b c}$ & 0 & 2 \\
\hline Hyperactivity & 3 & & & 2 & 3 & & 2 & 5 & & 2 & $2 a^{c}$ & 2 \\
\hline Conduct pbs & 0 & & & 0 & 0 & & 0 & 0 & & 0 & 0 & 0 \\
\hline Prblms with peers & 0 & & & 0 & 0 & & 0 & 1 & & 0 & 0 & 0 \\
\hline TOTAL & 4 & & & 2 & 3 & & 2 & 6 & & 4 & 2 & 4 \\
\hline Prosocial bhvr. & 9 & & & 10 & 9 & & $8 a^{b}$ & 10 & & $10 a^{C}$ & 9 & 9 \\
\hline \multicolumn{13}{|l|}{ BYI } \\
\hline Self-concept & 2 & 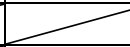 & 54 & 2 & 2 & 54 & $\infty$ & 2 & 56 & 2 & 2 & 50 \\
\hline Anxiety & 1 & 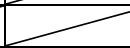 & 5 & 1 & 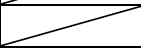 & 0 & 2 & 2 & 0 & 2 & 2 & 2 \\
\hline Depression & 7 & & 1 & 2 & 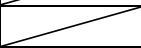 & 1 & 2 & 2 & 0 & 2 & 2 & 0 \\
\hline Anger & 2 & & 5 & 2 & 2 & 5 & $\infty$ & 2 & 3 & 2 & 2 & 1 \\
\hline Disruptive behvr & 2 & 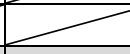 & 0 & 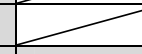 & 2 & 0 & 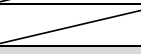 & 2 & - & 2 & 2 & - \\
\hline \multicolumn{13}{|l|}{ SCAS } \\
\hline Panic/agoraphobia & 0 & & 1 & 0 & 0 & 0 & 0 & 0 & 0 & 0 & 0 & 0 \\
\hline Generalised anx. & 4 & & 5 & 5 & $1 \# a$ & 3 & $2 \#^{b} a^{a b}$ & $2 a^{a}$ & $1 \#^{a} a^{a}$ & $4 a^{C}$ & $1 \#^{a} a^{a}$ & 3 \\
\hline Social phobia & 1 & & 1 & 3 & 0 & 1 & 3 & 1 & 0 & 1 & 0 & 0 \\
\hline Anx. Phys. Injury & 5 & & 4 & 4 & $3 a$ & 3 & 5 & $2 a^{a}$ & $1 a^{a}$ & 5 & $2 a^{a}$ & 3 \\
\hline OCD & 0 & & 2 & 1 & 0 & 2 & 0 & 0 & 2 & 0 & 0 & 0 \\
\hline Separation anxiety & 0 & & 1 & 0 & 0 & 0 & 0 & 0 & 0 & 0 & 0 & 1 \\
\hline TOTAL & 10 & & 14 & 13 & 4 & 9 & 10 & 5 & 4 & 10 & 3 & 7 \\
\hline \multicolumn{13}{|l|}{ CALIS } \\
\hline Child interference & 4 & & $\longrightarrow$ & 8 & 7 & 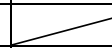 & 4 & 2 & $\longrightarrow$ & 5 & 1 & 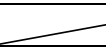 \\
\hline Fam. interference & 3 & & $>$ & 2 & 4 & & 1 & 0 & 2 & 0 & 0 & \\
\hline Child reported & 2 & 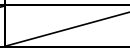 & 3 & 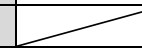 & $>$ & 9 & 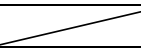 & 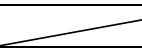 & $0 a^{b}$ & 2 & 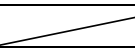 & 3 \\
\hline
\end{tabular}

NATURE OR SIZE OF CHANGE: *clinical population level; \#statistically significant change; alarge effect (positive change more than one SD of the scale); clinical change (going from a clinical to a non-clinical level on a scale); negative change

POINTS OF CHANGE: compared to ${ }^{\text {a }}$ : pre-treatment. ${ }^{\text {b }}$ : post-treatment ${ }^{c}$ : 3 -month follow-up 


\section{Appendix A. Quantitative Data at Four Points in Time: 4. TOM}

\begin{tabular}{|c|c|c|c|c|c|c|c|c|c|c|c|c|}
\hline \multirow[b]{2}{*}{ Scale } & \multicolumn{3}{|c|}{ Pre-treatment } & \multicolumn{3}{|c|}{ Post-treatment } & \multicolumn{3}{|c|}{ 3-month follow-up } & \multicolumn{3}{|c|}{ 15-month follow-up } \\
\hline & Mother & Father & Child & Mother & Father & Child & Mother & Father & Child & Mother & Father & Child \\
\hline \multicolumn{13}{|l|}{ SDQ } \\
\hline Emotional sympt. & 9* & & 5 & 8* & 8* & & $2 \#^{a b} a^{b}$ & $1 \#^{a b} a^{b}$ & & $5 * a^{b c}$ & $3 \#^{c} a^{b c}$ & 3 \\
\hline Hyperactivity & 5 & & 5 & $7^{*}$ & 8* & & $4 a^{b}$ & $3 \#^{b} a^{b}$ & & $4 a^{b}$ & $4 a^{b}$ & 3 \\
\hline Conduct pbs & 0 & & 1 & 0 & 0 & & 0 & 0 & & $2 a^{b c}$ & 0 & 1 \\
\hline Prblms with peers & 0 & & 0 & 0 & 0 & & 0 & 0 & & $4^{*} \#^{b c} a^{b c}$ & 0 & 0 \\
\hline TOTAL & 14 & & 11 & 15 & 16 & & $6 \#^{b} a^{b}$ & $4 \#^{a b} a^{b}$ & & $15 \#^{C} a^{C}$ & $7 \#^{b} a^{b}$ & 7 \\
\hline Prosocial bhvr. & 8 & & 6 & 9 & 10 & & 9 & 10 & & 8 & 10 & 7 \\
\hline & & & & & & & & & & & & \\
\hline \multicolumn{13}{|l|}{ BYI } \\
\hline Self-concept & 2 & & $39+$ & 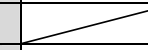 & 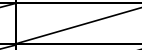 & 45 & 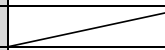 & 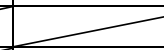 & $53 \#^{a} a^{a}$ & 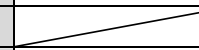 & 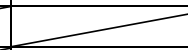 & $54 \#^{\mathrm{ab}} \mathrm{a}^{\mathrm{ab}}$ \\
\hline Anxiety & 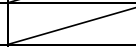 & & $19+$ & 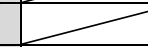 & 2 & $11 \#$ & 1 & 2 & $14+$ & 2 & 2 & $6 \#^{\mathrm{ac}} \mathrm{a}^{\mathrm{a}}$ \\
\hline Depression & 1 & & $11+$ & 1 & 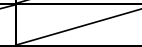 & $14+$ & 2 & 2 & $3 \#^{a b} a^{a b}$ & 2 & 2 & $5 \#^{b} a^{b}$ \\
\hline Anger & 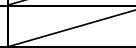 & & 10 & 2 & 7 & 11 & 2 & 2 & 7 & 2 & 2 & 6 \\
\hline Disruptive behvr & 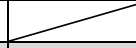 & & 6 & $\infty$ & & 1 & $\infty$ & $\infty$ & - & 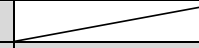 & 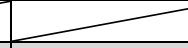 & - \\
\hline & & & & & & & & & & & & \\
\hline \multicolumn{13}{|l|}{ SCAS } \\
\hline Panic/agoraphobia & $7 *$ & & $7 *$ & $2 \# a$ & $2 \# a$ & $1 \# a$ & $2 \#^{a} a^{a}$ & $2 \#^{a} a^{a}$ & $0 \#^{\mathrm{a}} \mathrm{a}^{\mathrm{a}}$ & $5^{\star} \#^{\mathrm{abc}} a^{\mathrm{abc}}$ & $3^{*} \#^{a} a^{a}$ & $3 a^{a}$ \\
\hline Generalised anx. & $11^{*}$ & & $8^{*}$ & 9* & $7 * \# a$ & $5 a$ & $6^{*} \#^{a b} a^{a b}$ & $5 \#^{a} a^{a}$ & $1 \#^{a b} a^{a b}$ & $6^{\star} \#^{\mathrm{ab}} a^{\mathrm{ab}}$ & $8^{*} \#^{a} a^{a c}$ & $3 \#^{a} a^{a}$ \\
\hline Social phobia & 7 & & 5 & $4 a$ & $3 a$ & $1 \# a$ & $2 a^{a}$ & $1 a^{a}$ & $0 \#^{a} a^{a}$ & $3 a^{a}$ & $3 a^{a}$ & $2 a^{a}$ \\
\hline Anx. Phys. Injury & $7 *$ & & $5 *$ & $4 a$ & $4 a$ & $6 * a$ & $6^{\star}$ & $4 a^{a}$ & $2 a^{a b}$ & $4 a^{a}$ & $4 a^{a}$ & $1 \#^{b} a^{a b}$ \\
\hline OCD & 0 & & 3 & $2 a$ & $2 a$ & 2 & 1 & $0 a^{b}$ & $0 \mathrm{a}^{\mathrm{a}}$ & $2 a^{a}$ & $2 \mathrm{a}^{\mathrm{ac}}$ & 2 \\
\hline Separation anxiety & $13^{*}$ & & $12^{*}$ & $7 * \# a$ & $7 * \# a$ & $9 *$ & $6 \#^{a} a^{a}$ & $5 \#^{a} a^{a}$ & $2 \#^{a b} a^{a b}$ & $9 * a^{a}$ & $11^{*} \#^{c} a^{b c}$ & $4 \#^{b} a^{a b}$ \\
\hline TOTAL & $45 *$ & & 40 & 28* \#a & $25 \# a$ & $24 \# a$ & $23 \#^{a} a^{a}$ & $17 \#^{a} a^{a}$ & $5 \#^{a b} a^{a b}$ & $29 * \#^{a} a^{a}$ & $31 * \#^{a} a^{a c}$ & $15 \#^{a} a^{a}$ \\
\hline \multicolumn{13}{|l|}{ CALIS } \\
\hline Child interference & 15 & & 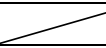 & $6 \# a$ & $6 \# a$ & 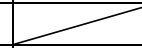 & $8 a^{a}$ & 9 & 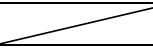 & 9 & 8 & 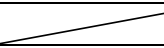 \\
\hline Fam. Interference & $15+$ & & 1 & 11 & $11+$ & 2 & 10 & $11+$ & 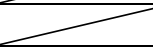 & 13 & $7 \#^{a} a^{a}$ & 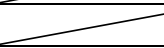 \\
\hline Child reported & 1 & & 10 & 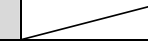 & $\infty$ & $2 a$ & 2 & $\infty$ & 4 & 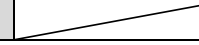 & 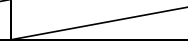 & 4 \\
\hline
\end{tabular}

NATURE OR SIZE OF CHANGE: *clinical population level; \#statistically significant change; alarge effect (positive change more than one SD of the scale); clinical change (going from a clinical to a non-clinical level on a scale); negative change

POINTS OF CHANGE: compared to ${ }^{\mathrm{a}}$ : pre-treatment. ${ }^{\mathrm{b}}$ : post-treatment ${ }^{\mathrm{c}}$ : 3 -month follow-up 


\section{Appendix A. Quantitative Data at Four Points in Time: 5. MARK}

\begin{tabular}{|c|c|c|c|c|c|c|c|c|c|c|c|c|}
\hline \multirow[b]{2}{*}{ Scale } & \multicolumn{3}{|c|}{ Pre-treatment } & \multicolumn{3}{|c|}{ Post-treatment } & \multicolumn{3}{|c|}{ 3-month follow-up } & \multicolumn{3}{|c|}{ 15-month follow-up } \\
\hline & Mother & Father & Child & Mother & Father & Child & Mother & Father & Child & Mother & Father & Child \\
\hline \multicolumn{13}{|l|}{ SDQ } \\
\hline Emotional sympt. & 2 & & & 2 & 1 & & 2 & $0 a^{a}$ & & 1 & 1 & 1 \\
\hline Conduct pbs & 2 & & & 2 & 2 & & $0 a^{a b}$ & 2 & & $6^{*} \#^{\mathrm{bc}} a^{\mathrm{bc}}$ & 3 & 0 \\
\hline Prblms with peers & 0 & & & 0 & $2 a$ & & 0 & $0 a^{b}$ & & 0 & $0 a^{C}$ & 2 \\
\hline TOTAL & 6 & & & 5 & 8 & & 4 & 4 & & 8 & 8 & 5 \\
\hline Prosocial bhvr. & 5 & & & 5 & $8 \# a$ & & $8 \#^{a b} a^{a b}$ & $7 a^{a}$ & & $4^{*} \#^{\mathrm{C}} a^{\mathrm{C}}$ & $4 \#^{b c} a^{b c}$ & 9 \\
\hline & & & & & & & & & & & & \\
\hline \multicolumn{13}{|l|}{ BYI } \\
\hline Self-concept & 2 & 2 & 49 & 2 & 2 & $40+\#$ & $\infty$ & 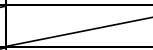 & $41+$ & 2 & 2 & $56 \#^{b c} a^{b c}$ \\
\hline Anxiety & 2 & 2 & $21+$ & 2 & 2 & - & 2 & 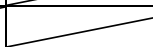 & $6 \#^{a} a^{a}$ & 2 & 2 & $1 \#^{\mathrm{a}} \mathrm{a}^{\mathrm{a}}$ \\
\hline Depression & 2 & & $21+$ & 2 & & - & 2 & 2 & $9 \#^{a} a^{a}$ & 2 & 2 & $1 \#^{\mathrm{ac}} a^{\mathrm{ac}}$ \\
\hline Anger & 2 & 2 & $19+$ & $\infty$ & $\infty$ & - & $\infty$ & $\infty$ & $16+$ & 2 & 2 & $0 \#^{\mathrm{ac}} \mathrm{a}^{\mathrm{ac}}$ \\
\hline Disruptive behvr & 2 & & $16+$ & 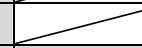 & 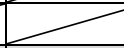 & - & 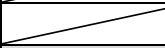 & 2 & - & 2 & 2 & \\
\hline & & & & & & & & & & & & \\
\hline Panic/agoraphobia & 0 & & 9* & 0 & 1 & $8^{*}$ & 0 & 1 & $4 \#^{a} a^{b}$ & 0 & 0 & $0 \#^{a b} a^{a b c}$ \\
\hline Generalised anx. & 5 & & 6 & 4 & 4 & $10 * \# a$ & $2 \#^{\mathrm{a}}$ & 3 & $6 \#^{b} a^{b}$ & 3 & $2 \#^{a} a^{a}$ & $4 \#^{b} a^{b}$ \\
\hline Social phobia & 7 & & $7^{*}$ & 7 & 9* & $7^{*}$ & 4 & $5 a^{b}$ & $6^{\star}$ & 5 & 6 & $3 \#^{\mathrm{ab}} a^{\mathrm{abc}}$ \\
\hline Anx. phys. Injury & $8^{*}$ & & $6^{*}$ & $5 a$ & $4 a$ & $6^{*}$ & $4 a^{a}$ & $3 a^{a}$ & $5^{\star}$ & $4 a^{a}$ & $2 \#^{a} a^{a}$ & 4 \\
\hline OCD & 2 & & $7^{*}$ & 1 & 1 & 8* & 0 & 1 & $5 a^{b}$ & 1 & 1 & $1 \#^{\mathrm{abc}} a^{\mathrm{abc}}$ \\
\hline Separation anxiety & $8^{*}$ & & 9* & $10 *$ & $8^{*}$ & $11^{*}$ & $4 \#^{b} a^{b}$ & 6 & $4 \#^{\mathrm{ab}} \mathrm{a}^{\mathrm{b}}$ & $4 \#^{b} a^{a b}$ & $3 \#^{a b} a^{a b}$ & $4 \#^{\mathrm{ab}} a^{\mathrm{abc}}$ \\
\hline TOTAL & $30 *$ & & $43^{*}$ & $27^{*}$ & $27^{*}$ & $47^{*}$ & $14 \#^{a b} a^{b}$ & $19 \#^{\mathrm{a}}$ & $30 * \#^{a b} a^{b}$ & $17 \#^{\mathrm{ab}} a^{\mathrm{a}}$ & $14 \#^{\mathrm{ab}} a^{\mathrm{ab}}$ & $16 \#^{\mathrm{abc}} \mathrm{a}^{\mathrm{abc}}$ \\
\hline \multicolumn{13}{|l|}{ CALIS } \\
\hline Child interference & 10 & & 1 & 5 & 11 & 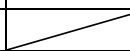 & $0 \#^{a} a^{a}$ & 10 & 1 & $2 a^{a}$ & 5 & P \\
\hline Fam. Interference & $15+$ & & 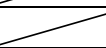 & $14+$ & $12+$ & 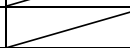 & $2 \#^{a b} a^{a b}$ & $7 \#^{a} a^{a}$ & 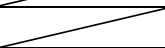 & $5 \#^{a b} a^{a b}$ & $3 \#^{\mathrm{ab}} a^{\mathrm{ab}}$ & 2 \\
\hline Child reported & $\longrightarrow$ & & 9 & $\longrightarrow$ & 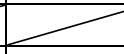 & 7 & 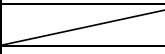 & r & 2 & 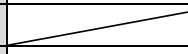 & W & 2 \\
\hline
\end{tabular}

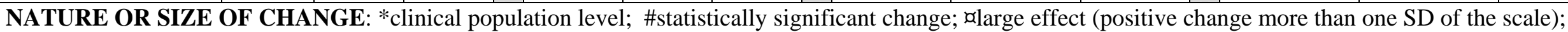
clinical change (going from a clinical to a non-clinical level on a scale); negative change

POINTS OF CHANGE: compared to ${ }^{\text {a }}$ : pre-treatment. ${ }^{\mathrm{b}}$ : post-treatment ${ }^{\mathrm{c}}$ : 3 -month follow-up 
Pragmatic Case Studies in Psychotherapy, http://pcsp.libraries.rutgers.edu

Volume 9, Module 2, Article 4, pp. 179-274, 06-26-13 [copyright by authors]

\section{Appendix A. Quantitative Data at Four Points in Time: 6. LENE}

\begin{tabular}{|c|c|c|c|c|c|c|c|c|c|c|c|c|}
\hline \multirow[b]{2}{*}{ Scale } & \multicolumn{3}{|c|}{ Pre-treatment } & \multicolumn{3}{|c|}{ Post-treatment } & \multicolumn{3}{|c|}{ 3-month follow-up } & \multicolumn{3}{|c|}{ 15-month follow-up } \\
\hline & Mother & Father & Child & Mother & Father & Child & Mother & Father & Child & Mother & Father & Child \\
\hline \multicolumn{13}{|l|}{ SDQ } \\
\hline Emotional sympt. & 3 & & 6 & 2 & & & & & & 2 & 3 & 4 \\
\hline Hyperactivity & 2 & & 6 & 2 & & & & & & 2 & 1 & 4 \\
\hline Conduct pbs & 0 & & 2 & 0 & & & & & & 0 & 1 & 1 \\
\hline Prblms with peers & 0 & & 0 & 0 & & & & & & 0 & 0 & 3 \\
\hline TOTAL & 5 & & 14 & 4 & & & & & & 4 & 5 & 12 \\
\hline Prosocial bhvr. & 10 & & 10 & 10 & & & & & & 10 & 10 & 9 \\
\hline & & & & & & & & & & & & \\
\hline \multicolumn{13}{|l|}{ BYI } \\
\hline Self-concept & 2 & 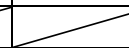 & 57 & 2 & 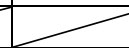 & $43 \#$ & 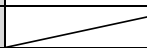 & 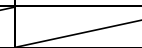 & & 2 & 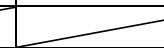 & $43 \#^{a} a^{a}$ \\
\hline Anxiety & 1 & 1 & 5 & 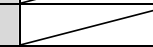 & 1 & $15+\# a$ & 2 & 2 & & 2 & 2 & 8 \\
\hline Depression & 1 & & 9 & 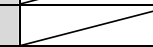 & 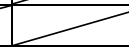 & $19+\# a$ & 2 & 2 & & 2 & 2 & $4 \#^{b} a^{b}$ \\
\hline Anger & 2 & & $20+$ & 2 & 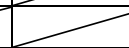 & $26+$ & 2 & 2 & & 2 & 2 & $8 \#^{a b} a^{a b}$ \\
\hline Disruptive behvr & 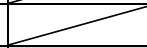 & & 8 & 2 & 2 & 6 & 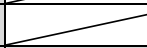 & 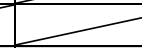 & & 2 & 2 & - \\
\hline & & & & & & & & & & & & \\
\hline \multicolumn{13}{|l|}{ SCAS } \\
\hline Panic/agoraphobia & 0 & & 2 & 0 & & 3 & & & & 1 & 1 & 4 \\
\hline Generalised anx. & 4 & & 7 & 3 & & $4 a$ & & & & 4 & 5 & $8 \#^{b} a^{b}$ \\
\hline Social phobia & 2 & & 1 & 2 & & 3 & & & & 1 & 0 & 1 \\
\hline Anx. Phys. Injury & $8 *$ & & 6 & $6 * a$ & & $9 * a$ & & & & 7 & $4 \#^{a} a^{a}$ & 8 \\
\hline OCD & 0 & & 1 & 0 & & 3 & & & & 0 & 0 & 1 \\
\hline Separation anxiety & 6 & & 3 & 6 & & $7 * a$ & & & & 4 & 4 & 6 \\
\hline TOTAL & 19 & & 20 & 17 & & $29 *$ & & & & 17 & 14 & 28 \\
\hline & & & & & & & & & & & & \\
\hline \multicolumn{13}{|l|}{ CALIS } \\
\hline Child interference & 6 & & 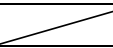 & 10 & & 2 & & & 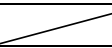 & 8 & 12 & 2 \\
\hline Fam. Interference & 9 & & 1 & 6 & & 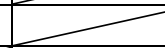 & & & 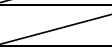 & 3 & 4 & 2 \\
\hline Child reported & $>$ & & 5 & 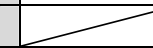 & 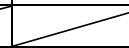 & 12 & L & 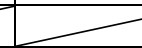 & & 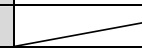 & 2 & 8 \\
\hline
\end{tabular}

NATURE OR SIZE OF CHANGE: *clinical population level; \#statistically significant change; alarge effect (positive change more than one SD of the scale); clinical change (going from a clinical to a non-clinical level on a scale); negative change

POINTS OF CHANGE: compared to ${ }^{\mathrm{a}}$ : pre-treatment. ${ }^{\mathrm{b}}$ : post-treatment ${ }^{\mathrm{c}}$ : 3-month follow-up 


\section{PREDISPOSING FACTORS}

\section{PERSONAL PREDISPOSING} FACTORS

Biological factors

Genetic vulnerability (mother with anxiety problems)

Psychological factors

Inhibited temperament

\section{CONTEXTUAL PREDISPOSING FACTORS}

Exposure to family problems in early life Maternal anxiety Anxiety and threat-sensitive family culture

PRECIPITATING FACTORS

Parent-child separation (father moved out) Changing school

\section{PERSONAL MAINTAINING FACTORS}

Psychological factors avoiding feared stimuli, approaching feared stimuli and withdrawing before anxiety subsides, threat- and danger- oriented cognitive set, external hypervigilance and misinterpreting neutral events as threatening, learning difficulties

\section{CONTEXTUAL MAINTAINING FACTORS}

Family system factors inadvertent modelling and reinforcement of threat sensitivity, hypervigilance and avoidant behaviour

Parental factors maternal anxiety disorder, external parental locus of control

Social network factors bullying at school
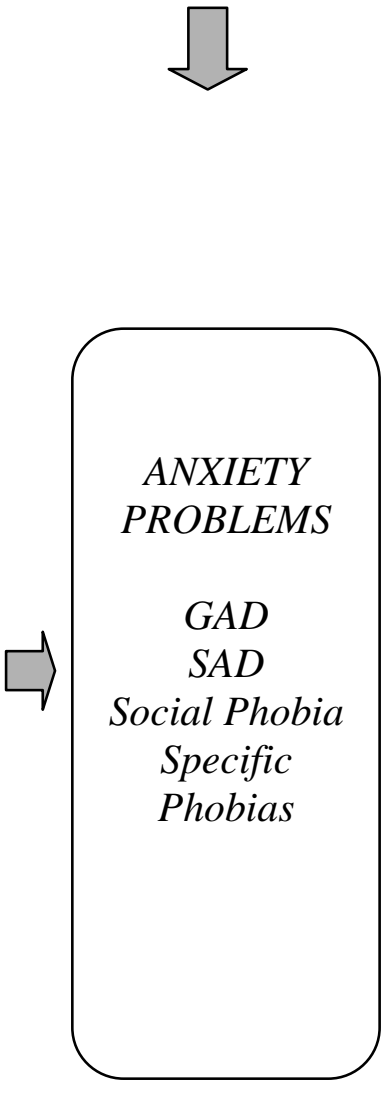

\section{PERSONAL PROTECTIVE FACTORS}

\section{Psychological factors good social skills \\ CONTEXTUAL PROTECTING FACTORS}

Treatment system factors

Family accepts there is a problem and is committed to resolving the problem

Family system factors secure parent-child attachment, clear family communication

\section{Parental factors} good parental adjustment,

Social network factors good social support network 
Part 2, Analysis of the Process and Outcome of Responders Versus Nonresponders

I. Lundkvist-Houndoumadi \& M. Thastum

Pragmatic Case Studies in Psychotherapy, http://pcsp.libraries.rutgers.edu

Volume 9, Module 2, Article 4, pp. 179-274, 06-26-13 [copyright by authors]

Appendix B. Case Formulations: 2. NIELS

\section{PREDISPOSING FACTORS}

PERSONAL PREDISPOSING FACTORS

Biological factors

Genetic vulnerability (parents with depression)

Psychological factors

Inhibited temperament

Low self-esteem

\section{CONTEXTUAL PREDISPOSING FACTORS}

Parent-child factors in early life

Anxious-ambivalent attachment style

Exposure to family problems in early life Parental depression

\section{PRECIPITATING FACTORS}

Parents suffering from depression and birth of sister (first time problems became apparent) Mother being operated (shortly before referral time)

\section{PERSONAL MAINTAINING FACTORS}

Psychological factors

Avoiding feared stimuli

Threat- and danger-oriented cognitive set

External hypervigilance and misinterpreting external events as threatening

\section{CONTEXTUAL} MAINTAINING FACTORS

Family system factors Insecure parent-child attachment

Periods of disengaged interaction, stress and neglectful parenting

\section{Parental factors}

Threat-sensitive cognitive set

Parents recognise Niels'

difficulties in themselves (could have influenced Niels through modelling)
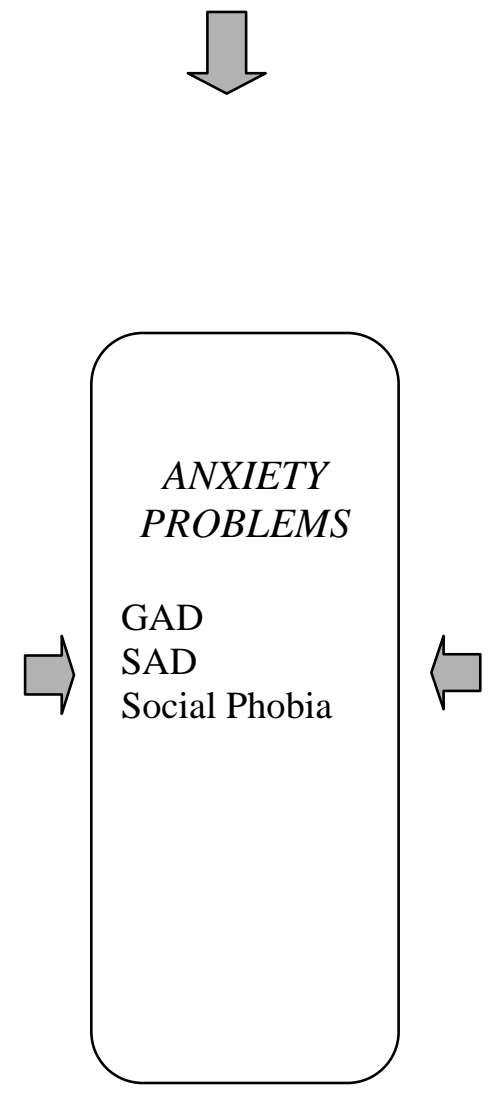

\section{PERSONAL} PROTECTIVE FACTORS Psychological factors High IQ

CONTEXTUAL PROTECTING FACTORS Treatment system factors

Family accepts there is a problem and both parents are committed to resolving the problem

Family system factors Flexible family organisation

Father involvement

\section{Parental factors}

Parents have gotten over their psychological problems

Social network factors Positive educational placemt Support from other family members (mother's sister) takes care of Niels' sister in order for parents to be able to attend therapy) 


\section{PREDISPOSING FACTORS}

No such factors are indicated other than normal

"fight or flight" reaction in the presence of perceived danger

\section{PRECIPITATING FACTORS}

Frightening incidents with dogs when 8-9 moths and in kindergarten

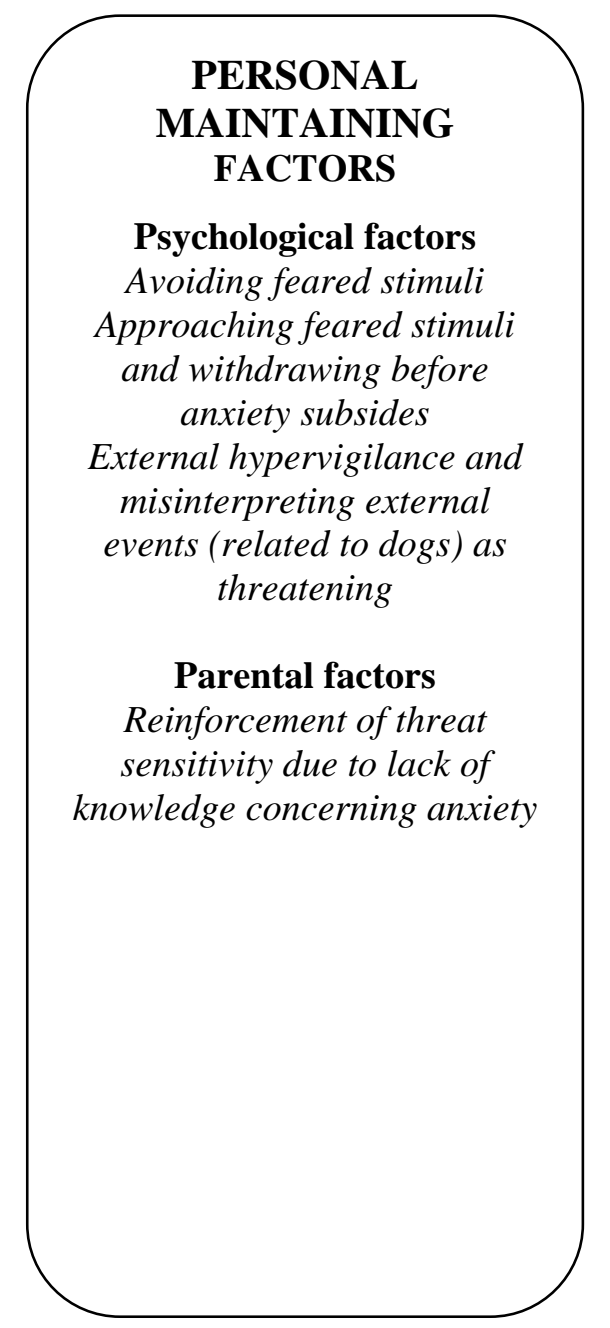

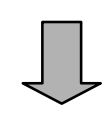

$+$

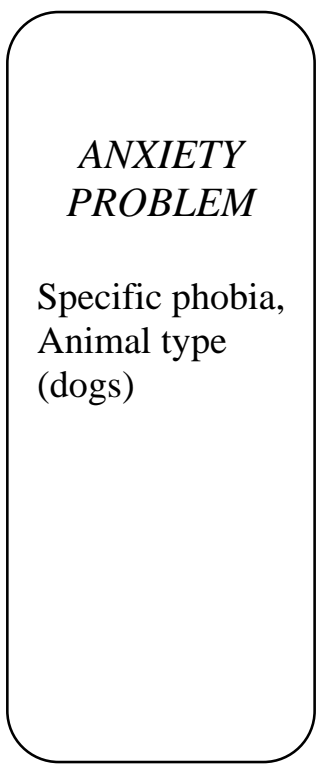

\section{PERSONAL PROTECTIVE FACTORS}

\section{Psychological factors \\ High self-esteem}

\section{CONTEXTUAL} PROTECTING FACTORS

\section{Treatment system factors}

family accepts there is a problem and is committed to

resolving the problem

Family system factors

Clear family communication and

Family cohesion

\section{Parental factors}

Good parental adjustment Internal parental locus of control

\section{Social network factors}

Good social support network 
Part 2, Analysis of the Process and Outcome of Responders Versus Nonresponders

I. Lundkvist-Houndoumadi \& M. Thastum

Pragmatic Case Studies in Psychotherapy, http://pcsp.libraries.rutgers.edu

Volume 9, Module 2, Article 4, pp. 179-274, 06-26-13 [copyright by authors]

Appendix B. Case Formulations: 4. TOM

PREDISPOSING FACTORS

PERSONAL PREDISPOSING FACTORS
Biological factors
Genetic vulnerability (mother with history of
depression)
Psychological factors
Inhibited temperament
Low self-esteem (seen on BYI)

\section{CONTEXTUAL PREDISPOSING FACTORS}

Parent-child factors in early life Anxious/insecure attachment

Exposure to family problems in early life

Parental depression and stress

\section{PRECIPITATING FACTORS}

Acute life stresses (mother suffering from post partum depression and father having episodes of stress)

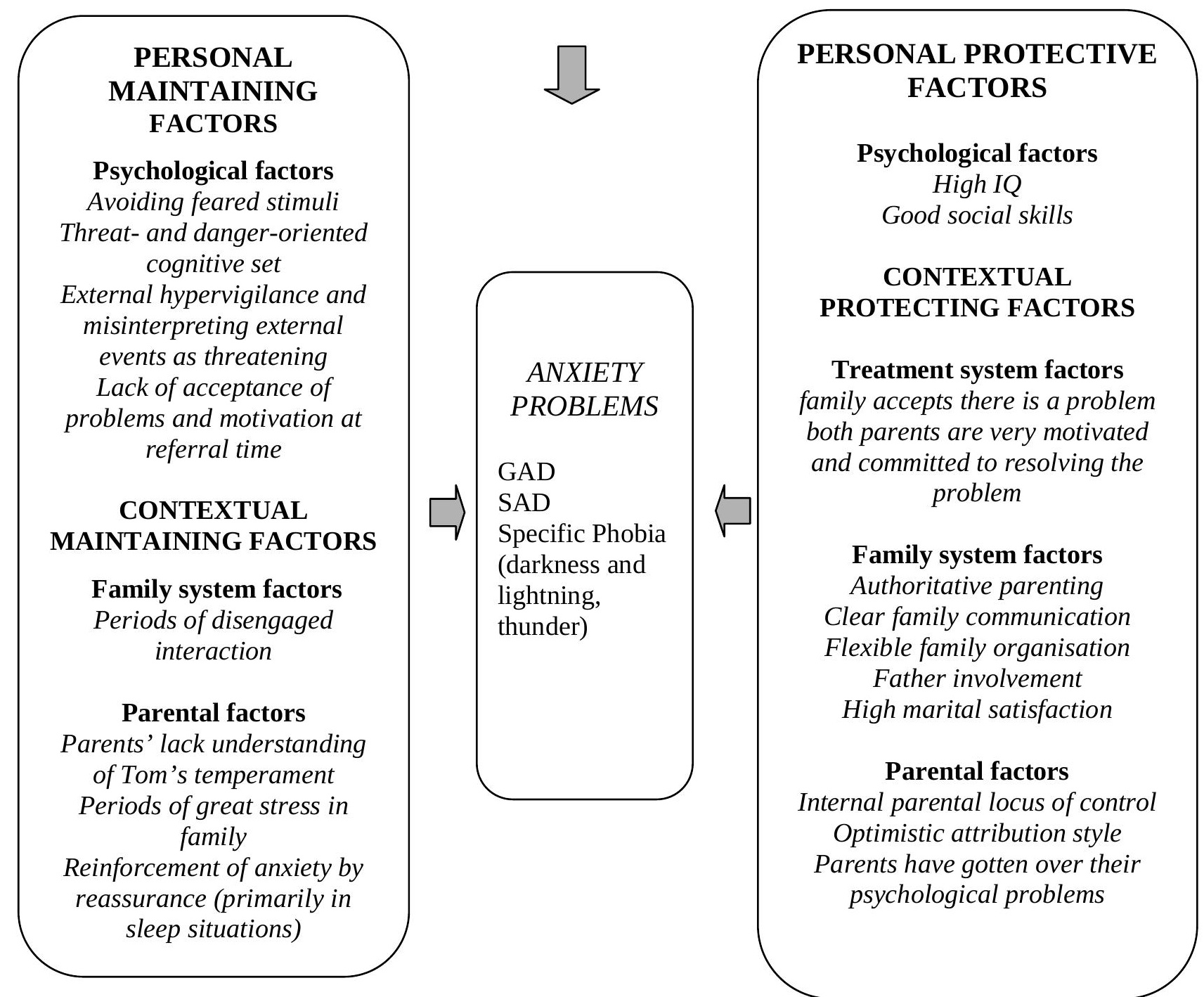


Appendix B. Case Formulations: 5. MARK

PREDISPOSING FACTORS

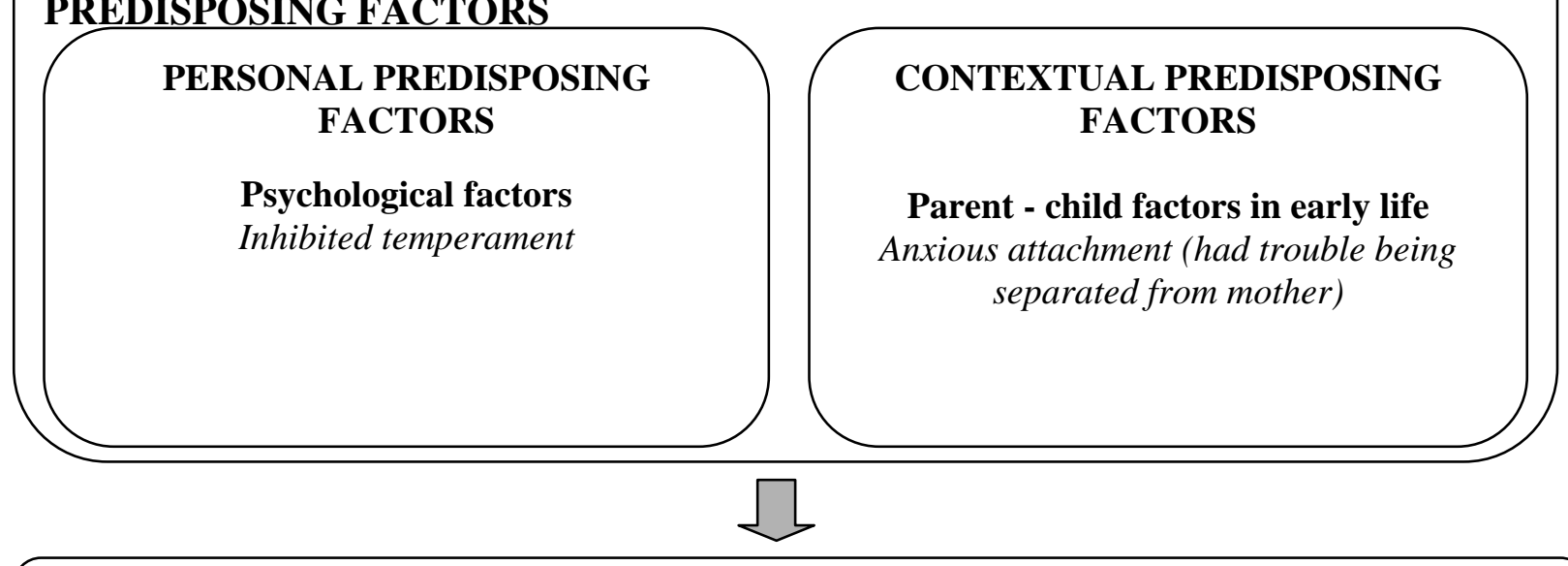

PRECIPITATING FACTORS

Incident where Mark's house was robbed

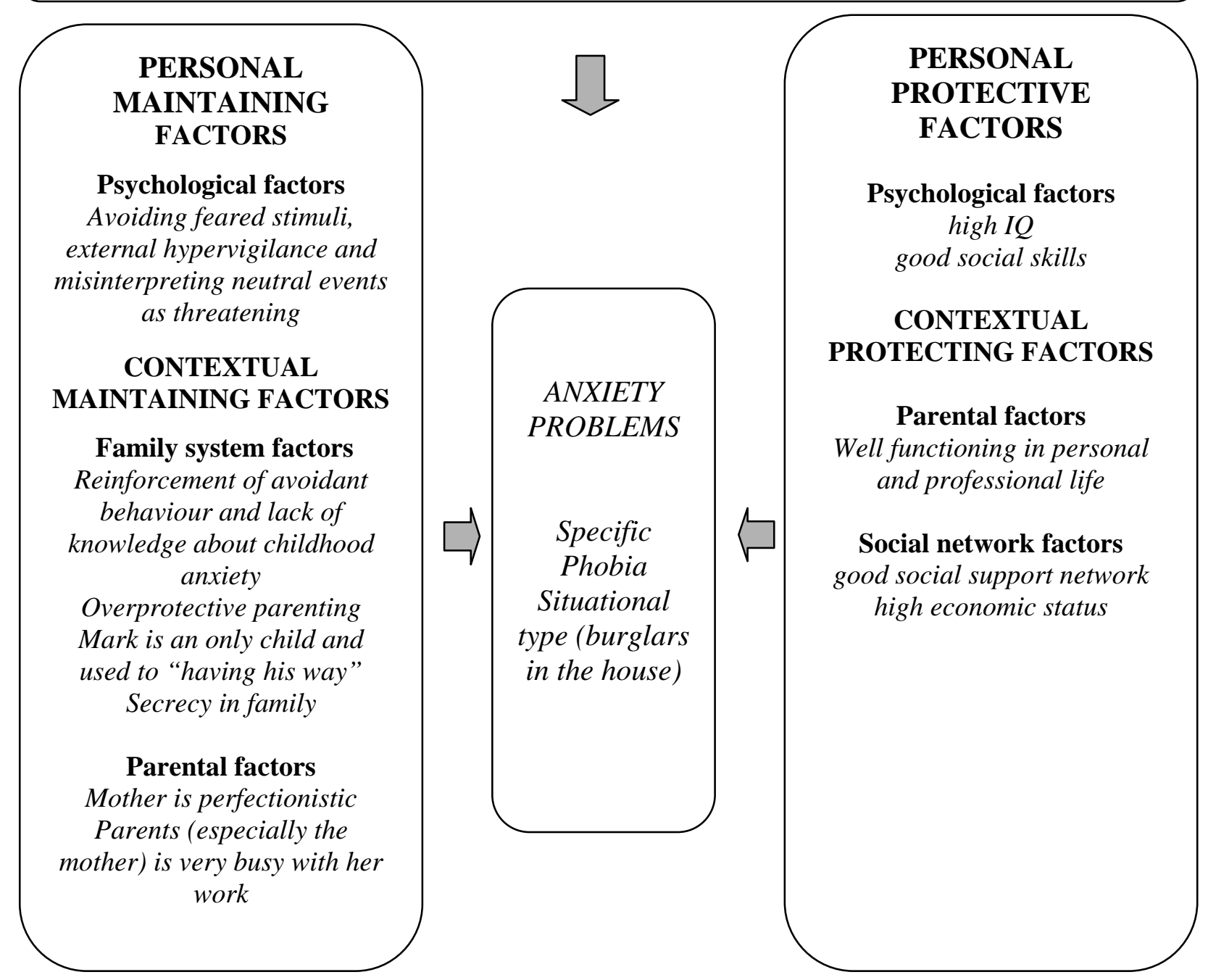


Part 2, Analysis of the Process and Outcome of Responders Versus Nonresponders

I. Lundkvist-Houndoumadi \& M. Thastum

Pragmatic Case Studies in Psychotherapy, http://pcsp.libraries.rutgers.edu

Volume 9, Module 2, Article 4, pp. 179-274, 06-26-13 [copyright by authors]

Appendix B. Case Formulations: 6. LENE

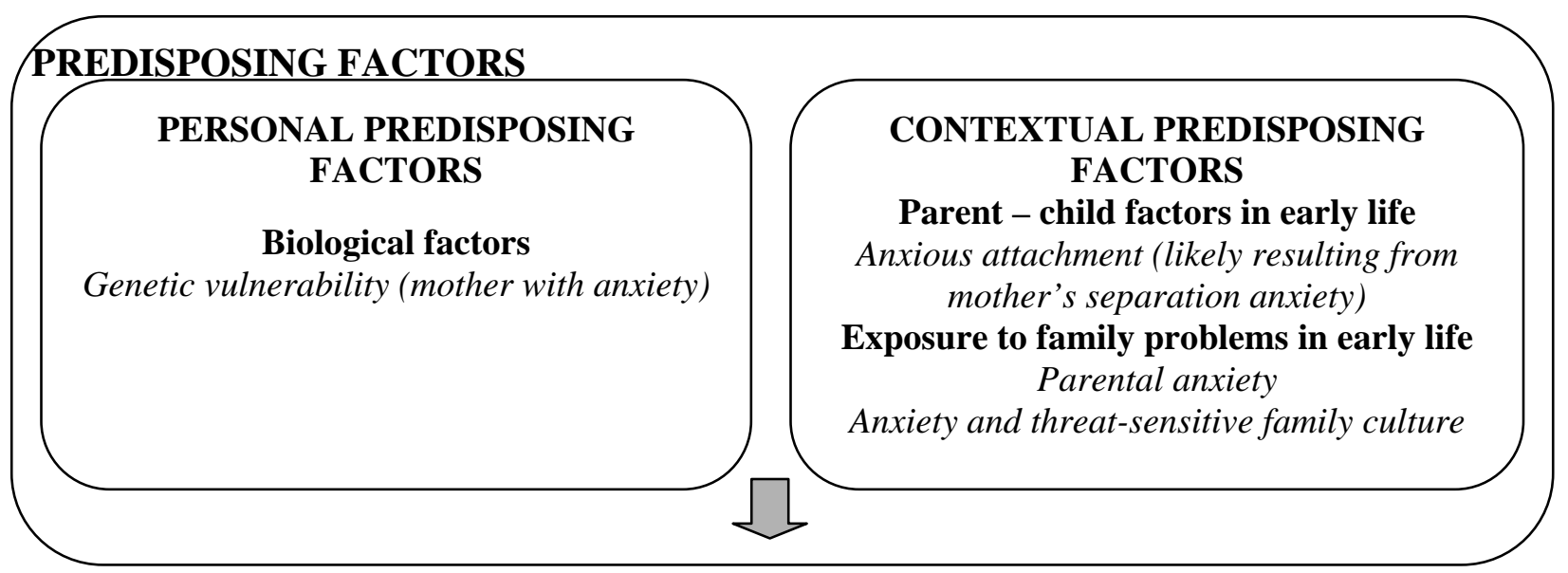

\section{PRECIPITATING FACTORS}

The father's overprotective care giving and anxious modelling

\section{PERSONAL MAINTAINING FACTORS}

Psychological factors

Avoiding feared stimuli, External hypervigilance and misinterpreting neutral events (related to dogs) as threatening CONTEXTUAL MAINTAINING FACTORS

Family system factors Inadvertent modelling and reinforcement of threat

Ssensitivity, hypervigilance and avoidant behavior

Overinvolved mother-child interactions (sleep in same bed), Marital discord

Father absence (working nightshifts)

Confused communication patterns

Parental factors

Mother and father suffer from anxiety

Low parental self-efficacy

Insecure internal models of relationships

Dysfunctional coping strategies

Social network factors

Period of bullying in school

\section{PERSONAL PROTECTIVE FACTORS}

\section{Psychological factors good social skills high self-esteem}

\section{CONTEXTUAL} PROTECTING FACTORS

Treatment system factors Mother accepts there is a problem and tries to resolve the problem 